\title{
Osteology of the Late Triassic aetosaur Scutarx deltatylus (Archosauria: Pseudosuchia)
}

\author{
William G Parker ${ }^{\text {Corresp. } 1,2}$ \\ 1 Division of Resource Management, Petrified Forest National Park, Petrified Forest, Arizona, United States \\ 2 Jackson School Museum of Earth History, University of Texas at Austin, Austin, Texas, United States \\ Corresponding Author: William G Parker \\ Email address: William_Parker@nps.gov
}

Aetosaurians are some of the most common fossils collected from the Upper Triassic Chinle Formation of Arizona, especially at the Petrified Forest National Park. Aetosaurians collected from lower levels of the park include Desmatosuchus spurensis, Paratypothorax, Adamanasuchus eisenhardtae, Calyptosuchus wellesi, and Scutarx deltatylus. Four partial skeletons collected from the park from 2002 through 2009 represent the holotype and referred specimens of Scutarx deltatylus. These specimens include much of the carapace, as well as the vertebral column, and shoulder and pelvic girdles, and a new naming convention proposed for osteoderms descriptions better differentiates portions of the carapace and ventral armor. A partial skull from the holotype specimen represents the first aetosaur skull recovered and described from Arizona since the 1930s. The key morphological feature distinguishing Scutarx deltatylus is the presence of a prominent, triangular boss located in the posteromedial corner of the dorsal surface of the dorsal paramedian osteoderms. Scutarx deltatylus can be distinguished from closely related forms Calyptosuchus wellesi and Adamanasuchus eisenhardtae not only morphologically, but also stratigraphically. Thus, Scutarx deltatylus is potentially an index taxon for the upper part of the Adamanian biozone. 


\section{Osteology of the Late Triassic aetosaur Scutarx deltatylus}

3 (Archosauria: Pseudosuchia).

4

5 William G. Parker ${ }^{1,2}$

$6{ }^{1}$ Division of Resource Management, Petrified Forest National Park, Petrified Forest, Arizona, 7 U.S.A.

$8{ }^{2}$ Jackson School Museum of Earth History, The University of Texas, Austin, Texas, U.S.A.

9 Corresponding Author:

10

11 William Parker

121 Park Road, \#2217, Petrified Forest, Arizona, 86028, U.S.A.

13 Email address: William Parker@nps.gov 


\section{Abstract}

15 Aetosaurians are some of the most common fossils collected from the Upper Triassic

16 Chinle Formation of Arizona, especially at the Petrified Forest National Park. Aetosaurians

17 collected from lower levels of the park include Desmatosuchus spurensis, Paratypothorax,

18 Adamanasuchus eisenhardtae, Calyptosuchus wellesi, and Scutarx deltatylus. Four partial

19 skeletons collected from the park from 2002 through 2009 represent the holotype and referred

20 specimens of Scutarx deltatylus. These specimens include much of the carapace, as well as the

21 vertebral column, and shoulder and pelvic girdles, and a new naming convention proposed for

22 osteoderms descriptions better differentiates portions of the carapace and ventral armor. A partial

23 skull from the holotype specimen represents the first aetosaur skull recovered and described from

24 Arizona since the 1930s. The key morphological feature distinguishing Scutarx deltatylus is the

25 presence of a prominent, triangular boss located in the posteromedial corner of the dorsal surface

26 of the dorsal paramedian osteoderms. Scutarx deltatylus can be distinguished from closely related

27 forms Calyptosuchus wellesi and Adamanasuchus eisenhardtae not only morphologically, but

28 also stratigraphically. Thus, Scutarx deltatylus is potentially an index taxon for the upper part of

29 the Adamanian biozone.

\section{Introduction}

The Triassic Period is a key transitional point in Earth history when remnants of

32 Paleozoic terrestrial biotas were replaced by a Mesozoic biota including components of recent

33 ecosystems (e.g., Fraser 2006). Prominent in this new radiation were the archosaurs, which

34 include the common ancestor of birds and crocodylians and all of their descendants (Gauthier

35 1986). The early appearance and diversification of this important clade is of interest because,

36 beginning in the Triassic, the archosaurs almost completely dominated all continental ecosystems 
37 throughout the entire Mesozoic (e.g., Nesbitt 2011). Because the Triassic globe had a coalesced

38 supercontinent, Pangaea, the Laurasian and Gondwanan continental faunas are often considered

39 to be cosmopolitan in their distribution, presumably because of a lack of major oceanic barriers

40 (Colbert 1971). Thus, many Triassic taxa have been considered widespread and widely applicable

41 for global biostratigraphy (e.g., Lucas 1998a).

42 More recent work suggests that this is a gross oversimplification of the taxonomic

43 diversity present at the time (e.g., Irmis et al. 2007a; Nesbitt, Irmis \& Parker 2007; Nesbitt et al.

44 2009a; Nesbitt et al. 2009b) and new research on many Triassic groups is showing evidence for

45 endemism of species-level taxa (e.g., Martz \& Small 2006; Parker 2008a; Parker 2008b; Stocker

46 2010), with distinct patterns of radiation of more inclusive clades into new areas (e.g., Nesbitt et

47 al. 2010). Key to this change in thinking are the utilization of testable techniques such as

48 apomorphy-based identification of fossils (Irmis et al. 2007b; Nesbitt \& Stocker 2008) and

49 improved phylogenetic approaches to archosaur relationships and paleobiogeography (e.g., Irmis

50 2008; Nesbitt 2011; Nesbitt et al. 2010). The apomorphy-based approach reveals hidden

51 diversity in faunal assemblages resulting in the recognition of distinct taxa (Nesbitt \& Stocker

52 2008).

53 Aetosaurians are quadrupedal, heavily armored, suchian archosaurs with a global

54 distribution, restricted to non-marine strata of the Late Triassic (Desojo et al. 2013).

55 Aetosaurians are characterized by their specialized skull with partially edentulous mandibles, an

56 upturned premaxillary tip, and laterally facing supratemporal fenestrae. Another key feature of

57 aetosaurians is a heavy carapace consisting of four columns of rectangular dermal armor, two

58 paramedian columns that straddle the midline, and two lateral columns (Walker 1961). Ventral

59 and appendicular osteoderms are also present in most taxa. Aetosaurian osteoderms possess 
60 detailed ornamentation on the dorsal surface, the patterning of which can be diagnostic for taxa

61 (Long \& Ballew 1985). Thus, the type specimens of several aetosaurian taxa consist solely of

62 osteoderms (e.g., Typothorax coccinarum Cope 1875; Paratypothorax andressorum Long and

63 Ballew 1985; Lucasuchus hunti Long and Murry 1995; Rioarribasuchus chamaensis Zeigler,

64 Heckert \& Lucas 2003; Apachesuchus heckerti Spielmann \& Lucas 2012) or consist chiefly of

65 osteoderms (e.g., Calyptosuchus wellesi Long \& Ballew 1985; Typothorax antiquus Lucas,

66 Heckert \& Hunt 2003; Tecovasuchus chatterjeei Martz \& Small 2006; Adamanasuchus

67 eisenhardtae Lucas, Hunt, \& Spielmann 2007; Sierritasuchus macalpini Parker, Stocker \& Irmis

68 2008). Aetosaurian osteoderms and osteoderm fragments are among the most commonly

69 recovered fossils from Upper Triassic strata (Heckert \& Lucas 2000). Because of this abundance,

70 in concert with the apparent ease of taxonomic identification, global distribution in non-marine

71 strata, and limited stratigraphic range (e.g., Upper Triassic), aetosaurians have been proposed as

72 key index fossils for use in regional and global non-marine biostratigraphy (Long \& Ballew

73 1985; Lucas \& Hunt 1993; Lucas \& Heckert 1996; Lucas et al. 1997; Lucas 1998; Heckert et al.

74 2007a; Heckert et al. 2007b; Lucas et al. 2007; Parker \& Martz 2011). Four Land Vertebrate

75 Faunachrons (LVF) were erected that use aetosaurians to divide the Late Triassic Epoch (Lucas

76 \& Hunt 1993); from oldest to youngest, these are the Otischalkian (middle Carnian); Adamanian

77 (late Carnian); Revueltian (Norian), and the Apachean (Rhaetian). These were redefined as

78 biozones by Parker and Martz (2011).

79 Aetosaurians are one of the most commonly recovered vertebrate fossils in the Upper

80 Triassic Chinle Formation at Petrified Forest National Park (PEFO), Arizona. Paleontological

81 investigations in the park between 2001 and 2009 resulted in the discovery of four partial

82 skeletons that are considered a new taxon (Parker 2016). The first specimen (PEFO 31217), 
83 discovered in 2001 and collected in 2002 from Petrified Forest Vertebrate Locality (PFV) 169

84 (Battleship Quarry; Figure 1), was initially assigned to Calyptosuchus (=Stagonolepis) wellesi

85 based on characters of the armor and vertebrae (Parker \& Irmis 2005). The second partial

86 skeleton was collected in 2004 from PFV 304 (Milkshake Quarry), at the south end of the park

87 (Figure 1). That specimen (PEFO 34045) was also mentioned by Parker and Irmis (2005), who

88 noted differences in the armor from Calyptosuchus wellesi and suggested that might represent a

89 distinct species. The other two specimens were collected in 2007 and 2009. The first (PEFO

90 34616), from the Billings Gap area (PFV 355; Figure 1) is notable because it included the first

91 aetosaurian skull to be recovered in the park. The second specimen (PEFO 34919) was recovered

92 from the Saurian Valley area of the Devils Playground (PFV 224; Figure 1). All four of these

93 specimens were originally assigned to Calyptosuchus wellesi by Parker and Martz (2011) and

94 used to construct the stratigraphic range for that taxon. Calyptosuchus is considered to be an

95 index taxon of the Adamanian biozone (Lucas \& Hunt 1993; Parker \& Martz 2011).

96 Subsequent preparation and more detailed examination of these four specimens led to the

97 discovery that they all shared a key autapomorphy, the presence of a prominent, raised triangular

98 protuberance in the posteromedial corner of the paramedian osteoderms. The protuberance is not

99 present on any of the osteoderms of the holotype of Calyptosuchus wellesi (UMMP 13950). It is

100 also absent on the numerous paramedian osteoderms of Calyptosuchus wellesi recovered from the

101 Placerias Quarry of Arizona in collections at the UCMP and the MNA. That autapomorphy and

102 several features of the cranium and pelvis differentiate these specimens (PEFO 31217; PEFO

103 34045; PEFO 34616; PEFO 34919) from all other known aetosaurians and form the basis for

104 assigning these materials to a new taxon, Scutarx deltatylus (Parker 2016). The goal of this

105 contribution is to provide a detailed osteological description of the holotype and paratype 
106 material of Scutarx deltatylus, and to discuss the potential biostratigraphic utility of the taxon

107 locally and regionally.

108

109

Institutional abbreviations -DMNH [PMNH], Perot Museum of Natural History, Dallas, Texas,

110 USA; DMNH [DMNS], Denver Museum of Nature and Science, Denver, Colorado, USA;

111 MCZD, Marischal College Zoology Department, University of Aberdeen, Aberdeen, Scotland,

112 UK; NCSM, North Carolina State Museum, Raleigh, North Carolina, USA; NHMUK, The

113 Natural History Museum, London, United Kingdom; NMMNH, New Mexico Museum of

114 Natural History and Science, Albuquerque, New Mexico, USA; MNA, Museum of Northern

115 Arizona, Flagstaff, Arizona, USA; PEFO, Petrified Forest National Park, Petrified Forest,

116 Arizona, USA; PFV, Petrified Forest National Park Vertebrate Locality, Petrified Forest, Arizona,

117 USA; PVL, Paleontología de Vertebrados, Instituto ‘Miguel Lillo’, San Miguel de Tucumán,

118 Argentina; PVSJ, División de Paleontologia de Vertebrados del Museo de Ciencias Naturales y

119 Universidad Nacional de San Juan, San Juan, Argentina; TMM, Texas Vertebrate Paleontology

120 Collections, University of Texas, Austin, Texas, USA; TTU P, Museum of Texas Tech, Lubbock,

121 Texas, USA; UCMP, University of California, Berkeley, California, USA; UMMP, University of

122 Michigan, Ann Arbor, Michigan, USA; USNM, National Museum of Natural History,

123 Smithsonian Institution, Washington, D.C., USA; VPL, Vertebrate Paleontology Lab, University

124 of Texas at Austin, Austin, Texas, USA; YPM, Yale Peabody Museum of Natural History, New

125 Haven, Connecticut, USA; ZPAL, Institute of Paleobiology of the Polish Academy of Sciences in

126 Warsaw, Warsaw; Poland. 
127

128

129

130

131

132

133

134

135

136

137

138

139

140

141

142

143

144

145

146

147

148

149

\section{GEOLOGICAL SETTING}

The four localities from which the material of Scutarx deltatylus was collected all occur in the lower part of the Sonsela Member of the Chinle Formation (Martz \& Parker 2010) (Figure 2). In the PEFO region the Sonsela Member can be divided into five distinct beds, the Camp Butte, Lot's Wife, Jasper Forest, Jim Camp Wash, and Martha's Butte beds (Martz \& Parker 2010). The Lot's Wife, Jasper Forest, and Martha's Butte beds are sandstone dominated, cliff forming units with source areas to the south and west (Howell \& Blakey 2013), whereas the Lot's Wife and Martha's Butte beds are slope forming units with a higher proportion of mudrocks than sandstones (Martz \& Parker 2010). All of these localities represent proximal floodplain facies associated with a braided river system (Howell \& Blakey 2013; Martz \& Parker 2010; Woody 2006).

PFV 169 and PFV 224 occur in the upper part of the Lot's Wife beds, PFV 355 is situated in the base of the Jasper Forest bed, and PFV 304 marks the highest stratigraphic occurrence, located in the lower part of the Jim Camp Wash beds (Figure 2). All of these sites are below the 'persistent red silcrete,' a thick, chert, marker bed that approximates the stratigraphic boundary between the Adamanian and Revueltian biozones (Martz \& Parker 2010; Parker \& Martz 2011). Exact locality information is available at Petrified Forest National Park to qualified researchers.

Non-disclosure of locality information is protected by the Paleontological Resources Preservation Act of 2009 .

A high concentration of volcanic material in mudrocks of the Chinle Formation includes detrital zircons and allows for determination of high precision radioisotopic dates for studied beds (Figure 2; Ramezani et al. 2011). Zircons from the top of the Lot's Wife beds provided an age of 219.317 $\pm 0.080 \mathrm{Ma}$ (sample SBJ; Ramezani et al. 2011). The base of the unit is constrained 
150 by a maximum depositional age of $223.036 \pm 0.059 \mathrm{Ma}$ for the top of the underlying Blue

151 Mesa Member (sample TPs; Ramezani et al. 2011). Maximum depositional ages of $218.017 \pm$

$1520.088 \mathrm{Ma}$ (sample GPL) and $213.870 \pm 0.078$ (sample KWI) are known from the Jasper Forest

153 bed and the overlying Jim Camp Wash beds further constraining the upper age for the fossil

154 specimens (Ramezani et al. 2011).

\section{MATERIALS AND METHODS}

All specimens were excavated utilizing small hand tools, although a backhoe tractor was used initially to remove overburden at PFV 304. B-15 Polyvinyl Acetate "Vinac" (Air Products \& Chemicals, Inc.) and B-76 Butvar (Eastman Chemical Company) dissolved in acetone were used as a consolidant in the field. PEFO 31217 was discovered partly in unconsolidated, heavily weathered sediment with numerous plant roots growing over and through the bones. Small handtools, including brushes, caused damage to the bone surface so plastic drinking straws were used to blow away sediment from the bone surface, which was then quickly hardened with a

163 consolidant. In the lab the same specimen (PEFO 31217) quickly deteriorated upon exposure and 164 applications of Polyvinyl Acetate (Vinac ${ }^{\mathrm{TM}}$, Air Products and Chemicals, Inc.) proved to result in

165 a flexible specimen, therefore liberal amounts of extremely thin Paleobond ${ }^{\mathrm{TM}}$ Penetrant Stabilizer

166 PB002 (Uncommon Conglomerates) were applied to stop disintegration and provide rigidity of

167 the bone. Because of the delicate nature of this specimen and the application of the

168 cyanoacrylate, many of the bones cannot be prepared further or removed from the original field

169 jackets. Furthermore, during collection the condition of the bones and surrounding matrix proved 170 to be so poor that a portion of the jacket with the scapulocoracoid in it was lost during turning.

171 This lost material consisted mostly of trunk vertebrae, ribs, and osteoderms. Unfortunately, this

172 block of material is too large to CT scan to obtain more information for these elements. 
174 the lab using B-72 ButvarTM (Eastman Chemical Company), with Paleobond ${ }^{\mathrm{TM}}$ PB40 and PB100

175 (Uncommon Conglomerates) cyanoacrylate used in many cases for permanent bonds.

176 Paleobond ${ }^{\mathrm{TM}} \mathrm{PB} 304$ (Uncommon Conglomerates) aerosol activator was originally used on some

177 of the bones in PEFO 34045, but was halted because it was causing discoloration of the bone

178 surface during the curing process. PEFO 34919 is coated with thin layers of hematite as is

179 common for fossil specimens recovered from sandy facies in the Devils' Playground region of

180 PEFO. Mechanical preparation with pneumatic tools damaged the bone surface upon removing

181 the coating and revealed that the hematite had permeated numerous microfractures in the bones, 182 expanding them slightly, or in some bones significantly. As a result, the non-osteoderm bones 183 from PFV 224 are highly deformed and often 'mashed' into the associated osteoderms. Further 184 preparation to remove the hematite coating was not attempted.

\section{Naming Conventions for Aetosaurian Osteoderms}

In this convention the dorsal armor (carapace) consists of two midline 'paramedian' columns

189 flanked laterally by two 'lateral' columns (Long \& Ballew 1985; Heckert \& Lucas, 1999; Desojo

190 et al. 2013). By convention, osteoderms of the dorsal region are named from the type of vertebrae

191 they cover [e.g., cervical, dorsal, and caudal; (Long \& Ballew 1985)]. However, the anteriormost 192 paramedian osteoderms lack equivalent lateral osteoderms causing a potential numbering offset

193 between the presacral paramedian and lateral rows (Heckert et al. 2010). Aetosaurians also

194 possess ventral armor at the throat, as well as ventral armor that underlies the 'dorsal' (=trunk)

195 and caudal vertebrae. The presence of ventral armor of the 'dorsal' series creates the awkward 
196 combination of 'ventral-dorsal' osteoderms. Therefore there is a need to standardize the

197 positional nomenclature for aetosaurian osteoderms.

198 The term carapace properly refers only to the dorsally situated network of osteoderms,

199 thus the term 'dorsal carapace' is incorrect and redundant. In this study, the term carapace refers

200 only to the dorsally situated osteoderms and the term ventral osteoderms is used for all ventrally

201 situated osteoderms (Heckert \& Lucas 1999).

202 The carapace can be divided into four anteroposteriorly trending columns of osteoderms

203 (Heckert \& Lucas 1999; Heckert et al. 2010). Those that straddle the mid-line are referred to as

204 the paramedians and the flanking osteoderms are called the lateral armor (Long \& Ballew 1985).

205 Each column is divided into rows (Figure 3) and as noted above these have traditionally been

206 given names based on the vertebral series they cover (in most taxa there is a 1:1 ratio between

207 osteoderms and vertebrae, except in the cervical series of desmatosuchines where six osteoderms

208 cover the nine cervical vertebrae).

209 The two anteriormost paramedian osteoderms fit into the back of the skull and are

210 generally mediolaterally oval and lack corresponding lateral osteoderms. These osteoderms are

211 termed the nuchal series (Figure 3; Sawin 1947; Desojo et al. 2013; Schoch \& Desojo 2016).

212 Posterior to these are roughly five, six, or nine rows of paramedian and lateral osteoderms that

213 cover the entire cervical vertebral series, termed cervical osteoderms (Figure 3; Long \& Ballew

214 1985). The patch of osteoderms beneath the cervical vertebrae in the throat area would be called

215 the gular osteoderms, based on the name given to these osteoderms in phytosaurians (Long \&

216 Murry 1995).

217 The next vertebral series initiates with the $10^{\text {th }}$ presacral vertebra. On this vertebra the

218 parapophysis has moved up to the top of the centrum, just below the level of the neurocentral

219 suture. In the previous nine vertebrae (the cervical series), the parapophysis is situated at the base

220 of the centrum, and in the eleventh vertebra the parapophysis is situated on the transverse

221 process. Thus the $10^{\text {th }}$ presacral is transitional in form and has been considered to be the first of

222 the 'dorsal' series (Case 1922; Walker 1961; Parker 2008a), and that convention is followed here. 
Historically in aetosaurians these vertebrae have been referred to as the dorsal series and

224 osteoderms covering these vertebrae are the 'dorsal osteoderms' (e.g., Long \& Ballew 1985;

225 Long \& Murry 1995; Heckert \& Lucas 2000; Desojo et al. 2013); however, this term has become

226 problematic because whereas all of the osteoderms below the vertebral column are termed the

227 ventral osteoderms, only those of above the vertebral column in the trunk region are called the

228 dorsals. Thus technically the osteoderms beneath the caudal vertebrae would be the caudal

229 ventral osteoderms and those beneath the 'dorsal' vertebrae would be the dorsal ventral

230 osteoderms. This is nonsensical so I suggest a new term be used for what have been known as the

231 dorsal vertebrae and osteoderms in aetosaurians. The terms "thoracic" and "lumbar" vertebrae

232 reflect the chest and loin areas respectively and are assigned depending on the presence or

233 absence of free ribs. This is not readily applicable to pseudosuchians which have ribs through the

234 entire series. Instead the term trunk vertebrae is used, which is commonly used for amphibians

235 and lepidosaurs, which also tend to have a ribs throughout the entire series (e.g., Wake 1992).

236 The osteoderms above the trunk vertebrae are the dorsal trunk paramedian and dorsal trunk

237 lateral osteoderms. The osteoderms located beneath the trunk vertebrae are the ventral trunk

238 osteoderms and consists of numerous columns of osteoderms (Figure 3; Walker 1961). Heckert et

239 al. (2010) utilized the term ventral thoracic osteoderms, which effectively solves the 'ventral

240 dorsal' problem; however, the term ventral trunk osteoderms is preferred here to maintain

241 consistency with the term dorsal trunk osteoderms.

242 The osteoderms above the caudal vertebrae are termed the dorsal caudal osteoderms and

243 consist of paramedian and lateral columns (Figure 3; Long \& Ballew 1985). The osteoderms

244 beneath the caudal vertebrae are the ventral caudal osteoderms (Heckert et al. 2010) and also

245 consist of paramedian and lateral columns behind the cloacal area (fourth row) to the tip of the

246 tail (Jepson 1948; Walker 1961), the first two lateral rows bear spines in Typothorax coccinarum

247 (Heckert et al. 2010). An assemblage of irregular shaped osteoderms located anterior to the

248 cloacal area is preserved in Stagonolepis robertsoni, Aetosaurus ferratus, and Typothorax

249 coccinarum (Walker 1961; Schoch 2007; Heckert et al. 2010), which can be called the cloacal

250 osteoderms. Small masses of irregular shaped osteoderms cover the limb elements of aetosaurians 
251 (e.g., Heckert \& Lucas 1999; Schoch 2007; Heckert et al. 2010). These have collectively been

252 termed as simply appendicular osteoderms. However, when found in articulation they can be

253 differentiated by the limb that is covered, including the humeral, radioulnar, femoral, and

254 tibiofibular osteoderms (Hill 2010).

\section{SYSTEMATIC PALEONTOLOGY}

256 Archosauria Cope 1869 sensu Gauthier \& Padian 1985.

257 Pseudosuchia Zittel 1887-90 sensu Gauthier \& Padian 1985.

258 Aetosauria Marsh 1884 sensu Parker, 2007.

259 Stagonolepididae Lydekker 1887 sensu Heckert \& Lucas 2000.

260 Scutarx deltatylus Parker 2016

261 (Figs. 4-29)

2621985 Calyptosuchus wellesi: Long and Ballew, p. 54, figs. 13a, 15. Pl. 5.

2631995 Stagonolepis wellesi: Long and Murry, p. 82, figs, 71b, 72b, e.

2642005 Stagonolepis wellesi: Parker and Irmis, p. 49, fig. 4a.

265 2005a Stagonolepis wellesi: Parker, p. 44.

266 2005b Stagonolepis wellesi: Parker, p. 35.

2672006 Stagonolepis wellesi: Parker, p. 53.

2682011 Calyptosuchus wellesi: Parker and Martz, p. 242.

2692013 Calyptosuchus wellesi: Martz et al., p. 342, figs. 7a-d.

2702014 Calyptosuchus wellesi: Roberto-Da-Silva et al., p. 247.

2712016 Scutarx deltatylus: Parker, p. 27, figs. 2-5.

272 Holotype - PEFO 34616, articulated posterior portion of a skull with the braincase;

273 detached left nasal; cervical and dorsal trunk paramedian and dorsal trunk lateral osteoderms;

274 ventral osteoderms, rib fragments, and paired gastral ribs. 
276 pectoral and pelvic girdles, osteoderms; PEFO 34919, much of a postcranial skeleton including

277 vertebrae, ribs, osteoderms, girdle fragments, ilium; PEFO 34045, much of a postcranial skeleton

278 including vertebrae, ribs, and osteoderms.

279 Referred Specimens - UCMP 126844, 10 partial dorsal trunk paramedian osteoderms

280 (PFV 162, Lot's Wife beds, Sonsela Member, Chinle Formation, PEFO, Arizona); UCMP 84916,

281 partial left dorsal trunk paramedian osteoderm (PFV 146, lower part of the Sonsela Member,

282 Chinle Formation, Billings Gap, Arizona; UCMP 36656, UCMP 35738, dorsal trunk paramedian

283 and dorsal trunk lateral osteoderms (UCMP locality V3205; lower part of the Sonsela Member,

284 Chinle Formation, 11 km north of Nazlini, Arizona); TTU P-09240, left and right dorsal trunk

285 paramedian osteoderms (Post Quarry, Cooper Canyon Formation, Dockum Group, Texas).

Locality, Horizon, and Age -- PFV 255 (The Sandcastle), Petrified Forest National Park,

287 Arizona; lower part of the Sonsela Member, Chinle Formation; Adamanian biozone, Norian,

$288 \sim 217 \mathrm{Ma}$ (Ramezani et al. 2011).

Diagnosis - From Parker (2016): Medium-sized aetosaurian diagnosed by the following

autapomorphies: the cervical and dorsal trunk paramedian osteoderms bear a strongly raised,

291 triangular tuberosity in the posteromedial corner of the dorsal surface of the osteoderm; the

292 occipital condyle lacks a distinct neck because the condylar stalk is mediolaterally broad; the

293 frontals and parietals are very thick dorsoventrally; and there is a distinct fossa or recess on the

294 lateral surface of the ilium between the supraacetabular crest and the posterior portion of the iliac

295 blade. An additional possible autapomorphy is that the base of the cultriform process of the

296 parabasisphenoid bears deep lateral fossae; however, in more complete, articulated aetosaur

297 skulls (e.g., SMNS 19003) the parabasisphenoid is articulated with the pterygoids making this 
298 difficult to observe. Scutarx deltatylus can also be differentiated from other aetosaurs a unique

299 combination of characters including moderately wide (W:L 2.7/1) dorsal trunk paramedian

300 osteoderms with a strongly raised anterior bar that possesses anteromedial and anterolateral

301 processes (shared with all aetosaurians except Desmatosuchini); osteoderm surface

302 ornamentation of radiating ridges and pits that emanate from a posterior margin contacting a

303 dorsal eminence (shared with Calyptosuchus wellesi, Stagonolepis robertsoni, Adamanasuchus

304 eisenhardtae, Neoaetosauroides engaeus, and Aetosauroides scagliai); lateral trunk osteoderms

305 with an obtuse angle between the dorsal and lateral flanges (shared with non-desmatosuchines); a

306 dorsoventrally short pubic apron with distinct obturator and thyroid fenestrae (shared with

307 Stagonolepis robertsoni); and an extremely anteroposteriorly short parabasisphenoid, with basal

308 tubera and basipterygoid processes almost in contact and a reduced cultriform process (shared

309 with Desmatosuchus).

DESCRIPTION

311 Skull

312

Much of the posterodorsal portion of the skull is present in PEFO 34616 (Figures 4-10).

313 Elements preserved include much of the left nasal, both frontals (the right is incomplete), both

314 postfrontals, the left parietal (badly damaged), the left and right squamosals, the right postorbital,

315 a portion of the left postorbital, and a nearly complete occipital region and braincase. The skull

316 was already heavily eroded when discovered and although the skull roof/braincase portion was

317 collected in situ, the remaining elements had to be carefully pieced together from many fragments

318 collected as float. Accordingly many of the skull roof elements are incomplete.

319 Much of the skull appears to have separated originally along some of the sutures, notably

320 those between the prefrontal-frontal, squamosal-quadrate, and postorbital-quadratojugal contacts. 
321 The left frontoparietal suture is also visible because of bone separation, and the sockets in the

322 squamosals for reception of the proximal heads of the quadrates are well-preserved. Thus, the

323 skull appears to have mostly fallen apart before burial and many of the anterior and ventral

324 elements were presumably scattered and lost during disarticulation, with the exception of the left

325 nasal, which is represented as an isolated piece. The skull of Scutarx deltatylus includes a well-

326 preserved braincase, which is described in detail below. Sutures are difficult to observe because

327 of the state of preservation of the specimen, and the skull of Longosuchus meadei (TMM 31185-

328 98) was used to infer the locations of various sutures, based on observable landmarks present in

329 PEFO 34616.

330 Nasal

331 The proximal half of the left nasal is preserved, consisting of the main body and the

332 posterior portion of the anterior projection through the mid-point of the external naris (Figure 4).

333 The main body is dorsoventrally thick and the entire element is slightly twisted dorsomedially so

334 that the dorsal surface is noticeably concave. Any surface ornamentation is obscured by a thin

335 coating of hematite. The midline symphysis is straight and slightly rugose (Figure 4). The lateral

336 surface is damaged along the lacrimal suture; however, more anteriorly, the sutural surface for

337 the ascending process of the maxilla is preserved and is strongly posteroventrally concave (Figure

338 4). Anteriorly the nasal narrows mediolaterally where it forms the dorsal margin of the external

339 naris. The ventral process of the nasal that borders the posterior edge of the naris is missing its tip

340 but it is clear from what is preserved that it was not elongate as in Aetosauroides scagliai (PVL

341 2059), but rather short as in Stagonolepis olenkae (ZPAL AbIII/346). 
342 Frontal

343 Both frontals are present, with the left nearly complete and the right missing the posterior

344 portion (Figure 5). The extreme dorsoventral thickness of the element is evident, as the

345 dorsoventral thickness is 0.35 times the midline length of the element. The frontals appear to be

346 hollow; however, this is most likely from damage during deposition and subsequent weathering

347 before the skull roof was collected and pieced back together. In dorsal view the posterior margin

348 of the frontal is slanted posterolaterally as in Stagonolepis robertsoni (Walker 1961) so that the

349 lateral margin of the frontal is longer than the medial margin, forming a distinct posterolateral

350 process (Figure 5). The anterior portion of that process meets the postfrontal laterally and the

351 parietal posteriorly as in Stagonolepis olenkae (Sulej 2010). Just anterior to the posterolateral

352 process the frontal forms the dorsal margin of the orbit. The position of the suture with the

353 postfrontal is not clear, but it should have been present as in all other aetosaurians.

354 The dorsal surfaces of the frontals are rugose, ornamented with deep pits, some associated

355 with more elongate grooves. Laterally above the round orbits and anteriorly there are wider,

356 anteroposteriorly oriented grooves as in Stagonolepis olenkae (Sulej 2010). These grooves

357 demarcate a raised central portion of the frontals as described for Stagonolepis robertsoni by

358 Walker (1961). The anterolateral margins of the frontals are dorsoventrally thick, rugose,

359 anteromedially sloping areas that are bounded posteriorly by a thin curved ridge. These are the

360 sutures for the prefrontals (Figures 5-6). There is no clear evidence for articulation of a palpebral

361 bone at this position as in Stenomyti huangae (Small \& Martz 2013), but the posteriormost

362 portion of the articular surface (Figure 6) is probably a suture for a palpebral as in Longosuchus

363 meadei (TMM 31184-98). The anterior margins of the frontals are thick and rugose for

364 articulation with the nasals (Figures 5, 7). The frontal/nasal suture is nearly transverse. The 
365 frontal also lacks the distinct, raised midline ridge present in Stenomyti huangae (Small \& Martz 366 2013).

367 The ventral surfaces of the frontals are broadly ventrally concave and smooth (Figure 7).

368 Medial to the orbital fossa is a distinct, slightly curved ridge that is the articulation point with the

369 laterosphenoid.

370 Postfrontal

371 The postfrontals are small, roughly triangular bones that form the posterodorsal margin of

372 the orbit. Both are certainly preserved in PEFO 34616, as in all aetosaurians, but the positions of

373 their sutures cannot be determined.

374 Parietal

375 The dorsal portions of both parietals are mostly missing, although the posterolateral

376 corner of the left one remains as well as a small fragment of the posterior portion of the right

377 where it contacts the dorsal process of the squamosal (Figure 5). The frontal/parietal suture is

378 visible along the posterior margin of the frontals, so it is clear that these elements were not fused.

379 The posterolateral portion forms the dorsal border of the supratemporal fenestra, but few other

380 details are visible.

381 The posterior flanges of both parietals are preserved (Figure 8). Their posteroventrally

382 sloping surfaces form the upper portion of the back of the skull. Ventrally, they contact the

383 paroccipital processes of the opisthotics. There is no evidence for the postemporal fenestrae,

384 which may have been obliterated by slight ventral crushing of the skull roof. The parietal flanges

385 contact the supraoccipital medially and the posterior process of the squamosal laterally. The

386 upper margins are damaged so that the presence of a shelf for articulation of the nuchal

387 paramedian osteoderms cannot be confirmed. 
388

389

390

391

392

393

394

395

396

397

398

399

400

401

402

403

404

405

406

407

408

409

\section{Squamosal}

The majority of both squamosals is present. As is typical for aetosaurians the squamosals are elongate bones that are fully exposed in lateral view, forming the posterior corner of the skull, as well as the posteroventral margin of the supratemporal fenestra (Figure 6). The anterior and posterior portions are separated by a dorsoventrally thin neck. The anterior portion divides into two distinct rami, a large, but mediolaterally thin, ventral lobe that presumably contacted the upper margin of the quadratojugal, and a much smaller triangular dorsal ramus that forms much of the anteroventral margin of the supratemporal fenestra. These two rami are separated by a posterior process of the postorbital. On the right side of PEFO 34616, the dorsal ramus is broken, clearly showing the articulation with the postorbital and exposing the prootic in this view (Figure 6). The ventral margin of the main body is concave and bears a flat surface that is the articulation surface with the quadrate (s.qu; Figure 7). Anterior to that articular surface the ventral margin of the anterior portion of the squamosal is confluent with the ventral margin of the postorbital. This arrangement suggests that the squamosal contributed little if anything to the margin of the infratemporal fenestra. This is similar to the condition in Stagonolepis robertsoni (Walker 1961) and differs from that in Stenomyti huangae (Small \& Martz 2013) in which the ventral margin of the squamosal is situated much lower that the ventral margin of the postorbital, and the squamosal contributes significantly to the margin of the infratemporal fenestra. and is mediolaterally thickened with a smooth anterior concave area that comprises the supratemporal fossa. The apex of the upper process contacts the parietal. The ventral posterior 
410 process forms a small hooked knob that projects off of the back of the skull. Medial to this is a

411 deep pocket in the medial surface of the squamosal that receives the dorsal head of the quadrate.

412 Dorsomedial to this pocket is the contact between the squamosal and the distal end of the

413 paroccipital process of the opisthotic (Figures 5, 7).

\section{Postorbital}

415 A portion of the left and almost the complete right postorbital are preserved in PEFO

41634616 (Figures 5-7). They are mediolaterally thin, triradiate bones that contact the postfrontal and

417 parietal dorsally, the jugal anteriorly, and the squamosal posteriorly. The upper bar forms the

418 posterior margin of the orbit and the anterior margin of the supratemporal fenestra. The posterior

419 process is triangular and inserts into a slot in the anterior portion of the squamosal. The ventral

420 margin is flat, and forms the dorsal border of the infratemporal fenestra and more anteriorly that

421 edge bears an articular surface with the jugal. The tip of the anterior process is broken, but it

422 would have overlain the posterior process of the jugal and formed the posteroventral margin of

423 the orbit. The postorbital of Scutarx appears to lack to broad ventral contact with the

424 quadratojugal (Figure 6) as in Paratypothorax (SMNS 19003) and Aetosaurus (Schoch, 2007),

425 and instead was like Desmatosuchus spurensis (Small, 2002) and Stagonolepis (Walker, 1961;

426 Sulej, 2010) where an anterior process of the squamosal separates the postorbital from the

427 quadratojugal.

\section{Supraoccipital}

429 The supraoccipital is present but poorly preserved (Figure 8). A median element, it forms

430 much of the dorsal portion of the occiput, but appears to be at least partially excluded from the

431 roof of the foramen magnum. Laterally it contacts the parietal flanges and ventrally the

432 otooccipitals. 
433

434

435

436

437

438

439

440

441

442

443

444

445

446

447

448

449

450

451

452

454

455

456

\section{Exoccipital/ opisthotic}

The exoccipitals and opisthotics are fused into a single structure, the otooccipital. The exoccipital portions form the lateral margins of the foramen magnum (Figure 8). A protuberance, or prong, is present on the left exoccipital at the dorsolateral corner of the foramen magnum (Figures 5, 8). The presence of similar structures in Neoaetosauroides engaeus (e.g., PVL 5698) was noted by Desojo and Báez (2007), and interpreted by them to be facets for reception of the proatlantes. Those authors considered the facets located on the supraoccipital; however, in Longosuchus meadei (TMM 31185-84) they are located on the exoccipital and the same appears to be true for PEFO 34616.

Anteriorly, a strong lateral ridge forms the posteroventral margin of the 'stapedial groove' as is typical for aetosaurs (Gower \& Walker 2002). In aetosaurians there are typically two openings for the hypoglossal nerve (XII) that straddle the lateral ridge (Gower \& Walker 2002); however, they are not apparent in PEFO 34616, and where the posterior opening of the left side should be situated there is a fragment of bone missing.

Both paroccipital processes are present and well-preserved (Figures 5-8). They are mediolaterally short (14 $\mathrm{mm})$ and stout, dorsoventrally taller than anteroposteriorly long (8 $\mathrm{mm}$ tall, $4 \mathrm{~mm}$ long), and contact the parietal flanges dorsally and the squamosal laterally. The distal end expands slightly dorsoventrally (Figure 8). The posterior surface is flat and distally the process forms the posterior border of the pocket for reception of the quadrate head, therefore there was a sizeable contact between the opisthotic and the quadrate.

The proximoventral portion of the paroccipital process opens into the 'stapedial groove'. That groove continues into the main body of the opisthotic, bounded by the lateral ridge of the exoccipital posteroventrally and the crista prootica anterodorsally Figure 9). Here there is a large opening for the fenestra ovalis and the metotic foramen; however, the two cannot be 
457 distinguished because the ventral ramus of the opisthotic that divides the two openings in

458 aetosaurians (Gower \& Walker 2002) is not preserved (Figure 9). It is not clear if the ventral

459 ramus was never originally preserved or if it was removed during preparation of the braincase.

460 Thus the perilymphatic foramen is not preserved as well. The embryonic metotic fissure is

461 undivided in aetosaurs and therefore the glossopharyngeal, vagal, and accessory (IX, X, XI)

462 nerves and the jugular vein would have exited the braincase via a single opening, the metotic

463 foramen (Gower \& Walker 2002; also see Rieppel 1985; Walker 1990). Just lateral to the metotic

464 foramen on the ventral surface of the crista prootica there should be a small opening for the facial

465 nerve (VII); however, it is not visible through the hematite build-up on the lateral wall of the

466 cranium.

467 A second distinct groove extends from the ventral border of the fenestra ovalis

468 anteroventrally along the lateral face of the parabasisphenoid to the posterodorsal margin of the

469 basipterygoid process, and is bordered anterodorsally by the anteroventral continuation of the

470 crista prootica (Figure 9). The termination of that groove houses the entrance of the cerebral

471 branch of the internal carotid artery (Gower \& Walker 2002; Sulej 2010).

\section{Prootic}

473 The entire braincase is slightly crushed and rotated dorsolaterally so that the left side of

474 the otic capsule is easier to view (Figure 9). Both prootics are preserved. Posteriorly, the prootic

475 overlaps the opisthotic medially, and ventrolaterally forms a thin ridge (crista prootica), which is

476 bounded ventrally by the upper part of the 'stapedial groove' and the groove in the

477 parabasisphenoid leading to an opening for the internal carotid. Anteroventrally, the prootic

478 meets the anterior portion of the parabasisphenoid, just posterior to the hypophyseal fossa.

479 Anteriorly and anterodorsally, the prootic meets the laterosphenoid and dorsally it is bounded by 
480 the parietal. The uppermost margin is deformed by a thick anteroposteriorly oriented mass of

481 bone, which could represent crushing of the parietal margin. Just posterior to the anterior suture

482 with the laterosphenoid is the opening for the trigeminal nerve (V) which is deformed and closed

483 by crushing (Figure 9). In PEFO 34616 the opening for the trigeminal nerve is completely

484 enclosed by the prootic. This is similar to the condition in Stagonolepis olenkae (Sulej, 2010),

485 Stagonolepis robertsoni (Walker, 1961), and Longosuchus meadei (TMM 31185-98) and appears

486 to be typical for all aetosaurs; however, Small (2002) shows the trigeminal opening subdivided in

487 the skull of Desmatosuchus smalli although he does not describe it.

\section{Laterosphenoid}

489 The laterosphenoids are ossified but poorly preserved. On the left side anterodorsal to the 490 opening for the trigeminal nerve (V), there is the cotylar crest, which is crescentic and opens

491 posteriorly (Figure 9). No other details of the laterosphenoid can be determined.

\section{Basioccipital/Parabasisphenoid}

493 The basioccipital and parabasisphenoid are complete and together comprise the best

494 preserved and most distinctive portion of the braincase in Scutarx deltatylus (Figure 10). The

495 occipital condyle is transversely ovate in posterior view rather than round like in other aetosaurs

496 such as Longosuchus meadei (TMM 31185-98) and Desmatosuchus smalli (TTU P-9024). The

497 dorsal surface is broad with a wide shallow groove for the spinal cord.

498 The condylar stalk is also broad ( $25 \mathrm{~mm}$ wide), and wider than the condyle. Thus there is

499 no distinct 'neck,' nor does a sharp ridge delineate the condyle from the stalk as in Longosuchus

500 meadei (TMM 31185-98; Parrish 1994) or Desmatosuchus smalli (TTU P-9024; Small 2002).

501 The ventral surface of the condylar stalk bears two low rounded 'keels' separated by a shallow,

502 but distinct, oblong pit. The broad stalk, lack of a distinct neck, and ventral keels all appear to be 
503 autapomorphic for Scutarx deltatylus. Anterolaterally the condylar stalk expands laterally to form

504 the ventral margin of the metotic fissure. The contacts with the exoccipitals are dorsal and

505 posterior to that margin.

506 The right basal tuber of the basioccipital is present, but the left is missing. The

507 basioccipital tuber is separated from the crescentic basal tuber of the parabasisphenoid by an

508 unossified cleft, typical for aetosaurians and other suchians (Figure 10; Gower \& Walker 2002).

509 The basal tubera of the basioccipital are divided medially by an anteroposteriorly oriented bony

510 ridge that bifurcates anteriorly to form the crescentic basal tubera of the parabasisphenoid and

511 enclose the posterior portion of the basisphenoid recess (sensu Witmer 1997). Posteriorly that

512 bony ridge is confluent with the posteriorly concave posterior margin of the basioccipital basal

513 tubera (Figure 10). The short, anterolaterally directed basipterygoid processes are located

514 anteriorly and in contact posteriorly with the anterior margin of the basal tubera of the

515 parabasisphenoid. The upper portion of the distal end of the left basipterygoid process is broken,

516 but the right is complete and bears a slightly expanded and slightly concave distal facet that faces

517 anterolaterally to contact the posterior process of the pterygoid.

518 The basipterygoid processes and the basal tubera are positioned in the same horizontal

519 plane (Figure 9), which is typical for aetosaurians and differs significantly from the condition in

520 Revueltosaurus callenderi (PEFO 34561) and Postosuchus kirkpatrickorum (TTU P-9000;

521 Weinbaum 2011; emend Parker 2016) in which the basicranium is oriented more vertically, with

522 the basipterygoid processes situated much lower dorsoventrally than the basal tubera.

523 Scutarx deltatylus differs from aetosaurians such as Stagonolepis robertsoni (MCZD 2),

524 Neoaetosauroides engaeus (PVL 5698), and Aetosauroides scagliai (PVSJ 326) in that there is a

525 broad contact between the basal tubera and the basipterygoid processes and that the basipterygoid 
526 processes are not elongate (Figure 10). This is nearly identical to the condition in Desmatosuchus

527 smalli (TTU P-9023) and Desmatosuchus spurensis (UMMP 7476; Case 1922). There are two

528 basicrania (UCMP 27414, UCMP 27419) from the Placerias Quarry with widely separated

529 (anteroposteriorly) basal tubera and (elongate) basipterygoid processes that apparently do not

530 pertain to either Desmatosuchus or Scutarx deltatylus, and may belong to Calyptosuchus wellesi.

531 This would demonstrate a potential important braincase difference between Calyptosuchus

532 wellesi and Scutarx deltatylus, despite the nearly identical structure of the osteoderms shared

533 between these two taxa.

534 In the anteroposteriorly short area between the basal tubera and the basipterygoid

535 processes, a deep, subrounded fossa (Figure 10) comprises the basisphenoid recess (=median

536 pharyngeal recess of Gower and Walker, 2002; =parabasisphenoid recess of Nesbitt, 2011),

537 which is formed by the median pharyngeal system (Witmer 1997). The presence of a 'deep

538 hemispherical fontanelle' (= basisphenoid recess) between the basal tubera and the basipterygoid

539 processes has been proposed as a synapomorphy of Desmatosuchus and Longosuchus (Parrish

540 1994), but, as discussed by Gower and Walker (2002), that condition is present in many

541 archosauriforms. The number of aetosaurian taxa with this feature was expanded by Heckert and

542 Lucas (1999), who also reported that a 'hemispherical fontanelle' is absent in Typothorax and

543 Aetosaurus. Unfortunately they did not list catalog numbers for examined specimens, and scoring

544 of character occurrences cannot be replicated. The basisphenoid recess is actually present in

545 Aetosaurus (Schoch 2007), Paratypothorax (SMNS 19003), Neoaetosauroides (PVL 5698), and

546 Typothorax (TTU P-9214; Martz 2002). Thus, the presence of that recess is an aetosaurian

547 synapomorphy. 
549 hypodigm of Desmatosuchus haplocerus, and recommended that the character be dropped from

550 phylogenetic analysis pending further review. However, rather than utilizing the presence or

551 absence of the structure, it has been proposed that the shape and depth may be of phylogenetic

552 significance (Gower \& Walker 2002). As noted above, it appears that there are two types of

553 aetosaurian basicrania, those with anteroposteriorly short parabasisphenoids and those with long

554 parabasisphenoids. These differences were used as rationale for splitting Desmatosuchus

555 haplocerus into two species (Parker 2005b). Among taxa with short parabasisphenoids, Scutarx

556 deltatylus (PEFO 34616) and Desmatosuchus spurensis (UMMP 7476) have deep, more or less

557 round basisphenoid recesses, and Desmatosuchus smalli has a shallow subtriangular recess. In

558 Longosuchus meadei (TMM 31185-98) the recess is round and shallow. Among taxa with

559 elongate basisphenoids, Aetosauroides scagliai (PVSJ 326) has a shallow, round recess and

560 Tecovasuchus chatterjeei (TTU P-545) has a deep, round recess. However, in Coahomasuchus

561 kahleorum (NMMNH P-18496; TMM 31100-437), which has an elongate basisphenoid, the

562 recess has the form of a moderately deep, anteroposteriorly elongate oval (Desojo \& Heckert

563 2004; pers. obs. of TMM 31100-437). Thus, the shape of this structure is highly variable and

564 most likely not phylogenetically informative, although the elongate form of the recess in $C$.

565 kahleorum may prove autapomorphic.

566 Anterior to the basisphenoid recess and between the bases of the basipterygoid processes

567 there is another shallow, anteroventrally opening recess (Figure 10). This recess is at the base of

568 the parasphenoid process, in the same position as the subsellar recess in theropod dinosaurs

569 (Witmer 1997; Rauhut 2004) and may be homologous to the latter. However, the function and 
570 origin of the recess are not understood (Witmer 1997). It is also present in Neoaetosauroides

571 engaeus (PVL 5698) and may have a broader distribution within Aetosauria.

572 Dorsal to the basipterygoid processes, two crescentic and dorsally expanding clinoid

573 processes flank the circular, concave hypophyseal fossa, which housed the pituitary gland (Figure

574 9). No openings are visible because of poor preservation, but the dorsum sellae should be pierced

575 by two canals for the abducens (VI) nerves (Hopson 1979; Gower \& Walker 2002). At the base

576 of the hypophyseal fossa in Stagonolepis robertsoni (MCZD 2) and Longosuchus meadei (TMM

577 31185-98) there is a triangular flange of bone termed the parabasisphenoid prow (Gower \&

578 Walker 2002). This structure is mostly eroded in PEFO 34616, although its base is preserved as a

579 small dorsal protuberance.

580 Anterior to this, the cultriform process of the parasphenoid is completely preserved

581 (Figures 9-10). This structure is delicate and usually missing, obscured, or in articulation with

582 the pterygoids in the few known aetosaur skulls, making comparisons difficult. However, the

583 process is notably short in PEFO 34616, barely extending past the anterior margins of the orbits

584 (Figure 9). In PEFO 34616 the basisphenoid has a length of $34.2 \mathrm{~mm}$, whereas the cultriform

585 process measures $20.2 \mathrm{~mm}$ in length (cultriform process/basisphenoid ratio $=0.59$ ). This is

586 noticeably different from the parabasisphenoid in Aetosauroides scagliai (PVSJ 326) which has a

587 basisphenoid length of $51 \mathrm{~mm}$ and a cultriform process length of at least $63 \mathrm{~mm}$, although the

588 anterior end of the process is concealed (ratio $=1.23$ ) beneath the left pterygoid. The cultriform

589 process is also preserved in Desmatosuchus spurensis (UMMP 7476), which has a relatively

590 short parabasisphenoid and a cultriform process/basisphenoid ratio of 0.96 .

591 The cultriform process is elongate and tapers anteriorly. It is Y-shaped in cross-section

592 with a ventral ridge, and dorsal trough for the ethmoid cartilage. Its posterolateral margins bear 
593 distinct oval recesses bound posterodorsally by strong ridges that are confluent with the

594 posterodorsal edge of the process (Figures 9-10). Thus the process is broader posteriorly, with

595 these recesses contributing greatly to the thinning of the element anteriorly. The parasphenoid

596 recesses appear to be unique to PEFO 34616, although the general lack of known aetosaurian

597 cultriform processes, or their preservation articulated with the pterygoids, makes it difficult to

598 determine this with certainty.

599 Postcranial skeleton

600 Vertebrae

601 Cervical Series

602 Post-axial Cervicals

603 Two articulated cervical vertebrae are preserved in PEFO 31217 (Figure 11). Although

604 both are crushed mediolaterally, they are nearly complete and preserve many details. The centra

605 are taller than long (Figure 11a) suggesting they represent part of the anterior (post-axial) series

606 (i.e., positions 3-6). Most notably, the difference in dimensions is not as pronounced as in

607 Typothorax coccinarum and Neoaetosauroides engaeus, in which the centra are greatly reduced

608 in length (Long \& Murry 1995; Desojo \& Báez 2005; Heckert et al., 2010). The centrum faces

609 are subcircular in anterior and posterior views and slightly concave, with slightly flared rims

610 (Figures 11b-c). The ventral surface of each centrum consists of two concave, ventromedially

611 inclined, rectangular surfaces divided by a sharp and deep mid-line keel (Figure 11d).

612 The short parapophyses are oval in cross-section and situated at the anteroventral corners

613 of the centrum. The parapophyses are directed posteriorly, and each forms the beginning of a

614 prominent ridge that extends to the posterior margin of the centrum. The lateral faces of the

615 centra are concave mediolaterally and dorsoventrally form discrete, but shallow, lateral fossae 
616 that contact the neural arch dorsally (Figure 11a). However, PEFO 31217 lacks the deep lateral

617 fossae, which are considered an autapomorphy of Aetosauroides scagliai (Desojo \& Ezcurra

618 2011). The neurocentral sutures are not apparent on this specimen, suggesting closure of the

619 sutures and that this individual is osteologically 'mature' although this cannot be completely

620 confirmed without histological sectioning of the sutural contact (Brochu 1996; Irmis 2007).

621 The diapophyses are centrally located at the base of the neural arch (Figure 11b). The best

622 preserved vertebra shows that they are slightly elongate, oval in cross-section, and curved

623 ventrolaterally. Because none of the diapophyses appears to be complete their exact length cannot

624 be determined. The neural canal is round in posterior view (Figure 11c) rather than rectangular as

625 in Desmatosuchus spurensis (UMMP 7504). The entire neural arch is taller than the

626 corresponding centrum face. The zygapophyses are well-formed, elongate, and oriented at

627 approximately 45 degrees from the horizontal.

628 Aetosaurian vertebrae bear several vertebral laminae and associated fossae. The

629 terminology for these structures follows Wilson (1999) and Wilson et al. (2011). There is a

630 weakly developed posterior centrodiapophyseal lamina (pcdl) that originates at the posteroventral

631 corner of the diapophysis and continues posteroventrally to the posterior edge of the neurocentral

632 suture. The only other apparent vertebral laminae are paired intrapostzygapophyseal laminae

633 (tpol) that originate on the posteroventral surface of the postzygapophyses and form two sharp

634 ridges (laminae) that meet at the dorsomedial margin of the neural canal (Figure 11b). Those

635 laminae delineate the medial margins of a pair of distinct lateral fossae, called the

636 postzygapophyseal centrodiapophyseal fossae (pocdf), as well as a sizeable medial fossa, called

637 the spinopostzygapophseal fossa (spof). This represents the first recognition of distinct

638 intrapostzygapophyseal laminae in an aetosaurian. Desmatosuchus spurensis (MNA V9300) has 
639 struts of bone from the dorsomedial margins of the postzygapophyses that join medially and then

640 extend ventrally as a single thickened unit to form a Y-shaped hyposphene (Parker 2008a: fig.

641 10a), similar to the pattern formed by the intrapostzygapophyseal laminae in Scutarx deltatylus.

642 Thus, it is possible that the structure of the hyposphene in aetosaurians is homologous (i.e., the

643 hyposphene is actually formed by paired vertebral laminae) with the presence of paired (but not

644 joined) intrapostzygapophyseal laminae, but this interpretation requires further investigation.

645 The neural spines are not complete; however, the base of the one on the second preserved

646 vertebra shows that the spine was anteroposteriorly elongate, with prominent

647 spinopostzygapophyseal laminae (spol) that are confluent with the dorsal surfaces of the

648 postzygapophyses (Figure 11b). Spinopostzygapophyseal laminae are also present on the cervical

649 vertebrae of Desmatosuchus spurensis (Parker 2008a).

\section{Trunk Series}

\section{Mid-trunk vertebrae}

652 Four mid-trunk vertebrae are preserved in PEFO 34045. In aetosaurs the cervical to trunk

653 transition occurs when the parapophysis fully migrates from the base of the neural arch, laterally

654 onto the ventral surface of the transverse process (Case 1922; Parker 2008a). PEFO 34045/FF-51

655 is well preserved, missing only the postzygapophyses (Figures 12a-c). The articular faces of the

656 centra are round and slightly concave with broad flaring rims. The centrum is longer $(45.78 \mathrm{~mm})$

657 than tall $(41.81 \mathrm{~mm})$, its lateral faces are deeply concave, and its ventral surface is narrow and

658 smooth. The neural canal is large and in anterior view, the margins of the neural arch lateral to

659 the canal are mediolaterally thin with sharp anterior edges.

660 The prezygapophyses are inclined at about 45 degrees from the horizontal and are

661 confluent laterally with a short horizontally oriented prezygadiapophyseal lamina (prdl) that 
662 terminates laterally at the parapophysis (Figure 12b). Between the prezygapophyses and ventral

663 to the base of the neural spine there is a well-developed broad, sub-triangular

664 spinoprezygapophyseal fossa (sprf). In combination with the flat prezygapophyses this creates a

665 broad shelf for reception of the posterior portion of the neural arch of the preceding vertebra

666 (Figure 12b). There is a horizontal, ventral bar that roofs the opening of the neural canal between

667 the ventromedial edges of the prezygapophyses (Figure 13a); thus, there is no developed

668 hypantrum as in Desmatosuchus spurensis or Aetobarbakinoides brasiliensis (Desojo, Ezcurra \&

669 Kischlat 2012; Parker 2008a). The ventral bar also occurs in Stagonolepis robertsoni (Walker

670 1961: fig 7j). Ventrolateral to the prezygapophysis there is a deep centroprezygapophyseal fossa

671 (cprf), which is bordered posteriorly by the main strut of the transverse process (Figure 12b).

672 Although the positions of these fossae appear homologous with those of saurischian dinosaurs

673 because they share distinct topological landmarks, it is not clear if these features are similarly

674 related to the respiratory system as they are in saurischians (Butler, Barrett \& Gower 2012;

675 Wilson et al. 2011).

676 In posterior view, the postzygapophyses (best preserved in PEFO 34045/14-R) are also

677 oriented about 45 degrees above the horizontal. They are triangular in posterior view with a well-

678 developed lateral postzygadiapophyseal lamina (podl). That lamina extends laterally to the

679 diapophysis and forms a broad dorsal shelf of the transverse process in dorsal view (Figure 12a).

680 The shelf is wider proximally and narrows distally along the transverse process. Along the dorsal

681 surface of the shelf, between the postzygapophyses and the neural spine is a pair of shallow

682 postzygapophyseal spinodiapophyseal fossae (posdf).

683 The neural spine is short $(32.3 \mathrm{~mm})$ relative to the centrum height as in Desmatosuchus

684 spurensis (MNA V9300) and Typothorax coccinarum (TTU P-9214). The spine is 
685 anteroposteriorly elongate, equal in length to the proximal portion of the neural arch, and the

686 distal end is mediolaterally expanded (spine table). The anterior and posterior margins of the

687 neural spine possess paired vertical spinoprezygapophyseal (sprl) and spinopostzygapophyseal

688 (spol) laminae as in Desmatosuchus spurensis (MNA V9300).

689 The postzygapophyses bound deep oval spinopostzygapophyseal fossae (spof). These

690 fossae are much taller than wide and are bounded laterally by thin, nearly vertical

691 intrapostzygapophyseal laminae (tpol). These laminae meet medially at a thickened triangular

692 area dorsal to the neural canal. Here the vertebra bears a strong posteriorly pointed projection that

693 inserts into the ventral portion of the spinoprezygapophyseal fossa (sprf) just above the ventral

694 bar. This projection is also present in Calyptosuchus wellesi (e.g., UCMP 139795). Ventrolateral

695 to the postzygapophyses there are two deep centropostzygapophyseal fossae (cpof) in the

696 proximal portions of the transverse processes.

697 The transverse processes extend laterally with a length of $81.6 \mathrm{~mm}$ in PEFO 34045/FF-51.

698 However, in two of the other vertebrae (PEFO 34045/14-R; PEFO 34045/19-V) the transverse

699 processes are directed more dorsolaterally (Figures 13a-b). This difference also occurs in

700 Stagonolepis robertsoni (Walker 1961) in the more anteriorly positioned trunk vertebrae.

701 Furthermore, the ventral surface of the centrum in these two vertebra (PEFO 34045/14-R; 19-V)

702 is more constricted forming a blunt ventral 'keel'. The keel and the orientation of the transverse

703 process are the only visible differences between and anterior and mid-trunk vertebrae in Scutarx 704 deltatylus.

\section{Posterior trunk vertebrae}

706 The currently available material of Scutarx deltatylus includes seven posterior trunk

707 vertebrae; three from PEFO 34045, three from PEFO 31217, and one from PEFO 34919. As in 
708

709

710

711

712 loss of distinct parapophyses and diapophyses along the series. Furthermore, the centra become

713 anteroposteriorly shorter than they are dorsoventrally tall (Figure 13e). The neural spine

714 characteristics are identical to those of the mid-trunk vertebrae with regard to the presence of the

715 various vertebral laminae and associated fossae. An isolated posterior trunk vertebra from PEFO

71631217 (Figure 14c) shows that the prezygadiapophyseal laminae are even more strongly

717 developed and extend farther laterally than in the more anterior trunk vertebrae. In the more

718 posterior vertebra, the length ratio between the transverse process length $(86.84 \mathrm{~mm})$ and centrum

719 width $(53.26 \mathrm{~mm})$ equals 1.63 , thus the process is more than 1.5 times the width of the centrum.

720 This is comparable to a ratio of 1.58 for the mid-trunk vertebrae.

721

722

723

724

725

726

727

728

729

730
This same vertebra from PEFO 31217 also lacks distinct diapophyses and parapophyses

and a single-headed rib is fused onto the distal end of the process (Figure 14c). This is also seen in Desmatosuchus spurensis (Parker 2008a), Stagonolepis robertsoni (Walker 1961), and

Calyptosuchus wellesi (UMMP 13950). An isolated posterior trunk vertebra from PEFO 34045

(Figures 13a-b) preserves the entire transverse processes and the associated fused ribs. However, the specimen differs from the previously described vertebra from PEFO 31217 in that the parapophysis and diapophysis are distinct and the rib is double-headed (Figures 14a-b). Although the ribs and transverse processes are fused, the fusion is incomplete; gaps are present within the individual articulations and another gap is apparent between the anterior surface of the distal end of the transverse process and the medial surface of the capitulum of the rib (Figure 14b). This 
731 suggests that several vertebrae in the posterior trunk series fuse with the ribs, and loss of a

732 distinct parapophysis and diapophysis of the transverse process and of the tuberculum and

733 capitulum of the dorsal ribs only occurred in the last one or two presacrals. Examination of

734 UMMP 13950 (Case 1932; Long \& Murry 1995) suggests that this loss occurs in the last three

735 presacrals. In Stagonolepis robertsoni that condition occurs in the final two presacral vertebrae

736 (Walker 1961). There is no evidence in Scutarx deltatylus that the last presacral was incorporated

737 into the sacrum as in Desmatosuchus spurensis (Parker 2008a). The last presacral in PEFO 31217

738 also shows a distinct vertical offset in the ventral margins of the articular faces of the centra with

739 the anterior face situated more ventrally. This is also the case in Stagonolepis robertsoni (Walker

740 1961) and Desmatosuchus spurensis (Parker 2008a).

741 Another posterior trunk vertebra, PEFO 34045/22 (Figures 13d-e), lacks the transverse

742 processes, but preserves other key characteristics of the posterior presacrals. Its neural spine is

743 taller $(81.94 \mathrm{~mm})$ than the height of the centrum $(61.24 \mathrm{~mm})$, differing from the condition in the

744 anterior and mid-trunk vertebrae where the neural spine is shorter than the centrum (Figure 13d).

745 This transition occurs at the beginning of the posterior trunk vertebrae series, because the

746 specimen from PEFO 34045 with the fused ribs, but distinct rib facets (Figures 14a-b), has a

747 centrum and neural spine of equal height. PEFO 34045/22 also preserves the pointed posterior

748 projection above the neural arch that is present throughout the trunk series (Figure 13e).

749 Sacral vertebrae

750 A sacral vertebra, probably the second, is visible in ventral view in PEFO 31217 in

751 articulation with the rest of the pelvis (Figure 15). It is recognizable by the presence of a strong,

752 broad sacral rib that expands laterally and anterodorsally to contact the posterodorsal margin of

753 the left ilium. Unfortunately no other details are available for that specimen. 


\section{Caudal series.}

755 Vertebrae

756 Eight vertebrae occur in semi-articulation in PEFO 31217 posterior to the sacral vertebra

757 described previously (Figure 15). The first two are robust with thick flaring rims on the centra.

758 The first vertebra has a length of $57.3 \mathrm{~mm}$, and its anterior face is indistinguishable from the

759 posterior face of the preceding sacral vertebra. Furthermore, the centrum is constricted which is

760 unusual for an aetosaur, because the sacrals and anterior caudals usually have wide ventral

761 surfaces (e.g., Desmatosuchus spurensis, MNA V9300). The vertebra in PEFO 31217 lacks a

762 ventral groove and chevron facets. It is possible that this is a sacral vertebra that has been forced

763 backwards, but the poor preservation of the specimen does not allow a firm determination. The

764 second caudal vertebra (assuming the first described is from the caudal series) has a centrum

765 length of $52.2 \mathrm{~mm}$ and a width of $61.6 \mathrm{~mm}$, thus it is wider than long as is typical for the anterior

766 caudals of aetosaurians (Long \& Murry 1995). The centrum is ventrally broad and a chevron is

767 articulated to the posterior margin. The base of the caudal rib originates from the base of the

768 neural arch, but laterally the rib is incomplete.

769 Two anterior caudal vertebrae are also known from PEFO 34045, which roughly

770 correspond in morphology to the second and third caudal centra of PEFO 31217 (Figures 16a-f).

771 These two vertebrae have blocky centra that are wider (flared centrum faces) than long. The

772 ventral surfaces are broad, with a deep median trough bordered by two lateral ridges. These

773 ridges terminate posteriorly into two posteroventrally facing hemispherical chevron facets

774 (Figures 16d-e). The articular faces of the centra are round in anterior and posterior views, and in

775 lateral view these faces are offset from each other (Figure 16f). The ventral margin of the

776 posterior face is situated much farther ventrally than that of the anterior face, as is typical for

777 aetosaurs (e.g., Desmatosuchus spurensis, MNA V9300). Although the neural spines are missing, 
778 it is apparent that the neural arch complex was much taller than the height of the centrum (Figure

779 16c). The neural canal is oval with a taller dorsoventral axis.

780 The pre- and postzygapophyseal stalks are thickened and the facets are closely situated

781 medially. They are oriented at about 30 degrees from the horizontal. The neural arch is directed

782 posterodorsally and the postzygapophyses project posteriorly significantly beyond the posterior

783 centrum face (Figure 16c). The caudal vertebrae lack diapophyseal and zygapophyseal laminae,

784 but spinozygapophyseal fossae occur between the prezygapophyses (Figures 16a-b). The caudal

785 ribs are fully fused to the centrum. They are anteroposteriorly broad and dorsoventrally thin with

786 flat dorsal surfaces and buttressed ventral margins. The ribs are directed slightly posteriorly and

787 laterally they arc ventrally (Figures 16a-c). Unfortunately their lateral extent is unknown.

788 The third and fourth caudal vertebrae in PEFO 31217 are longer than wide, with the

789 centrum narrowing mediolaterally and with reduced flaring of the rims as in the previous

790 vertebrae (Figure 15). The posteroventral margins possess chevron facets. The caudal ribs are

791 broad, flat, and were elongate, as in Desmatosuchus spurensis (MNA V9300), even though the

792 distal ends are not preserved. The third centrum has a length of $56.4 \mathrm{~mm}$ and the fourth has a

793 length of $56.4 \mathrm{~mm}$. Details of the neural arches and spines are buried in the block and

794 irretrievable by mechanical preparation.

795 The fifth and sixth caudal vertebrae are mostly concealed beneath armor, bone fragments,

796 and what are probably the eighth and ninth caudal vertebrae. Only the left caudal ribs are

797 apparent, jutting out of the block. They are dorsoventrally flat and laterally elongate, typical for

798 aetosaurs, but they are poorly preserved and no other details are apparent.

799 The anterior face of what is probably the seventh caudal vertebra is visible underneath

800 matrix and an osteoderm about six centimeters behind where the sixth caudal vertebra is buried in 
801 the block, breaking the line of articulation. The neural canal is prominent on this vertebra and

802 what is visible of the neural arch shows that it was tall. The centrum is amphicoelous and

803 mediolaterally constricted. The ventral surface consists of a median ventral groove bounded

804 laterally by two sharp ridges. The ridges would terminate posteriorly with the chevron facets, but

805 the relevant area is obliterated. A vertebra from approximately the same position is preserved in

806 PEFO 34919 (Figures 17a-c) and provides more details.

807 The centrum is much longer than wide (57 $\mathrm{mm}$ to $\sim 30 \mathrm{~mm})$, mediolaterally compressed,

808 and grooved ventrally. Its rims flare minimally, but the articular faces are deeply concave (Figure

$80917 \mathrm{~b}-\mathrm{c})$. The neural arch is dorsoventrally shorter than in the more anteriorly positioned caudal

810 vertebrae, but the neural spine was certainly tall in this position as well (Figure 17b). The

811 zygapophyses are reduced and each pair is closely situated medially. The postzygapophyses do

812 not project far posteriorly. The caudal rib is situated anteroventrally on the neural arch. It is broad

813 and flat, extends laterally $(\sim 50 \mathrm{~mm})$, and is slightly arcuate in anterior view (Figure $17 \mathrm{~b})$.

814 What are probably the eighth and ninth caudal vertebrae are well-preserved at the edge of

815 the block in PEFO 31217 (Figure 15). The centra are much longer than wide. The ninth centrum

816 has a length of $66.3 \mathrm{~mm}$ and a width of $40.2 \mathrm{~mm}$. The lateral faces of the centrum are concave

817 and, as on the preceding centra, the ventral face is narrow with a deep median groove terminating

818 at the chevron facets. The neural arches and spines are complete and tall, with a height of 100.9

$819 \mathrm{~mm}$ in the eighth vertebra and $98.4 \mathrm{~mm}$ in the ninth. The neural spines are tall and roughly

820 triangular in lateral view, with an anteroposteriorly broad base and tapering distally. The

821 zygapophyses are closely situated medially and extend anteriorly and posteriorly beyond the

822 articular faces of the centra. The caudal ribs are greatly reduced in lateral length. 
824 centrum is longer than tall $(65 \mathrm{~mm}$ to $35 \mathrm{~mm})$ and mediolaterally compressed. Its articular faces

825 are deeply concave and oval with the longest axis situated dorsoventrally. The neural arch is

826 dorsolaterally reduced and mediolaterally compressed. The caudal ribs are greatly reduced and

827 eroded. The neural spine is elongate, but its full dorsal extent is unknown (Figure 17d).

\section{Chevrons}

829 Only half of a single chevron and part of the head of a second are preserved in PEFO

83034045 (Figures 18a-b). A few are smashed beneath other elements in PEFO 34919 and a badly

831 preserved chevron is present beneath the second caudal vertebra of PEFO 31217. Although the

832 details are poor the latter suggests, in accordance with the lack of facets on the first caudal

833 vertebra of PEFO 31217, that chevrons started on the second caudal centrum. This is different

834 from the condition in Desmatosuchus spurensis, in which they first appear on the third caudal

835 centrum (Parker 2008a), but similar to the condition in Typothorax coccinarum (Heckert et al.

836 2010). The two preserved chevrons in PEFO 34045 are of the 'slim' elongate type and, therefore,

837 from the anterior portion of the tail (Parker 2008a).

838 Ribs

839 Presacral

840 No cervical ribs are preserved in any of the specimens, but trunk ribs are common. The

841 sacral and caudal ribs have been described above along with their associated vertebrae. The

842 anterior and mid-trunk ribs are double-headed (Figure 18c-d). They extend laterally for the first

843 quarter of their total length and then turn sharply ventrolaterally, are straight for half of the total

844 length, and then gently turn more ventrally. Proximally the rib body is oval in cross-section, 
845 becoming ovate and then flattened more distally; it is broadest at the point of the sharp

846 ventrolateral turn.

847 The capitulum is oval in cross-section, with a sharp posterior projection. The capitulum

848 and tuberculum are separated by $44 \mathrm{~mm}$. The dorsal surface of the neck is marked by a transverse

849 groove that terminates at a fossa on the proximal surface of the tuberculum (Figure 18e). That

850 groove probably hosted the ventral portion of the vertebrarterial canal as in Alligator (Reese

851 1915). A thin flange of bone originates on the dorsal surface of the tuberculum and extends

852 laterally, becoming confluent with the rib body just lateral to the ventrolateral hook. That flange

853 forms a deep, elongate groove along the posterodorsal surface of the rib. Dorsally the rib is

854 flattened and forms a thin anterior blade. The posteriormost ribs are single headed and fused with

855 the transverse processes of the trunk vertebrae (Figure 14c).

\section{Gastralia}

857 It has been suggested that aetosaurians lack gastralia (Nesbitt 2011), but they are present

858 in Typothorax coccinarum and Stenomyti huangae (Heckert et al. 2010; Small and Martz, 2013).

859 In Typothorax coccinarum (e.g., NMMNH P-56299), the gastralia are preserved in the

860 posteroventral portion of the thoracic region, are medially fused and laterally elongate. The

861 gastralia of Stenomyti huangae (DMNH [DMNS] 60708) are presently undescribed. A single

862 gastralia set is preserved in PEFO 34616 demonstrating that they were present in Scutarx

863 deltatylus as well (Figure 18f). This set consists of incomplete but medially fused ribs with a

864 short anterior projection. 
865 Appendicular Girdles

866 Scapulocoracoid

867 The left scapulocoracoid is preserved in PEFO 31217; unfortunately the coracoid is

868 covered by osteoderms that cannot be removed without causing significant damage, so only the

869 dorsal-most portion of the coracoid, where it sutures to the scapula, is visible. In lateral view the

870 general outline of the scapula of PEFO 31217 (Figure 19a) strongly resembles the

871 scapulocoracoid of Stagonolepis robertsoni (Walker 1961: fig. 12a); although it is broader

872 anteroposteriorly. The proximal end is expanded anterolaterally with the posterior projection

873 situated more dorsally than the anterior projection. The posterior projection has a rounded

874 posterior margin, as in Stagonolepis robertsoni (Walker 1961) differing from the pointed

875 projection in Stagonolepis olenkae (ZPAL AbIII/694). The anterior projection is poorly preserved

876 but appears to be pointed as in Stagonolepis robertsoni (Walker 1961). The scapular blade is

877 gently bowed medially and the posterior edge is straight except for a slight posterior projection

878 (the triceps tubercle) about $62 \mathrm{~mm}$ above the glenoid lip (Figure 19a). The anterior edge of the

879 blade is straight for most of its length until it strongly flares anteriorly, forming a prominent

880 deltoid ridge (=acromion process; Brochu 1992; Martz 2002). Below this there is a prominent

881 foramen, although its anterior edge is broken away. Likewise the ventral margin of the posterior

882 edge of the scapular blade strongly flares posteriorly forming the supraglenoid buttress. The

883 glenoid facet opens posteriorly. Laterally there is a sharp ridge, which probably represents

884 deformation and crushing along the scapulocoracoid suture.

\section{Ilium}

886 Ilia are preserved in PEFO 34919 (right ilium; Figure 20) and PEFO 31217 (both ilia; Figures 15,

887 21). When articulated the ilia of Scutarx deltatylus were oriented so that the acetabula faced

888 ventrally as in some aetosaurs such as Aetosauroides scagliai (PVL 2073) and Typothorax 
889 coccinarum (PEFO 33980); however, to avoid confusion in this description, the anatomical

890 directions will be provided as if the reader is viewing the ventral surface as the lateral surface

891 (see Figure 20a-b). The right ilium of PEFO 34919 is nearly complete, missing only a portion of

892 the anterior margin of the acetabulum (Figures 20a-b). As usual for the bones from this specimen,

893 the ilium is covered with a thin layer of weathered hematite that cannot be removed without

894 damaging the underlying bone. The iliac blade is complete, with a length of $196 \mathrm{~mm}$ and a mid-

895 height of $66.8 \mathrm{~mm}$. The 'dorsal' margin of the iliac blade is mediolaterally narrow, expanding

896 anteriorly so that the dorsal margin of the anterior process is thicker and more robust than the rest

897 of the blade. The anterior portion of the iliac blade is triangular in lateral view, and does not

898 extend anteriorly beyond the edge of the pubic peduncle as in Stagonolepis robertsoni (Walker,

899 1961). There is a prominent recess on the dorsal surface between the supraacetabular crest and

900 the posterior iliac blade (Figure 20a) that appears to be unique to Scutarx deltatylus.

901 The dorsoventral height of the posterior portion of the iliac blade diminishes posteriorly,

902 terminating in a point. From there the posteroventral margin slopes anteroventrally into a curving

903 posterior margin that distally hooks posteriorly and thickens to form the ischiadic peduncle. The

904 posterior projection of the ischiadic peduncle is proportionally larger and more pointed than the

905 same structure in Aetosauroides scagliai (PVL 2073) and Stagonolepis robertsoni (NHMUK

906 R4789a), and more like that of TMM 31100-1, which represents a desmatosuchine aetosaurine

907 (unpublished data). The ventral margins of the pubic and ischiadic peduncles meet at an angle of

90890 degrees ventral to the acetabulum, with the ilium contributing to the majority of the

909 acetabulum. In ventral view the margins of the peduncles are comma-shaped, thinning into the

910 ventral margin of the broadly concave acetabulum. The medial side of the acetabulum is smooth

911 and slightly convex. 
912 Dorsal to the iliac neck, the medial side of the posterior portion of the iliac blade bears a

913 prominent ventral ridge that forms a shelf for sacral rib articulation (Figure 20b). The rib scar is

914 situated just above the ridge and forms a concave sulcus that extends anteriorly to just dorsal to

915 the anterior margin of the neck.

916 Both ilia are present in PEFO 31217 as portions of a complete sacrum. Of the two the left

917 is the better preserved. The acetabula are deeply concave and oriented ventrally (Figures 15, 21).

918 Originally this was thought to be the result of crushing of the pelvis; however, the acetabula are

919 oriented ventrally in many other uncrushed aetosaurian specimens including Aetosauroides

920 scagliai (Heckert \& Lucas 2002), the holotype of Typothorax antiquus (Lucas, Heckert \& Hunt

921 2003), and Typothorax coccinarum (Heckert et al. 2010). The supraacetabular ridge in these ilia

922 is strong, but not as strong as in rauisuchids. As in PEFO 34919, there is a deep fossa/recess on

923 the dorsal surface between the supraacetabular ridge and the posterior portion of the iliac blade, a

924 condition that appears to be autapomorphic for this taxon. That fossa is bordered posteroventrally

925 by the thickened margin of the neck, a feature which is ventrally confluent with the ischiadic

926 peduncle. The left iliac blade measures $188.6 \mathrm{~mm}$ in length and $67.4 \mathrm{~mm}$ in height, producing a

927 relatively tall iliac blade. The posterior portion of the iliac blade has a posterior margin that

928 projects well beyond the iliac peduncle. The extent of the ventral portions of the ilia is hard to

929 determine because they are indistinguishably fused to the ischia and pubes; however, the left

930 acetabulum is more or less rounded, $116.5 \mathrm{~mm}$ tall and $111 \mathrm{~mm}$ wide.

\section{Ischium}

932 The left ischium and part of the right are present, but poorly preserved (Figures 15, 21).

933 The ischium consists of the main body with a sharp, rounded acetabular rim, and an elongate

934 posterior process. The upper margin of the posterior process slopes gradually from the posterior 
935 margin of the ischiadic peduncle, and the entire ischium measures $183 \mathrm{~mm}$ in length. The

936 anteroventral margin is flat where the two ischia are fused, forming a wide, slightly concave

937 ventral shelf. Overall the ischium is similar to that of other aetosaurians such as Stagonolepis

938 robertsoni (Walker 1961), but lacks the prominent ventral kink found in Desmatosuchus

939 spurensis (MNA V9300; Parker 2008a).

940 Pubis

941 Both pubes are present and in articulation with the pelvis, although they are moderately

942 distorted by crushing and were damaged by weathering before collection (Figures 15, 21). The

943 body of the pubis consists of an elongate, narrow rod that curves anteroventrally and expands

944 medially into two broad sheets of bone that meet in a median symphysis. This pubic apron is

945 convex anteriorly and concave posteriorly. It is dorsoventrally short, barely extending past the

946 ventral margin of the puboischiadic plate, more like the condition in Typothorax coccinarum

947 (Long \& Murry 1995) rather than the extremely deep pubic apron found in Desmatosuchus

948 spurensis (MNA V9300). Two distinct oval foramina pierce the pubic apron in the proximal part

949 of the element. The bone is broken around the more anterior foramen of the right pubis, but it is

950 clear that it was the larger of the two openings (Figure 21). Two pubic foramina are also

951 described for Stagonolepis robertsoni (Walker 1961), and the upper (anterior) opening

952 considered homologous to the single foramen found in other aetosaurs (e.g., MNA V9300,

953 Desmatosuchus spurensis). The distal ends of the pubes are shaped like elongate commata,

954 narrow and curving into the symphysis (Figure 21), different from the strong, knob-like

955 projections (pubic boots) found in Desmatosuchus spurensis (MNA V9300). 


\section{Osteoderms}

\section{Paramedian osteoderms}

\section{Cervical}

959 Cervical osteoderms are present in PEFO 31217, PEFO 34045, and PEFO 34616. All of the

960 osteoderms are wider than long (w/l ratio of 1.85). The cervical osteoderms are dorsoventrally

961 thick with well-developed anterior bars (sensu Long and Ballew, 1985), which bear prominent

962 anteromedial projections. The lateral edges are strongly sigmoidal, and lack anterolateral

963 projections (Figures 22a, c; 23a).

964 The dorsal surface is relatively featureless, with the ornamentation poorly developed. The

965 dorsal eminence is low, broad, and mounded, contacting the posterior plate margin (Figures 22a,

966 c). The eminence is also slightly offset medially, closer to the midline margin. The characteristic

967 triangular protuberance that diagnoses Scutarx deltatylus is present in the posteromedial corner of

968 the osteoderm, but is greatly reduced in area (Figures 22a, c, d; 23a). In the cervical paramedian

969 osteoderms the shape of that protuberance is more of a right triangle than the equilateral triangles

970 found in the trunk series (see below).

971 In posterior view, the osteoderms are gently arched (Figures 22b, d). The median margins

972 are sigmoidal in medial view and dorsoventrally thick as is typical for aetosaurians. Scutarx

973 deltatylus lacks the 'tongue-and-groove' lateral articular surfaces present in Desmatosuchus (e.g.,

974 MNA V9300) and Longosuchus meadei (TMM 31185-84b).

975 The more posterior cervical paramedian osteoderms are similar, but increase in width (w/l

976 ratio of 2.05) and lack the strongly sigmoidal lateral margin. The margin is still sigmoidal but

977 bears a strong anterolateral projection (Figure 23a). Moreover, the anterior and posterior plate

978 margins are gently curved anterolaterally. In posterior view, these osteoderms have a lesser

979 degree of arching and are dorsoventrally thinner than the more anteriorly situated osteoderms.

980 The dorsal eminence is strongly offset medially and slightly more developed, becoming raised

981 and more pyramidal in shape, although this could be an individual variation (see description of

982 caudal paramedian osteoderms). 
983 Trunk

984 The osteoderm transition between the cervical and trunk series is difficult to identify, but 985 anterior dorsal trunk osteoderms are considered here to have higher width/length ratios and be 986 dorsoventrally thinner than the cervical paramedian osteoderms. Furthermore, the triangular 987 protuberance is more equilateral. However, it is difficult to differentiate these osteoderms from 988 those of the anterior caudal region.

989 Osteoderms with the maximum width/length ratio (2.72/1) are found in the mid-trunk 990 region. They bear a strongly raised anterior bar with prominent anteromedial and anterolateral 991 projections. Prominent (greatly elongate) anterolateral projections also occur in Calyptosuchus 992 wellesi (UMMP 7470), Adamanasuchus eisenhardtae (PEFO 34638), and Neoaetosauroides 993 engaeus (PVL 3525). The anterolateral projections are shorter in Stagonolepis robertsoni 994 ((NHMUK 4790a) and Aetosauroides scagliai (PVL 2073). The dorsal eminence in Scutarx 995 deltatylus is medially offset, and forms a broad, low mound. Anterior to this on the anterior bar is 996 a prominent, pointed anterior projection. The area of the anterior bar medial to this process is 997 'scalloped out,' and as a result is deeply concave (Figure 22e, f, j, k). This 'scalloping' of the 998 anterior bar is a synapomorphy of aetosaurine aetosaurs, occurring throughout the clade. The 999 length of the anterior bar decreases significantly within the arc of this concavity. The triangular 1000 protuberance is prominent and equilateral (Figures 22e-k; 23b, d). is slightly embayed for slight overlap of the associated lateral osteoderm. In posterior view the osteoderm is only slightly arched (Figure 22h). In what are presumed to be more posteriorly positioned osteoderms, the osteoderm is more strongly arched (Figures 221-m). The triangular protuberances are particularly visible in posterior view, extending even further dorsally that the main dorsal eminence (Figures 23c, e). The ventral surface of the dorsal trunk paramedian osteoderms are smooth, with a slight embayment situated on the underside of the dorsal

1008 eminence. 
The surface ornamentation of the dorsal trunk paramedian osteoderms is barely apparent 1010 in PEFO 34045, but much better developed in the other specimens. The ornament consists of 1011 pitting surrounding the dorsal eminence and radiating grooves and ridges over the rest of the 1012 surface.

1013 There is no direct evidence for a constriction ('waist') in the carapace anterior to the 1014 pelvis as in Aetosaurus ferratus (Schoch 2007), Calyptosuchus wellesi (Case 1932), and 1015 Aetosauroides scagliai (Heckert \& Lucas 2002); however, because the lateral osteoderm shapes 1016 in Scutarx deltatylus are identical to those of Calyptosuchus wellesi, it is probable that Scutarx 1017 deltatylus also possessed a 'waisted' carapace although this cannot be confirmed.

1018 Overall the paramedian cervical and trunk osteoderms of Scutarx deltatylus are similar to 1019 those of Calyptosuchus wellesi in all characteristics except for the presence of the posteromedial 1020 triangular protuberance (Figure 24). This character must be present to differentiate 1021 Calyptosuchus wellesi and Scutarx deltatylus paramedian osteoderms and in osteoderms where 1022 this area is not preserved an alpha taxonomic assignment cannot be made.

\section{Caudal}

1024 Like the cervical-trunk transition, the trunk-caudal transition is also difficult to determine 1025 in unarticulated aetosaurian carapaces (Parker 2008a). The latter transition is generally 1026 characterized by reduction of osteoderm width-length ratios and greater development of the 1027 dorsal eminences (Heckert \& Lucas 2000). The extreme is found in Rioarribasuchus chamaensis, 1028 in which the barely visible dorsal eminences in the mid-dorsal region transition posteriorly to 1029 elongate, anteromedially curved spines in the anterior caudal region (Parker 2007). 1030 The trunk-caudal transition for Scutarx deltatylus is best preserved in PEFO 34919 in 1031 which the dorsal eminences show a marked increase in height from $16.35 \mathrm{~mm}$ in the mid-trunk 1032 region to $40.07 \mathrm{~mm}$ in the anterior dorsal caudal region. Width/length ratios across this same 1033 transition are 2.54 to 2.16 , showing the corresponding decrease. The dorsal eminence is a tall 
1034 pyramid, with a posterior vertical keel (Figure 25). In all other respects the anterior caudal 1035 osteoderms are similar to those of the trunk region.

1036 Dorsal mid-caudal paramedians are relatively equal in width and length $(\mathrm{w} / \mathrm{l}$ ratio $=1.08)$. 1037 Those osteoderms still possess the pronounced dorsal eminence (Figures 26a-j), as well as the 1038 anteromedial and anterolateral projections of the anterior bar. In PEFO 34045 these osteoderms 1039 are extremely thickened (Figures 26a-b, e-f).

1040 The posterior dorsal caudal paramedians (Figures 26k-n) become longer than wide (w/l 1041 ratios of 0.73 and 0.66 ), and the dorsal eminence is reduced to a raised, anteroposteriorly elongate 1042 keel with a posterior projection that extends beyond the posterior margin of the osteoderm. 1043 Presumably these continue until they become elongate strips of bone as in Aetosaurus ferratus 1044 (Schoch 2007) and Typothorax coccinarum (NMMNH P56299; Heckert et al. 2010).

\section{Lateral osteoderms}

1046 The best guide for the distribution of the lateral osteoderms is UMMP 13950, the holotype 1047 of Calyptosuchus wellesi, which preserves the posterior dorsal armor and much of the caudal 1048 lateral armor in articulation (Case 1932). Scutarx deltatylus possesses lateral plates that are 1049 identical in shape to those of Calyptosuchus wellesi, allowing for determination of caudal and 1050 posterior dorsal osteoderms. Therefore, any lateral osteoderms falling outside of those 1051 morphotypes probably are from more anterior regions. Anterior dorsal lateral osteoderms are 1052 preserved in the articulated holotype of Aetosauroides scagliai (PFV 2073), which can be used to 1053 help assign isolated osteoderms.

1054 Lateral osteoderms can be distinguished from paramedian osteoderms primarily by the 1055 lack of the prominent anterolateral projection. Furthermore, the anteromedial corner of the 1056 osteoderm is 'cut-off' and beveled for reception of the anterolateral projection of the associated 1057 adjacent paramedian osteoderm (poa; Figure 27). 
1058

1059

1060

1061

1062

1063

1064

1065

1066

1067

1068

1069

1070

1071

1072

1073

1074

1075

1076

1077

1078

1079

1080

1081

1082

1083

1084

\section{Cervical}

There are no lateral osteoderms in the material present that can unequivocally be assigned to the cervical region.

\section{Trunk}

Anterior lateral trunk osteoderms are not preserved in the holotype of Calyptosuchus wellesi, but they are preserved in Aetosaurus ferratus (Schoch 2007). In Aetosaurus those osteoderms are strongly asymmetrical with the dorsal flanges roughly half the dimensions of the lateral flanges. Furthermore, the dorsal flanges are triangular or trapezoidal in dorsal view rather than rectangular, with a slight, medially projecting posterior tongue.

Two osteoderms from the left side in PEFO 34616 and a third from the right side in PEFO 34045 match this anatomy and are probably from the anterior portion of the carapace (Figures 27a-d). In addition to the features just mentioned, those osteoderms possess a distinct anterior bar. The anteromedial corner of the anterior bar is beveled for articulation with the anterolateral process of the paramedian osteoderm. The dorsal eminence of the lateral osteoderm is a prominent pyramidal boss that contacts the posterior plate margin and extends anteriorly, covering two-thirds of the osteoderm length. Surface ornamentation consists of elongate grooves and ridges radiating from the dorsal eminence. In posterior view, the osteoderms are only slightly angulated, with the angle between flanges strongly obtuse (Figures 27b, d). Similarly shaped osteoderms are found in the anterior lateral trunk region of Aetosauroides scagliai (PVL 2073).

Posterior-mid trunk osteoderms (from roughly the ninth through $12^{\text {th }}$ positions) are subrectangular with a distinct, posteromedially sloping lateral edge (Figures 27e-h; Case 1932). The dorsal flange is sub-rectangular in dorsal view. The medial edge of the dorsal flange is beveled and slightly sigmoidal with a 'cut-off' anterior corner for the anterolateral projection of the paramedian plate. The osteoderm is moderately flexed with the lateral flange extending at about 45 degrees relative to the dorsal flange (Figures $27 \mathrm{f}, \mathrm{h}$ ). Both flanges are roughly the same size, although the sloping lateral edge produces a small anteromedial 'wing' that extends that edge a bit farther laterally and provides a trapezoidal shape for the lateral flange (alw; Figures 27e, g). 
1085 The dorsal eminence is pyramidal, and the degree of its development differs between specimens, 1086 from a low mound in PEFO 34045 to a distinct tall, triangular boss in PEFO 34919. On the dorsal 1087 surface a distinct anterior bar is present and the surface ornamentation consists of small pits and 1088 elongate grooves radiating from the dorsal eminence. Ventrally the osteoderms are smooth, 1089 except for longitudinal striations along the posterior margin where this margin would overlap the 1090 anterior bar of the preceding lateral osteoderm.

1091 The posteriormost lateral trunk osteoderms $\left(15^{\text {th }}\right.$ and $16^{\text {th }}$ positions $)$ are similar to the 1092 posterior mid-trunk osteoderms but lack the anterolateral 'wing' and are much more strongly 1093 flexed, enclosing an angle of approximately 90 degrees in posterior view (Figures 27i-j). They 1094 are similar to the posterior lateral trunk osteoderms in Calyptosuchus wellesi (Case 1932).

\section{Caudal}

1096 Caudal lateral osteoderms are more equal in dimension, and bear rectangular dorsal 1097 flanges (Figures 27k-p). The angle enclosed between the dorsal and lateral flanges is about 45-50 1098 degrees (Figures 271, n, p). Overall these osteoderms possess some of the same surficial features 1099 as the other osteoderms, such as an anterior bar, radial ornamentation, and a posteriorly placed 1100 dorsal eminence. However, the anterior caudal osteoderms in some specimens (e.g., PEFO 110134919 ) possess some of the tallest dorsal eminences in the carapace (Figures 25; 27n). The caudal 1102 lateral osteoderms also decrease in width posteriorly (Figure 27m-n). The height of the dorsal 1103 eminence is gradually reduced and becomes an elongate sharp ridge.

\section{Ventral trunk osteoderms}

1105 Ventral trunk osteoderms are preserved in all of the PEFO specimens, including an

1106 articulated, but badly preserved, set in PEFO 31217. They consist mainly of square to rectangular 1107 osteoderms, with reduced anterior bars, no dorsal eminence and a surface ornamentation of pits 1108 and elongated pits in a radial pattern emanating from the center of the osteoderm (Figures 28a-f).

1109 Because no complete set is preserved the exact numbers of rows and column cannot be 
1110 determined; however, they would have been overlapping as in Stagonolepis robertsoni (Walker,

1111 1961) and Typothorax coccinarum (Heckert et al., 2010).

\section{Appendicular osteoderms}

1113 A few irregular, small, rounded osteoderms most likely represent appendicular

1114 osteoderms. There are two types: one featureless except for a distinct raised keel (Figure 28g),

1115 and the other with a surface ornamentation of radial pits (Figure $28 \mathrm{~g}$ i). A triangular osteoderm

1116 (Figure 28h) from PEFO 34616 could represent a different type of appendicular osteoderm, or it

1117 could also be an irregularly shaped osteoderm from the ventral carapace possibly from the

1118 vicinity of the cloaca (A. Heckert, pers. comm., 2016).

\section{Broken osteoderms}

1120 An interesting aspect of PEFO 34045 is the presence of many irregularly shaped

1121 osteoderms recovered with the specimen (Figure 29). All of the edges on these osteoderms are

1122 compact bone and do not represent recent breaks. Close examination shows that these specimens

1123 are the lateral ends of dorsal paramedian osteoderms because they possess anterior bars with

1124 strong anterolateral projections and sigmoidal edges (Figures 29a-d). It is unclear why these

1125 osteoderms are incomplete but two possibilities exist. The first possibility is that these

1126 osteoderms were incompletely ossified. Alternatively, they were broken and then the edges

1127 healed during the life of the animal. However, there is no visible sign of pathology because the

1128 edges are smooth and the dorsoventral thickness of the osteoderms remains constant. The

1129 osteoderms are also from opposite sides of the body precluding a cause from a single injury if

1130 they are pathologic in nature. Histological examination could help determine the ontogeny of

1131 these elements. If growth rings are uniform throughout the specimen, it would demonstrate that

1132 either damage occurred at a young age or that the remainder of the element did not ossify. If the 
1133 osteoderms were broken at a later ontogenetic stage and healed, then that should be reflected in

1134 the bone histology showing a disruption in the growth rings, or establishment of new rings along

1135 the broken edge.

\section{DISCUSSION}

1137 Scutarx deltatylus exemplifies the importance of utilizing a detailed apomorphy-based

1138 approach to differentiate Late Triassic archosauromorph taxa (e.g., Nesbitt, Irmis \& Parker 2007;

1139 Nesbitt \& Stocker 2008; Stocker 2010). The material here referred to Scutarx deltatylus was

1140 originally assigned to Calyptosuchus wellesi (Long \& Murry 1995; Parker \& Irmis 2005; Martz

1141 et al. 2013), which was differentiated from Stagonolepis robertsoni by the presence of the

1142 triangular protuberance on the paramedian osteoderms (Martz et al. 2013). However,

1143 reexamination of the holotype of Calyptosuchus wellesi (UMMP 13950) as well as referred

1144 material from the Placerias Quarry of Arizona shows that material of Calyptosuchus wellesi

1145 actually lacks the triangular protuberance. Moreover, the skull of Scutarx deltatylus possesses

1146 characters of the braincase (e.g., foreshortened parabasisphenoid) that are more similar to

1147 Desmatosuchus than to other aetosaurians that are similar to Stagonolepis. Unfortunately, the

1148 skull of Calyptosuchus wellesi is still mostly unknown. The Placerias Quarry contains a number

1149 of isolated aetosaurian skull bones (most notably basicrania), with differing anatomical

1150 characteristics, but none of these can be referred with certainty to Calyptosuchus wellesi (Parker

1151 2014). Nonetheless, prior to the discovery of the skull of Scutarx deltatylus, Calyptosuchus

1152 wellesi was assumed to have a skull more like that of Stagonolepis robertsoni and Aetosauroides

1153 scagliai (i.e. with an elongate parabasisphenoid). That assumption can no longer be maintained.

1154 A phylogenetic analysis (Parker, 2016) recovers Scutarx deltatylus as the sister taxon to

1155 Adamanasuchus eisenhardtae and forming a clade with Calyptosuchus wellesi. The unnamed

1156 clade formed by these three taxa is the sister taxon of Desmatosuchini (Parker, 2016) within

1157 Desmatosuchinae (Figure 30). The presence of a aetosaurian with armor similar to Stagonolepis

1158 robertsoni (sensu Heckert and Lucas, 2000), but with a skull more like that of desmatosuchins 
1159 provides further support that certain characteristic of the armor that were once used to unite taxa,

1160 such as paramedian osteoderm ornamentation (Heckert \& Lucas 2000; Long \& Ballew 1985;

1161 Long \& Murry 1995), may have wider distributions across Aetosauria than previously recognized

1162 (Parker 2008b; Desojo \& Ezcurra, 2011; Small \& Martz, 2013; Heckert et al. 2015).

\section{Implications for Late Triassic Vertebrate Biochronology} assigned to Calyptosuchus wellesi (Long \& Murry 1995; Martz et al. 2013; Parker \& Irmis 2005; Parker \& Martz 2011), a proposed index taxon of the Adamanian biozone (Parker \& Martz 2011), which is earliest Norian in age (Irmis et al. 2011). However, all of the recognized specimens of Scutarx deltatylus originate only from the Adamanian portion of the Sonsela Member of the

1169 Chinle Formation and the middle part of the Cooper Canyon Formation of Texas (Martz et al. 2013; Parker \& Martz 2011). The reassignment of this material restricts the stratigraphic range of

1171 Calyptosuchus wellesi to the Bluewater Creek and Blue Mesa members of the Chinle Formation

1172 as well as the Tecovas Formation of Texas (Heckert 1997; Long \& Murry 1995), which are 1173 stratigraphically lower than the Sonsela Member and middle part of the Cooper Canyon (Martz et 1174 al. 2013).

1177 list of Adamanian taxa of the Chinle Formation that noted which are known solely from the Blue

1178 Mesa Member and which are known only from the lower part of the Sonsela Member. The list of

1179 taxa shared by both units is small and consists of Placerias hesternus (a dicynodont synapsid), 
1180 the archosauromorph Trilophosaurus dornorum, the poposaurid Poposaurus gracilis, a

1181 paratypothoracin aetosaur similar to Tecovasuchus chatterjeei, and Calyptosuchus wellesi (Martz

1182 et al. 2013). The reassignment of the Sonsela material previously placed in Calyptosuchus wellesi

1183 to Scutarx deltatylus further reduces that list. Scutarx deltatylus also occurs in the upper

1184 Adamanian Post Quarry of Texas, which contains taxa elsewhere only found in the lower part of

1185 the Sonsela Member (e.g., Desmatosuchus smalli, Trilophosaurus dornorum, Typothorax

1186 coccinarum, Paratypothorax sp.; Martz et al. 2013). Thus, Scutarx deltatylus can presently be

1187 considered an index taxon of the upper part of the Adamanian biozone, which is presently

1188 considered to be middle Norian in age (Figure 30; Irmis et al., 2011).

1189 Hunt et al. (2005) previously divided the Adamanian biozone into older and younger

1190 parts, respectively called the St. Johnsian and Lamyan sub-biochrons. Index taxa of the Lamyan

1191 are the aetosaur Typothorax antiquus (=Typothorax coccinarum) and the pseudopalatine

1192 phytosaur Machaeroprosopus (Hunt et al., 2005). However, the lowest known occurrence of

1193 Machaeroprosopus would represent the base of the Revueltian biozone (Martz \& Parker, in

1194 press), thus the Lamyan would be Revueltian in age and not represent a subdivision of the

1195 Adamanian (Heckert, 2006; Parker, 2006). Accordingly I leave any proposed subdivisions

1196 presently unnamed.

\section{CONCLUSIONS}

Scutarx deltatylus is a new taxon of aetosaurian from the middle Norian (late Adamanian)

1199 of the American Southwest, based on material that was originally assigned to Calyptosuchus

1200 wellesi. This taxon is known from several carapaces and includes rare skull material from western

1201 North America. Scutarx deltatylus differs from all other aetosaurians in the presence of a raised 
1202 triangular boss in the posteromedial corner of the presacral paramedian osteoderms, a

1203 dorsoventrally thickened skull roof, and an anteroposteriorly shortened parabasisphenoid. A

1204 phylogenetic analysis places it as the sister taxon of Adamanasuchus eisenhardtae near the base

1205 of Desmatosuchinae (Parker, 2016). Scutarx deltatylus appears to have utility as an index taxon

1206 for the late Adamanian biozone.

1207 ACKNOWLEDGEMENTS

1208 Much of this manuscript was a part of a doctoral dissertation submitted to the University

1209 of Texas at Austin. Reviews of that earlier version were provided by Tim Rowe, Chris Bell,

1210 Sterling Nesbitt, and Hans-Dieter Sues. Reviews by Sarah Werning, Julia Desojo, and Andrew

1211 Heckert greatly improved the manuscript and figures. Thank you to the management and staff of

1212 Petrified Forest National Park (PEFO) for their support of this project. For fieldwork assistance at

1213 the Petrified Forest I thank Daniel Woody, David Gillette, Sue Clements, Dan Slais, Randall

1214 Irmis, Sterling Nesbitt, Jeff Martz, Michelle Stocker, Raul Ochoa, Lori Browne, Chuck Beightol,

1215 Rachel Guest, Matt Smith, and Kenneth Bader. Raul Ochoa discovered the type specimen of

1216 Scutarx deltatylus. I appreciate the assistance provided by the Maintenance Division staff of

1217 PEFO in the final collection of many of these specimens. Preparation of PEFO specimens was

1218 completed by Pete Reser, Matt Brown, Matt Smith, and Kenneth Bader. All specimens were

1219 collected under a natural resources permit from the National Park Service.

1220 Access to specimens under their care was provided by T. Scott Williams and Matt Smith

1221 (PEFO); Pat Holroyd, Mark Goodwin, and Kevin Padian (UCMP); David and Janet Gillette

1222 (MNA); Julia Desojo (MACN); the late Jaime Powell (PVL); Ricardo Martinez (PVSJ); Sandra

1223 Chapman, Lorna Steel, and David Gower (NHMUK); Lindsay Zanno and Vince Schneider

1224 (NCSM); Sankar Chatterjee and Bill Mueller (TTUP); Matthew Carrano (USNM); Tony Fiorillo

1225 and Ron Tykoski (DMNH [PMNH]); Alex Downs (GR); Charles Dailey and Dick Hilton (Sierra

1226 College); Tim Rowe, Lyndon Murray, Matt Brown, and Chris Sagebiel (VPL).

1227 This is Petrified Forest National Park Paleontological Contribution number 39. 


\section{REFERENCES}

1229 Atchley SC, Nordt LC, Dworkin SI, Ramezani J, Parker WG, Ash SR, and Bowring SA. 2013. A 1230 linkage among Pangean tectonism, cyclic alluviation, climate change, and biologic 1231 turnover in the Late Triassic: the record from the Chinle Formation, southwestern United States. Journal of Sedimentary Research 83:1147-1161.

1233 Brochu CA. 1992. Ontogeny of the postcranium in crocodylomorph archosaurs M.S. University $1234 \quad$ of Texas, Austin.

1235 Brochu CA. 1996. Closure of neurocentral sutures during crocodilian ontogeny: implications for 1236 maturity assessment in fossil archosaurs. Journal of Vertebrate Paleontology 16:49-62.

1237 Butler RJ, Barrett PM, and Gower DJ. 2012. Reassessment of the evidence for postcranial 1238 skeletal pneumaticity in archosaurs, and the early evolution of the avian respiratory system. PLoS One 7(3):e34094.

1240 Case EC. 1922. New reptiles and stegocephalians from the Upper Triassic of western Texas. . 1241 Carnegie Institute of Washington Publication 321:1-84.

1242 Case EC. 1932. A perfectly preserved segment of the armor of a phytosaur, with associated vertebrae. Contributions from the Museum of Paleontology, University of Michigan 4:57-

1245 Colbert EH. 1971. Tetrapods and continents. Quarterly Review of Biology 46:250-269.

1246 Cope ED. 1869. Synopsis of the extinct Batrachia, Reptilia, and Aves of North America. . 1247 Transactions of the American Philisophical Society, ns 14:1-252.

1248 Cope ED. 1875. Appendix LL: Report on the geology of that part of northwestern New Mexico 1249 examined during the field season of 1874. In: Wheeler GM, ed. Appendix GI: Annual Report upon the Geographical Explorations and Surveys West of the One Hundredth 


$$
\text { Department, U.S. Army, 61-116. }
$$

1253 Desojo JB, and Báez AM. 2005. El esqueleto postcraneano de Neoaetosauroides (Archosauria: Aetosauria) del Triásico Superior del centro-oeste de Argentina. Ameghiniana 42:115-126.

1255

1256

1258

1259

1260

1261

1262

1263

1264

1265

1266

1267

1268

1269

1270

1271 1272

1273 1274

Desojo JB, and Báez AM. 2007. Cranial morphology of the Late Triassic South American archosaur Neoaetosauroides engaeus: evidence for aetosaurian diversity. Palaeontology 50:267-276.

Desojo JB, and Ezcurra MD. 2011. A reappraisal of the taxonomic status of Aetosauroides (Archosauria, Aetosauria) specimens from the Late Triassic of South America and their proposed synonymy with Stagonolepis. Journal of Vertebrate Paleontology 31:596-609.

Desojo JB, Ezcurra MD, and Kischlat E-E. 2012. A new aetosaur genus (Archosauria: Pseudosuchia) from the early Late Triassic of southern Brazil. Zootaxa 3166:1-33.

Desojo JB, and Heckert AB. 2004. New information on the braincase and mandible of Coahomasuchus (Archosauria: Aetosauria) from the Otischalkian (Carnian) of Texas. Neues Jahrbuch für Geologie und Paläontologie Monatshefte 2004:605-616.

Desojo JB, Heckert AB, Martz JW, Parker WG, Schoch RR, Small BJ, and Sulej T. 2013. Aetosauria: a clade of armoured pseudosuchians from the Upper Triassic continental beds. In: Nesbitt SJ, Desojo JB, and Irmis RB, editors. Anatomy, Phylogeny, and Paleobiology of Early Archosaurs and their Kin: Special Publications of the Geological Society of London p203-239.

Fraser NC. 2006. Dawn of the Dinosaurs: Life in the Triassic. Bloomington: Indiana University Press.

Gauthier J. 1986. Saurischian monophyly and the origin of birds. Memoirs of the California Academy of Sciences 8:1-55. 
1275 Gauthier J, and Padian K. 1985. Phylogenetic, functional, and aerodynamic analyses of the origin 1276 of birds and their flight. In: Hecht MK, Ostrom JH, Viohl G, and Wellnhofer P, eds. The 1277 Beginning of Birds: Proceedings of the International Archaeopteryx Conference. Eichstätt: Freunde des Jura Museums, 185-197.

1279 Gower DJ, and Walker AD. 2002. New data on the braincase of the aetosaurian archosaur 1280 (Reptilia: Diapsida) Stagonolepis robertsoni Agassiz. Zoological Journal of the Linnean Society 136:7-23.

1282

1283

1284

1285

Heckert AB. 1997. The tetrapod fauna of the Upper Triassic lower Chinle Group (Adamanian: latest Carnian) of the Zuni Mountains, west-central New Mexico. New Mexico Museum of Natural History and Science Bulletin 11:29-39.

Heckert AB. 2006. Geographic and stratigraphic distribution of the enigmatic Upper Triassic (Adamanian: Carnian) vertebrate fossil Colognathus obscurus Case. Museum of Northern Arizona Bulletin 62: 155-156.

Heckert AB, and Lucas SG. 1999. A new aetosaur (Reptilia: Archosauria) from the Upper Triassic of Texas and the phylogeny of aetosaurs. Journal of Vertebrate Paleontology 19:50-68.

Heckert AB, and Lucas SG. 2000. Taxonomy, phylogeny, biostratigraphy, biochronology, paleobiogeography, and evolution of the Late Triassic Aetosauria (Archosauria: Crurotarsi). Zentralblatt für Geologie und Paläontologie Teil I 1998 1539-1587.

Heckert AB, and Lucas SG. 2002. South American occurrences of the Adamanian (Late Triassic: latest Carnian) index taxon Stagonolepis (Archosauria: Aetosauria) and their biochronological significance. Journal of Paleontology 76:852-863.

Heckert AB, Lucas SG, Hunt AP, and Spielmann J. 2007a. Late aetosaur biochronology revisited. New Mexico Museum of Natural History \& Science Bulletin 41:49-50.

Heckert AB, Spielmann J, Lucas SG, and Hunt AP. 2007b. Biostratigraphic utility of the Upper Triassic aetosaur Tecovasuchus (Archosauria: Stagonolepididae), an index taxon of St. 
1300

1301

1302

1303

1304

1305

1306

1307

1308

1309

1310

1311

1312

1313

1314

1315

1316

1317

1318

1319

1320

1321

1322

1323

Johnsian (Adamanian: Late Carnian) time. New Mexico Museum of Natural History and Science, 51-57.

Heckert AB, Lucas SG, Rinehart LF, Celeskey MD, Spielmann JA, and Hunt AP. 2010. Articulated skeletons of the aetosaur Typothorax coccinarum Cope (Archosauria: Stagonoleopididae) from the Upper Triassic Bull Canyon Formation (Revueltian: earlymid Norian), eastern New Mexico, USA. Journal of Vertebrate Paleontology 30:619-642.

Heckert AB, Schneider VP, Fraser NC, and Webb RA. 2015. A new aetosaur (Archosauria: Suchia) from the Upper Triassic Pekin Formation, Deep River Basin, North Carolina, U.S.A., and its implications for early aetosaur evolution. Journal of Vertebrate Paleontology 35:e881831.

Hill RV. 2010. Osteoderms of Simosuchus clarki (Crocodyliformes: Notosuchia) from the Late Cretaceous of Madagascar. Journal of Vertebrate Paleontology Memoir 10:154-176.

Hopson JA. 1979. Paleoneurology. In: Gans C, Northcutt RG, and Ulinsky P, eds. Biology of the Reptilia 9, neurology A. London: Academic Press, 39-146.

Howell ER, and Blakey RC. 2013. Sedimentological constraints on the evolution of the Cordilleran arc: New insights from the Sonsela Member, Upper Triassic Chinle Formation, Petrified Forest National Park (Arizona, USA). Geological Society of America Bulletin 125:1349-1368. 10.1130/B30714.1.

Hunt AP, Lucas SG, and Heckert AB. 2005. Definition and correlation of the Lamyan: a new biochronological unit for the non-marine late Carnian (Late Triassic). New Mexico Geological Society Guidebook 56: 357-366.

Irmis RB. 2007. Axial skeleton ontogeny in the Parasuchia (Archosauria: Pseudosuchia) and its implications for ontogenetic determination in archosaurs. Journal of Vertebrate Paleontology 27:350-361. 
1324 Irmis RB. 2008. Perspectives on the origin and early diversification of dinosaursPhD. University 1325 of California.

1326 Irmis RB, Mundil R, Martz JW, and Parker WG. 2011. High-resolution U-Pb ages from the 1327 Upper Triassic Chinle Formation (New Mexico, USA) support a diachronous rise of 1328 dinosaurs. Earth and Planetary Science Letters 309:258-267.

1329 Irmis RB, Nesbitt SJ, Padian K, Smith ND, Turner AH, Woody D, and Downs A. 2007a. A Late 1330 Triassic dinosauromorph assemblage from New Mexico and the rise of dinosaurs. Science 1331 317:358-361.

Irmis RB, Parker WG, Nesbitt SJ, and Liu J. 2007b. Early ornithischian dinosaurs: the Triassic 1333 record. Historical Biology 19:3-22.

Jepson GL. 1948. A Triassic armored reptile from New Jersey. In: Johnson ME, ed. State of New 1336 Geologic Survey, 5-20.

1337 Long RA, and Ballew KL. 1985. Aetosaur dermal armor from the Late Triassic of Southwestern 1338 North America, with special reference to material from the Chinle Formation of Petrified Forest National Park. Museum of Northern Arizona Bulletin 54:45-68.

1340 Long RA, and Murry PA. 1995. Late Triassic (Carnian and Norian) tetrapods from the 1341 southwestern United States. New Mexico Museum of Natural History and Science Bulletin 4:1-254.

1343 Lucas SG. 1998. Global Triassic tetrapod biostratigraphy and biochronology. Palaeogeography, $1344 \quad$ Palaeoclimatology, Palaeoecology 143:347-384.

1345 Lucas SG, and Heckert AB. 1996. Late Triassic aetosaur biochronology. Albertiana 17:57-64.

1346 Lucas SG, Heckert AB, Estep JW, and Anderson OJ. 1997. Stratigraphy of the Upper Triassic 1347 Chinle Group, Four Corners Region. New Mexico Geological Society Guidebook 48:811348 108. 
1349 Lucas SG, Heckert AB, and Hunt AP. 2003. A new species of the aetosaur Typothorax 1350 (Archosauria: Stagonolepididae) from the Upper Triassic of east-central New Mexico. $1351 \quad$ New Mexico Museum of Natural History and Science Bulletin 21:221-233.

1352 Lucas SG, and Hunt AP. 1993. Tetrapod biochronology of the Chinle Group (Upper Triassic), 1353 western United States. New Mexico Museum of Natural History and Science Bulletin $1354 \quad 3: 327-329$.

1355 Lucas SG, Hunt AP, Heckert AB, and Spielmann JA. 2007. Global Triassic tetrapod 1356 biostratigraphy and biochronology: 2007 status. New Mexico Museum of Natural History 1357 and Science Bulletin 41:229-240.

1358 Lucas SG, Hunt AP, and Spielmann J. 2007. A new aetosaur from the Upper Triassic 1359 (Adamanian: Carnian) of Arizona. New Mexico Museum of Natural History and Science $1360 \quad$ Bulletin 40:241-247.

1361 Lydekker R. 1887. The fossil vertebrata of India. Records of the Geological Survey of India $1362 \quad 20: 51-80$.

1363 Marsh OC. 1884. The classification and affinities of dinosaurian reptiles. Nature:68-69.

1364 Martz JW. 2002. The morphology and ontogeny of Typothorax coccinarum (Archosauria, 1365 Stagonolepididae) from the Upper Triassic of the American Southwest M.S. Texas Tech 1366 University.

1367 Martz JW, Mueller BD, Nesbitt SJ, Stocker MR, Atanassov M, Fraser NC, Weinbaum JC, and 1368 Lehane J. 2013. A taxonomic and biostratigraphic re-evaluation of the Post Quarry 1369 vertebrate assemblage from the Cooper Canyon Formation (Dockum Group, Upper 1370 Triassic) of southern Garza County, western Texas. . Earth and Environmental Science 1371 Transactions of the Royal Society of Edinburgh 103:339-364. 
1372 Martz JW, and Parker WG. 2010. Revised lithostratigraphy of the Sonsela Member (Chinle 1373 Formation, Upper Triassic) in the southern part of Petrified Forest National Park, Arizona. $1374 \quad$ PLoS One 5:e9329, 9321-9326.

1375 Martz JW, and Parker WG. In Press. Revised formulation of the Late Triassic land vertebrate 1376 "faunachrons" of western North America. In: Zeigler KE, and Parker WG, eds. 1377 Deciphering Complex Depositional Systems: Elsevier.

1378 Martz JW, and Small BJ. 2006. Tecovasuchus chatterjeei, a new aetosaur (Archosauria: 1379 Stagonolepididae) from the Tecovas Formation (Carnian, Upper Triassic) of Texas. $1380 \quad$ Journal of Vertebrate Paleontology 26:308-320.

1381 Nesbitt SJ. 2011. The early evolution of archosaurs: relationships and the origin of major clades. 1382 Bulletin of the American Museum of Natural History 352:1-292.

1383 Nesbitt SJ, Irmis RB, and Parker WG. 2007. A critical re-evaluation of the Late Triassic dinosaur 1384 taxa of North America. Journal of Systematic Palaeontology 5:209-243.

1385 Nesbitt SJ, Sidor CA, Irmis RB, Angielczyk KD, Smith RMH, and Tsuji LA. 2010. Ecologically 1386 distinct dinosaurian sister group shows early diversification of Ornithodira. Nature $1387 \quad 464: 95-98$.

1388 Nesbitt SJ, Smith ND, Irmis RB, Turner AH, Downs A, and Norell MA. 2009a. A complete 1389 skeleton of a Late Triassic saurischian and the early evolution of dinosaurs. Science $1390 \quad 326: 1530-1533$.

1391 Nesbitt SJ, and Stocker MR. 2008. The vertebrate assemblage of the Late Triassic Canjilon 1392 Quarry (northern New Mexico, USA), and the importance of apomorphy-based 1393 assemblage comparisons. Journal of Vertebrate Paleontology 28:1063-1072.

1394 Nesbitt SJ, Stocker MR, Small BJ, and Downs A. 2009b. The osteology and relationships of 1395 Vancleavea campi (Reptilia: Archosauriformes). Zoological Journal of the Linnean 1396 Society 157:814-864. 
1397 Parker WG. 2005a. Faunal review of the Upper Triassic Chinle Formation of Arizona. Mesa $1398 \quad$ Southwest Museum Bulletin 11:34-54.

1399 Parker WG. 2005b. A new species of the Late Triassic aetosaur Desmatosuchus (Archosauria: $1400 \quad$ Pseudosuchia). Comptes Rendus Palevol 4:327-340.

1401 Parker WG. 2006. The stratigraphic distribution of major fossil localities in Petrified Forest 1402 National Park, Arizona. Museum of Northern Arizona Bulletin 62:46-61.

1403 Parker WG. 2007. Reassessment of the aetosaur 'Desmatosuchus' chamaensis with a reanalysis of 1404 the phylogeny of the Aetosauria (Archosauria: Pseudosuchia). Journal of Systematic 1405 Palaeontology 5:41-68. 10.1017/S1477201906001994

1406 Parker WG. 2008a. Description of new material of the aetosaur Desmatosuchus spurensis 1407 (Archosauria: Suchia) from the Chinle Formation of Arizona and a revision of the genus 1408 Desmatosuchus. PaleoBios 28:1-40.

1409 Parker WG. 2008b. How many valid aetosaur species are there? Reviewing the alpha-taxonomy 1410 of the Aetosauria (Archosauria: Pseudosuchia) and its implications for Late Triassic 1411 global biostratigraphy. Journal of Vertebrate Paleontology 28:125A.

1412 Parker WG. 2014. Taxonomy and phylogeny of the Aetosauria (Archosauria: Pseudosuchia) 1413 including a new species from the Upper Triassic of Arizona Ph.D. The University of $1414 \quad$ Texas at Austin.

1415 Parker WG. 2016. Revised phylogenetic analysis of the Aetosauria (Archosauria: Pseudosuchia); 1416 assessing the effects of incongruent morphological character sets. PeerJ 4:e1583. $1417 \quad 10.7717 /$ peerj.1583

1418 Parker WG, and Irmis RB. 2005. Advances in Late Triassic vertebrate paleontology based on new 1419 material from Petrified Forest National Park, Arizona. New Mexico Museum of Natural $1420 \quad$ History and Science Bulletin 29:45-58. 
1421 Parker WG, and Martz JW. 2011. The Late Triassic (Norian) Adamanian-Revueltian tetrapod 1422 faunal transition in the Chinle Formation of Petrified Forest National Park, Arizona. 1423 Earth and Environmental Science Transactions of the Royal Society of Edinburgh $1424 \quad 101: 231-260$.

1425 Parker WG, Stocker MR, and Irmis, R.B. 2008. A new desmatosuchine aetosaur (Archosauria: 1426 Suchia) from the Upper Triassic Tecovas Formation (Dockum Group) of Texas. Journal 1427 of Vertebrate Paleontology 28:692-701.

1428 Parrish JM. 1994. Cranial osteology of Longosuchus meadei and the phylogeny and distribution 1429 of the Aetosauria. Journal of Vertebrate Paleontology 14:196-209.

1430 Ramezani J, Hoke GD, Fastovsky DE, Bowring SA, Therrien F, Dworkin SI, Atchley SC, and 1431 Nordt LC. 2011. High-precision U-Pb zircon geochronology of the Late Triassic Chinle 1432 Formation, Petrified Forest National Park (Arizona, USA): temporal constraints on the 1433 early evolution of dinosaurs. Geological Society of America Bulletin 123:2142-2159.

1434 Rauhut OWM. 2004. Braincase structure of the Middle Jurassic theropod dinosaur 1435 Piatnitzkysaurus. Canadian Journal of Earth Sciences 41:1109-1122.

1436 Reese AM. 1915. The Alligator and its Allies. New York: Knickerbocker Press.

1437 Reichgelt T, Parker WG, Martz JW, Conran JG, Van Konijnenburg-Van Cittert JHA, and 1438 Kürschner WM. 2013. The palynology of the Sonsela Member (Late Triassic, Norian) at 1439 Petrified Forest National Park, Arizona, USA. Review of Palaeobotany and Palynology 1440 189:18-28.

1441 Rieppel O. 1985. The recessus scalae tympani and its bearing on the classification of lizards. $1442 \quad$ Journal of Herpetology 19:373-384.

1443 Roberto-Da-Silva L, Desojo JB, Cabriera SF, Aires ASS, Müller ST, Pacheco CP, and Dias-da1444 Silva S. 2014. A new aetosaur from the Upper Triassic of the Santa Maria Formation, 1445 southern Brazil. Zootaxa 3764:240-278. 
1446 Sawin HJ. 1947. The pseudosuchian reptile Typothorax meadei. Journal of Paleontology 21:2012387.

1448 Schoch RR. 2007. Osteology of the small archosaur Aetosaurus from the Upper Triassic of 1449 Germany. Neues Jahrbuch für Geologie und Paläontologie Abhandlugen 246:1-35.

1450 Schoch RR, and Desojo JB. 2016. Cranial anatomy of the aetosaur Paratypothorax andressorum 1451 Long \& Ballew, 1985, from the Upper Triassic of Germany and its bearing on aetosaur 1452 phylogeny. Neues Jahrbuch für Geologie und Paläontologie Abhandlugen 279:73-95.

1453 Small BJ. 2002. Cranial anatomy of Desmatosuchus haplocerus (Reptilia: Archosauria: 1454 Stagonolepididae). Zoological Journal of the Linnean Society 136:97-111.

1455 Small BJ, and Martz JW. 2013. A new basal aetosaur from the Upper Triassic Chinle Formation 1456 of the Eagle Basin, Colorado, USA. In: Nesbitt SJ, Desojo JB, and Irmis RB, eds. 1457 Anatomy, Phylogeny and Palaeobiology of Early Archosaurs and their Kin. Bath: The 1458 Geological Society Publishing House, 393-412.

1459 Spielmann J, and Lucas SG. 2012. Tetrapod fauna of the Upper Triassic Redonda Formation, 1460 east-central New Mexico: the characteristic assemblage of the Apachean land-vertebrate faunachron. New Mexico Museum of Natural History \& Science Bulletin 55:1-119.

1462 Stocker MR. 2010. A new taxon of phytosaur (Archosauria: Pseudosuchia) from the Late Triassic 1463 (Norian) Sonsela Member (Chinle Formation) in Arizona, and a critical reevaluation of $1464 \quad$ Leptosuchus Case 1922. Palaeontology 53:997-1022.

1465 Sulej T. 2010. The skull of an early Late Triassic aetosaur and the evolution of the stagonolepidid 1466 archosaurian reptiles. Zoological Journal of the Linnean Society 158:860-881.

1467 Wake MH. 1992. Hyman's comparative vertebrate anatomy, revised third edition. Chicago: $1468 \quad$ University of Chicago Press. 
1469 Walker AD. 1961. Triassic Reptiles from the Elgin Area: Stagonolepis, Dasygnathus and Their

1470

1471

1472

1474

1475

1476

1477

1478

1479

1480

1481

1482

1483

1484

1485

1486

1487

1488

1489

Allies. Philosophical Transactions of the Royal Society of London Series B, Biological Sciences 244:103-204.

Walker AD. 1990. A revision of Spenosuchus acutus Haughton, a crocodylomorph reptile from the Elliott Formation (Late Triassic or Early Jurassic) of South Africa. Philosophical Transactions: Biological Sciences 330:1-120.

Weinbaum JC. 2011. The skull of Postosuchus kirkpatricki (Archosauria: Paracrocodyliformes) from the Upper Triassic of the United States. PaleoBios 30:18-44.

Wilson JA. 1999. A nomenclature for vertebral laminae in sauropods and other saurischian dinosaurs. Journal of Vertebrate Paleontology 19:639-653.

Wilson JA, D'Emic MD, Ikejiri T, Moacdieh EM, and Whitlock JA. 2011. A nomenclature for vertebral fossae in sauropods and other saurischian dinosaurs. PLoS One 6(2):e17114.

Witmer LM. 1997. Craniofacial air sinus systems. In: Currie PJ, and Padian K, eds. Encyclopedia of Dinosaurs. San Diego: Academic Press.

Woody DT. 2006. Revised stratigraphy of the lower Chinle Formation (Upper Triassic) of Petrified Forest National Park, Arizona. Museum of Northern Arizona Bulletin 62:17-45.

Zeigler KE, Heckert AB, and Lucas SG. 2003 [imprint 2002]. A new species of Desmatosuchus (Archosauria: Aetosauria) from the Upper Triassic of the Chama Basin, north-central New Mexico. New Mexico Museum of Natural History and Science Bulletin 21:215-219.

Zittel KA. 1887-1890. Handbuch der Palaeontologie. 1. Abteilung: Palaeozoologie, 3. München \& Leipzig. 
1491 Figure 1. Map of Petrified Forest National Park showing relevant vertebrate fossil localities. 1492 Modified from Parker \& Irmis (2005).

1493 Figure 2. Regional stratigraphy of the Petrified Forest area showing the stratigraphic position of 1494 the localities discussed in the text. All occurrences are in the lower part of the Sonsela Member 1495 of the Chinle Formation and are within the Adamanian biozone. Stratigraphy from Martz \& 1496 Parker, 2010. Biozones from Parker \& Martz (2011) and Reichgelt et al. (2013). Ages from 1497 Ramezani et al. (2011) and Atchley et al. (2013).

1498 Figure 3. Differention and terminology for aetosaurian osteoderms, based on Stagonolepis 1499 robertsoni. Reconstruction courtesy of Jeffrey Martz.

1500 Figure 4. Photos and interpretive sketches of the left nasal (PEFO 34616) in dorsal (A) and 1501 ventral (B) views. Arrows point anteriorly and scale bars equal $1 \mathrm{~cm}$. Abbreviations: en, external nares; fr, frontal; la, lacrimal; mx, maxilla; s., suture with listed element.

1503 Figure 5. Photo and interpretive sketch of posterodorsal portion of the skull of Scutarx deltatylus 1504 (PEFO 34616) in dorsal view. Scale bar equals $1 \mathrm{~cm}$. Abbreviations: bo, basioccipital; gr, 1505 groove; ex, exoccipital; lfr, left frontal; ls, laterosphenoid; na, nasal; orb, orbit; pa, parietal; par, 1506 paroccipital process of the opisthotic; plpr, palpebral; po, postorbital; pof, postfrontal; pr, 1507 prootic; prf, prefrontal; rfr, right frontal; s., suture with listed element; so, supraoccipital; sq, 1508 squamosal; stf; supratemporal fenestra.

1509 Figure 6. Partial skull of Scutarx deltatylus (PEFO 34616) in right lateral view. Scale bar equals $15101 \mathrm{~cm}$. Abbreviations: bo, basioccipital; bpt, basipterygoid processes; bsr, basisphenoid recess; 1511 bt, basal tubera; cp, cultriform process; fr, frontal; ls, laterosphenoid; na, nasal; of, orbital fossa; 1512 orb, orbit; pa, parital; palp, palpebral; po, postorbital; pof, postfrontal; pr, prootic; prf, 1513 prefrontal; qj, quadratojugal; qu, quadrate; sq, squamosal; stf, supratemporal fenestra; uc, 1514 unossified cleft of the basal tubera.

1515 Figure 7. Partial skull of Scutarx deltatylus (PEFO 34616) in ventral view. Scale bar equals 1 1516 cm. Abbreviations: bo, basioccipital; btp, basipterygoid processes; bsr, basisphenoid recess; bt, 1517 basal tubera; cp, cultriform process; f., fossa for specified element; lfr, left frontal; ls, 1518 laterosphenoid; mf, metotic fissure; na, nasal; of, orbital fossa; orb, orbit; pa, parietal; palp, 1519 palpebral; par, paroccipital process of the opisthotic; po, postorbital; pof, postfrontal; pr, 1520 prootic; prf, prefrontal; qj, quadratojugal; qu, quadrate; rfr, right frontal; sq, squamosal; stf, 1521 supratemporal fenestra; uc, unossified cleft of the basal tubera.

1522 Figure 8. Partial skull of Scutarx deltatylus (PEFO 34616) in posterior view. Scale bar equals 1 1523 cm. Abbreviations: bo, basioccipital; bpt, basipterygoid processes; bs, basisphenoid; ex, 1524 exoccipital; ex.pr; exoccipital prong; fm, foramen magnum; lfr, left frontal; pa, parietal; par.op, 1525 paroccipital process of the opisthotic; po, postorbital; rfr, right frontal; sq, squamosal. 
1526 Figure 9. Braincase of Scutarx deltatylus (PEFO 34616) in ventrolateral view. Scale bar equals 1

1527

1528

1529

1530

1531

1532

1533

1534

1535

1536

1537

1538

1539

1540

1541

1542

1543

1544

1545

1546

1547

1548

1549

1550

1551

1552

1553

1554

1555

1556

1557

1558

1559

1560

1561

1562

1563 cm. Abbreviations: bpt, basipterygoid processes; bsr, basisphenoid recess; bt, basal tubera; cc, cotylar crest; clp, clinoid process; cp, cultriform process; crp, crista prootica; fo, foramen ovale; hypf, hypophyseal fossa; ic, exit area of the internal carotid artery; lfr, left frontal; lr, lateral ridge; ls, laterosphenoid; mf, metotic foramen; na, nasal; oc, occipital condyle; orb, orbit; pa, parietal; par, paroccipital process of the opisthotic; po, postorbital; pr, prootic; prf, prefrontal; psr, parasphenoid recess; rfr, right frontal; s., suture with designated element; sq, squamosal; uc, unossified cleft of the basal tubera; $\mathbf{V}$, passageway for the Trigeminal nerve.

Figure 10. Parabasisphenoid of Scutarx deltatylus (PEFO 34616) in ventral view. Scale bar equals $1 \mathrm{~cm}$. Abbreviations: bpt, basipterygoid processes; bsr, basisphenoid recess; bt, basal tubera; cp, cultriform process; crp, crista prootica; f., fossa for specified element; lfr, left frontal; $\mathbf{l r}$, lateral ridge; ls, laterosphenoid; of, orbital fossa; orb, orbit; par, paroccipital process of the opisthotic; po, postorbital; prf, prefrontal; pr, prootic; prf, prefrontal; psr, parasphenoid recess; quadrate; rfr, right frontal; sq, squamosal; ssr, subsellar recess; stf, supratemporal fenestra; uc, unossified cleft of the basal tubera.

Figure 11. Articulated anterior post-axial vertebrae of Scutarx deltatylus (PEFO 31217) in posterolateral (A), posterior (B), anterior (C), and ventral (D) views. Scale bar equals $1 \mathrm{~cm}$. Abbreviations: diap, diapophysis; k, keel; nc, neural canal; ns, neural spine; parp, parapophysis; pocdf, postzygapophyseal centrodiapophyseal fossa; posz, postzygapophysis; prez, prezygapophysis; spof, spinopostzygapophyseal fossa; spol, spinopostzygapophyseal lamina; tpol, intrapostzygapophyseal lamina.

Figure 12. Trunk vertebrae of Scutarx deltatylus. A-C, PEFO 34045/FF-51, mid-trunk vertebra in posterior (A), anterior (B), and lateral (C) views. Scale bar equals $1 \mathrm{~cm}$. Abbreviations: b., broken designated element; cpof, centropostzygapophyseal fossa,; cprf, centroprezygapophyseal fossa; diap, diapophysis; nst, neural spine table; parp, parapophysis; podl, postzygadiapophyseal lamina; posz, postzygapophysis; prez, prezygapophysis; pro, projection; sprf, spinoprezygapophyseal fossa; spol, spinopostzygapophyseal lamina.

Figure 13. Trunk vertebrae of Scutarx deltatylus. A-C, PEFO 34045/19, Anterior trunk vertebra in anterior (A), posterior (B), and lateral (C) views. D-E, PEFO 34045/22, Posterior trunk vertebra in anterior (D) and lateral (E) views. Scale bar equals $1 \mathrm{~cm}$. Abbreviations: b., broken designated element; bf, bone fragment; cpof, centropostzygapophyseal fossa; k, keel; nst, neural spine table; parp, parapophysis; podl, postzygadiapophyseal lamina; posdf, postzygapophyseal spinodiapophyseal fossa; posz, postzygapophysis; prez, prezygapophysis; pro, projection; sprf, spinoprezygapophyseal fossa; tp, transverse process; vb, ventral bar.

Figure 14. Posterior trunk vertebrae of Scutarx deltatylus. A-B, PEFO 34045 in anterior (A) and dorsal (B) view. C, PEFO 31217 in anterior view. Scale bar equals $1 \mathrm{~cm}$. Abbreviations: cp, capitulum; cprf, centroprezygapophyseal fossa; diap, diapophysis; ns, neural spine; nst, neural spine table; parp, parapophysis; prdl, prezygadiapophyseal lamina; posdf, postzygapophyseal 
1564 spinodiapophyseal fossa; posz, postzygapophysis; prez, prezygapophysis; sprf, 1565 spinoprezygapophyseal fossa; tb, tuberculum; tp, transverse process; vb, ventral bar.

1566 Figure 15. Photo and interpretive sketch of a partially articulated sacrum and anterior portion of 1567 the tail of Scutarx deltatylus (PEFO 31217). Scale bar equals $10 \mathrm{~cm}$. Abbreviations: ac, acetabulum, apib, anterior process of the iliac blade; cdv, caudal vertebra; $\mathbf{d v}$, trunk vertebra; $\mathbf{f}$, foramen; isc, ischia; l.il, left ilium; l.pu, left pubis; lo, lateral osteoderm; os, osteoderm; pos, paramedian osteoderm; r.il, right ilium; r.pu, right pubis; scv, sacral vertebra.

1571

1572

1573

1574

1575

1576

1577

1578

1579

1580

1581

1582

1583

1584

1585

1586

1587

1588

1589

1590

1591

1592

1593

1594

1595

1596

1597

1598

1599

1600
Figure 16. Anterior caudal vertebrae of Scutarx deltatylus (PEFO 34045). A-D, anterior caudal in posterior (A), anterior (B), lateral (C), and ventral (D). E-F, Anterior caudal vertebra in ventral (E) and lateral (F). Scale bar equals $1 \mathrm{~cm}$. Abbreviations: b., broken designated element; cf, chevron facet; cr, caudal rib; gr, ventral groove; posz, postzygapophysis; prez, prezygapophysis; spof, spinopostzygapophseal fossa, ; sprf, spinoprezygapophyseal fossa.

Figure 17. Mid-caudal vertebrae of Scutarx deltatylus. A-C, anterior mid-caudal vertebra (PEFO 34919) in lateral (A), anterior (B), and posterior (C) views. D, posterior mid-caudal vertebra (PEFO 34045) in lateral view. Scale bar $=1 \mathrm{~cm}$. Abbreviations: cf, chevron facet; cr, caudal rib; ns, neural spine; prez, prezygapophysis; posz, postzygapophysis.

Figure 18. Chevrons and ribs of Scutarx deltatylus. A-B, partial anterior chevrons from PEFO 34045 in posterior view; C-D, left trunk rib from PEFO 34045 in posterior (C) and anterior (D) views. E, close-up view of head of trunk rib from PEFO 34045. F, paired gastral ribs from PEFO 34616. Scale bars equal $1 \mathrm{~cm}$. Abbreviations: cp, capitulum; fo, fossa; gr, groove; tb, tuberculum.

Figure 19. Left scapulocoracoid of Scutarx deltatylus. of PEFO 31217 in lateral view. Scale bar equals $10 \mathrm{~cm}$. Abbreviations: ap, acromion process; cor, coracoid; fm, foramen; ost, osteoderms; sgb, supraglenoid buttress; $\mathbf{t t}$, triceps tubercle.

Figure 20. Close-up of pelvis of Scutarx deltatylus (PEFO 31217). Scale bar equals $5 \mathrm{~cm}$. Abbreviations: ac, acetabulum, apib, anterior process of the iliac blade; f, foramen; isc, ischia; l.il, left ilium; l.pu, left pubis; r.il, right ilium; r.pu, right pubis.

Figure 21. A-B, right ilium of PEFO 34919 in 'lateral' and 'medial' views (see text for discussion regarding anatomical direction of the ilium). Scale bar equals $1 \mathrm{~cm}$. Abbreviations: ac, acetabulum; apib, anterior process of the iliac blade; fm, foramen; ip, ischiadic peduncle; pp, pubic peduncle; ppib, posterior process of the iliac blade; re, recess; sac, supraacetabular crest; sh, shelf; sras, sacral rib attachment surfaces.

Figure 22. Cervical and dorsal trunk paramedian osteoderms of Scutarx deltatylus from PEFO 34045. A-B, left mid-cervical osteoderm in dorsal (A) and posterior (B) views. C-D, right midcervical osteoderm in dorsal (C) and posterior (D). E-F, left (E) and right (F) dorsal trunk osteoderms in dorsal view. G-I, left $(\mathrm{G}, \mathrm{H})$ and right (I) dorsal trunk osteoderms in dorsal (G, I) and posterior $(\mathrm{H})$ views. J-K, left $(\mathrm{J})$ and right $(\mathrm{K})$ dorsal trunk osteoderms in dorsal view. L-M, 
1601 posterior dorsal trunk osteoderm in dorsal (L) and posterior (M) views. Scale bar $=1 \mathrm{~cm}$. 1602 Abbreviations: ab, anterior bar; alp, anterolateral process; amp, anteromedial process; anp, 1603 anterior process; de, dorsal eminence; trp, triangular protuberance.

1604 Figure 23. Holotype paramedian osteoderms of Scutarx deltatylus from PEFO 34616. A, 1605 posterior cervical osteoderm in dorsal view. B-C, right dorsal trunk paramedian osteoderm in 1606 dorsal (B) and posterior (C) views. D-E, partial right dorsal trunk paramedian osteoderm in dorsal 1607 (D) and posterior (E) views. Note the prominence of the triangular protuberance in the posterior 1608 views. Scale bar equals $1 \mathrm{~cm}$. Abbreviations: ab, anterior bar; alp, anterolateral process; amp, 1609 anteromedial process; de, dorsal eminence; trp, triangular protuberance.

1610 Figure 24. Comparison of dorsal trunk paramedian osteoderms of Calyptosuchus wellesi (A) and 1611 Scutarx deltatylus (B-D) in dorsal view. A, MNA 2930, left osteoderm of Calyptosuchus wellesi 1612 lacking the triangular protuberance (trp). B, UCMP 36656, right osteoderms of Scutarx deltatylus 1613 showing the triangular protuberance. C, UCMP 126844, medial portion of left osteoderm of 1614 Scutarx deltatylus showing the triangular protuberance. D, UCMP 35738, medial half of left 1615 osteoderm of Scutarx deltatylus showing the triangular protuberance. Scale bar equals $5 \mathrm{~cm}$. 1616 Abbreviations: ab, anterior bar; alp, anterolateral process; amp, anteromedial process; de, dorsal 1617 eminence; trp, triangular protuberance.

1618 Figure 25. Fused semi-articulated anterior dorsal caudal paramedian and dorsal caudal lateral 1619 osteoderms of Scutarx deltatylus (PEFO 34919) in a lateral view showing extreme development 1620 of the dorsal eminences. Scale bar equals $1 \mathrm{~cm}$. Abbreviations: lo, lateral osteoderm; po, 1621 paramedian osteoderm.

1622 Figure 26. Dorsal caudal paramedian osteoderms of Scutarx deltatylus. A-B, left anterior mid1623 caudal osteoderm (PEFO 34045) in dorsal (A) and posterior (B) views. C-D, right anterior mid1624 caudal osteoderm (PEFO 34919) in dorsal (C) and posterior (D) views; E-F, left mid-caudal 1625 osteoderm (PEFO 34045) in dorsal (E) and posterior (F) views. G-H, right mid-caudal osteoderm (PEFO 34919) in dorsal (G) and posterior (H) views. I-J, left mid-caudal osteoderm (PEFO 34919 ) in dorsal (I) and posterior (J) views. K-L, right posterior caudal osteoderm (PEFO 34045) in dorsal $(\mathrm{K})$ and posterior (L) views. M-N, left posterior caudal osteoderm (PEFO 34045) in dorsal $(\mathrm{M})$ and posterior $(\mathrm{N})$ views. Scale bar equals $1 \mathrm{~cm}$. Abbreviations: ab, anterior bar; alp, anterolateral process; amp, anteromedial process; de, dorsal eminence; me, medial edge.

1631 Figure 27. Lateral osteoderms of Scutarx deltatylus. A-B, left anterior trunk osteoderm (PEFO 1632 34616) in dorsal (A) and posterior (B) views; C-D, right anterior trunk osteoderm (PEFO 34045) in dorsal (C) and posterior (D) views; E-F, right posterior mid-trunk osteoderm (PEFO 34045) in 1635 dorsal (E) and posterior (F) views; G-H, left posterior mid-trunk osteoderm (PEFO 34045) in dorsal $(\mathrm{G})$ and posterior $(\mathrm{H})$ views; I-J, right posterior trunk osteoderm (PEFO 34045) in dorsal (I) and posterior (J) views; K-L, right anterior dorsal caudal osteoderm (PEFO 34045) in dorsal (K) and posterior (L) views; right posterior dorsal mid-caudal osteoderm (PEFO 34919) in dorsal 1639 (M) and posterior (N) views; O-P, left dorsal mid-caudal osteoderm (PEFO 34616) in dorsal (O) and posterior $(\mathrm{P})$ views. Scale bar equals $1 \mathrm{~cm}$. Abbreviations: ab, anterior bar; alw, anterolateral 
1640 wing; de, dorsal eminence; df, dorsal flange; mf, medial flange; poa, paramedian osteoderm 1641 articular surface.

1642 Figure 28. Ventral trunk and appendicular osteoderms of Scutarx deltatylus from PEFO 34616. 1643 A-F, square ventral osteoderms. G, round, keeled appendicular osteoderm. H, triangular ventral 1644 (cloacal?) osteoderm. I, round, ornamented appendicular osteoderm. Scale bar equals $1 \mathrm{~cm}$. 1645 Abbreviations: ab, anterior bar; $\mathbf{k}$, keel.

1646 Figure 29. Incompletely formed trunk paramedian osteoderms from PEFO 34045. A-B, right 1647 osteoderms in dorsal view; C, left osteoderm in dorsal view; D, right osteoderm in dorsal view. 1648 Scale bar equals $1 \mathrm{~cm}$. Abbreviations: ab, anterior bar; alp, anterolateral process.

1649 Figure 30. Time-calibrated phylogeny of the Aetosauria showing estimated ranges of taxa in the 1650 Triassic stages and associated vertebrate biozones. The Adamanian biozone is highlighted in 1651 blue. 


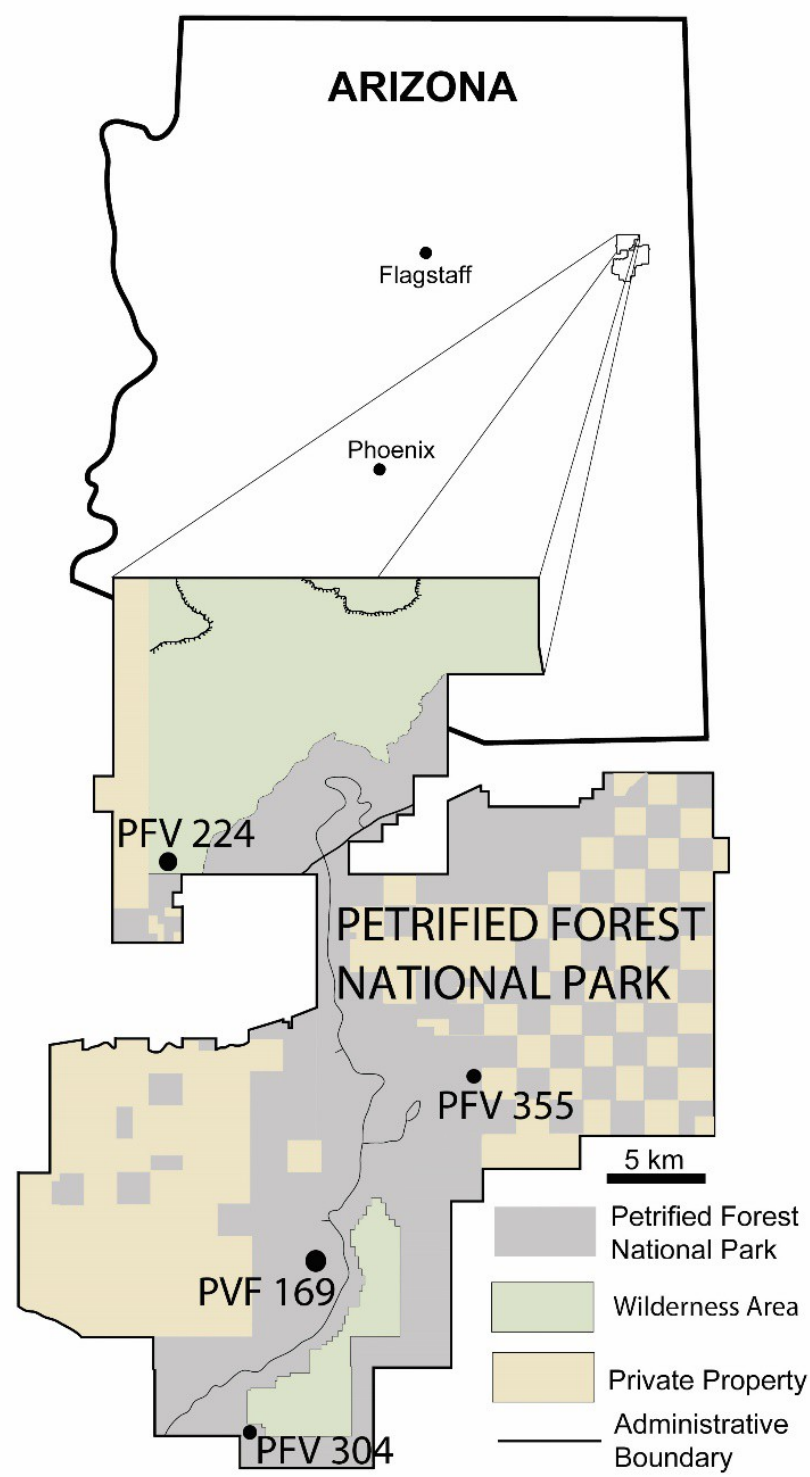




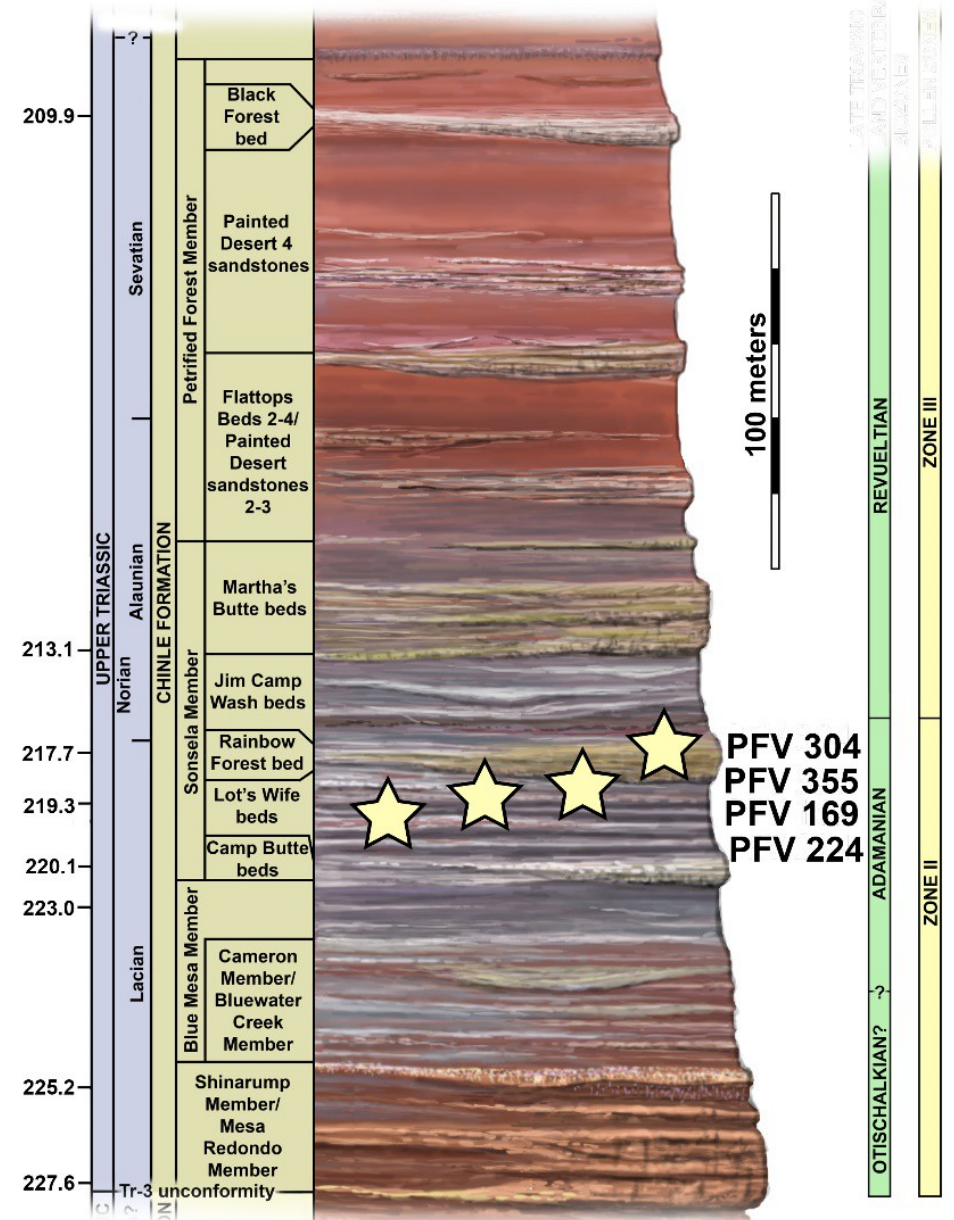



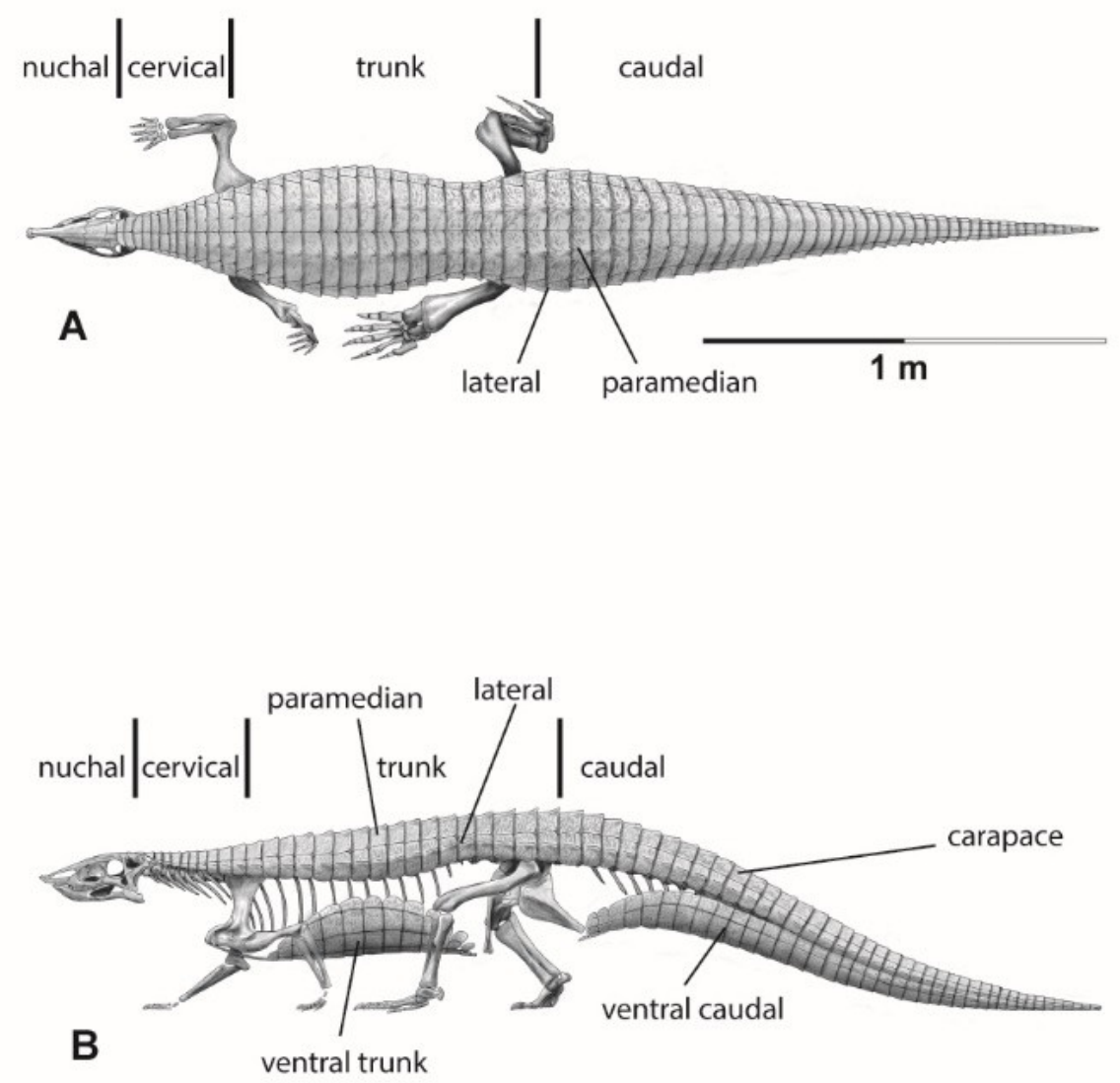

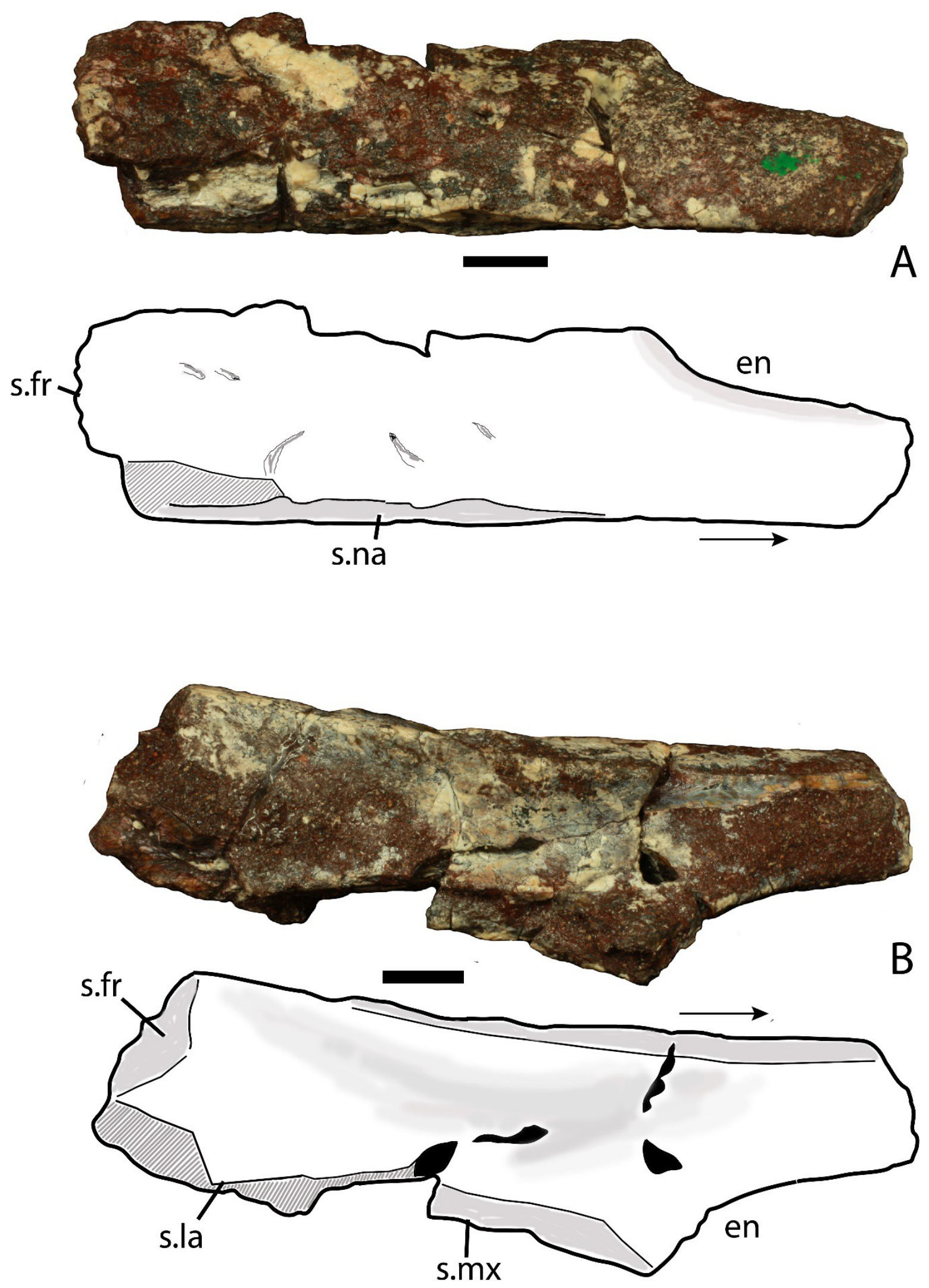


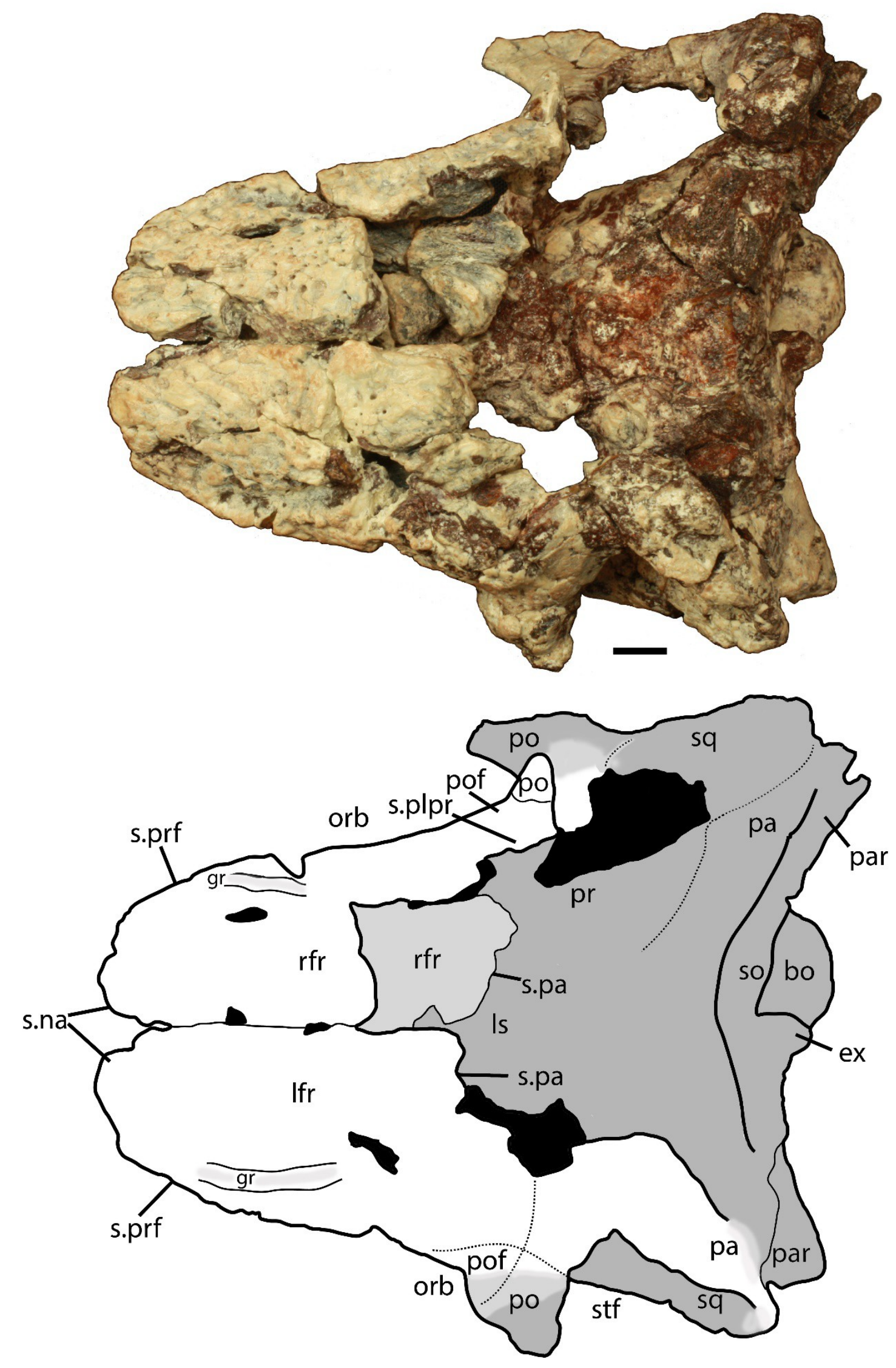



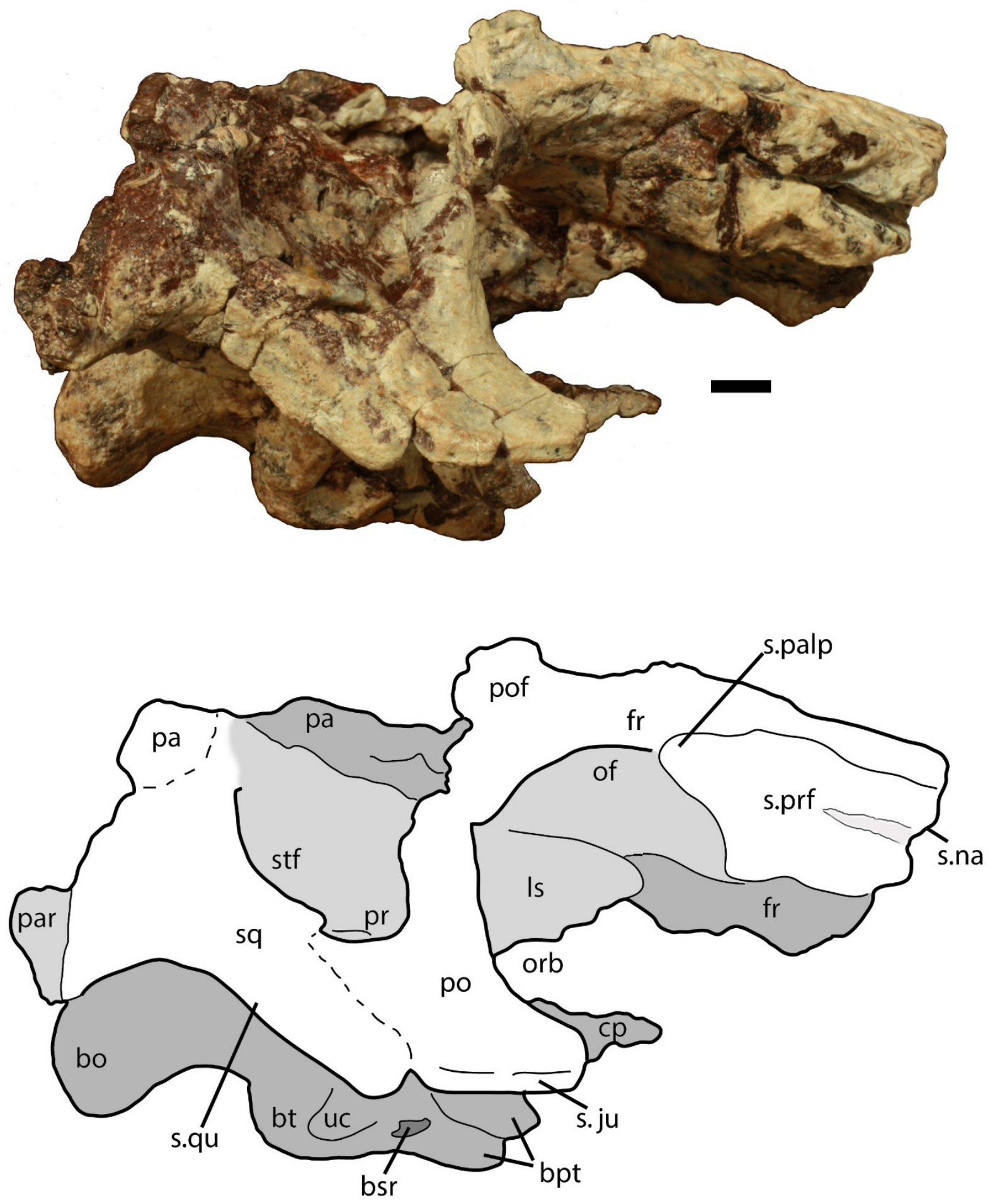


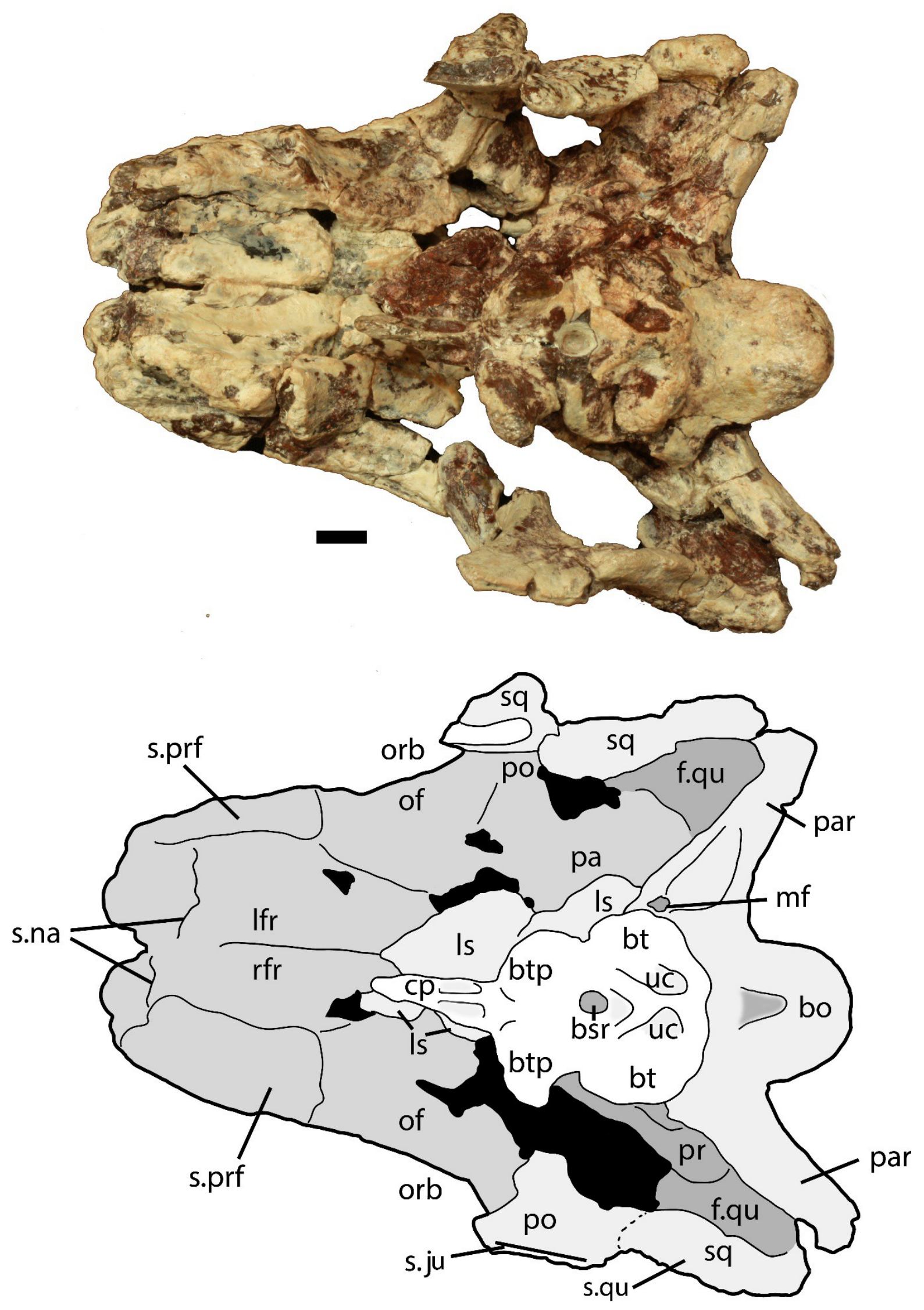



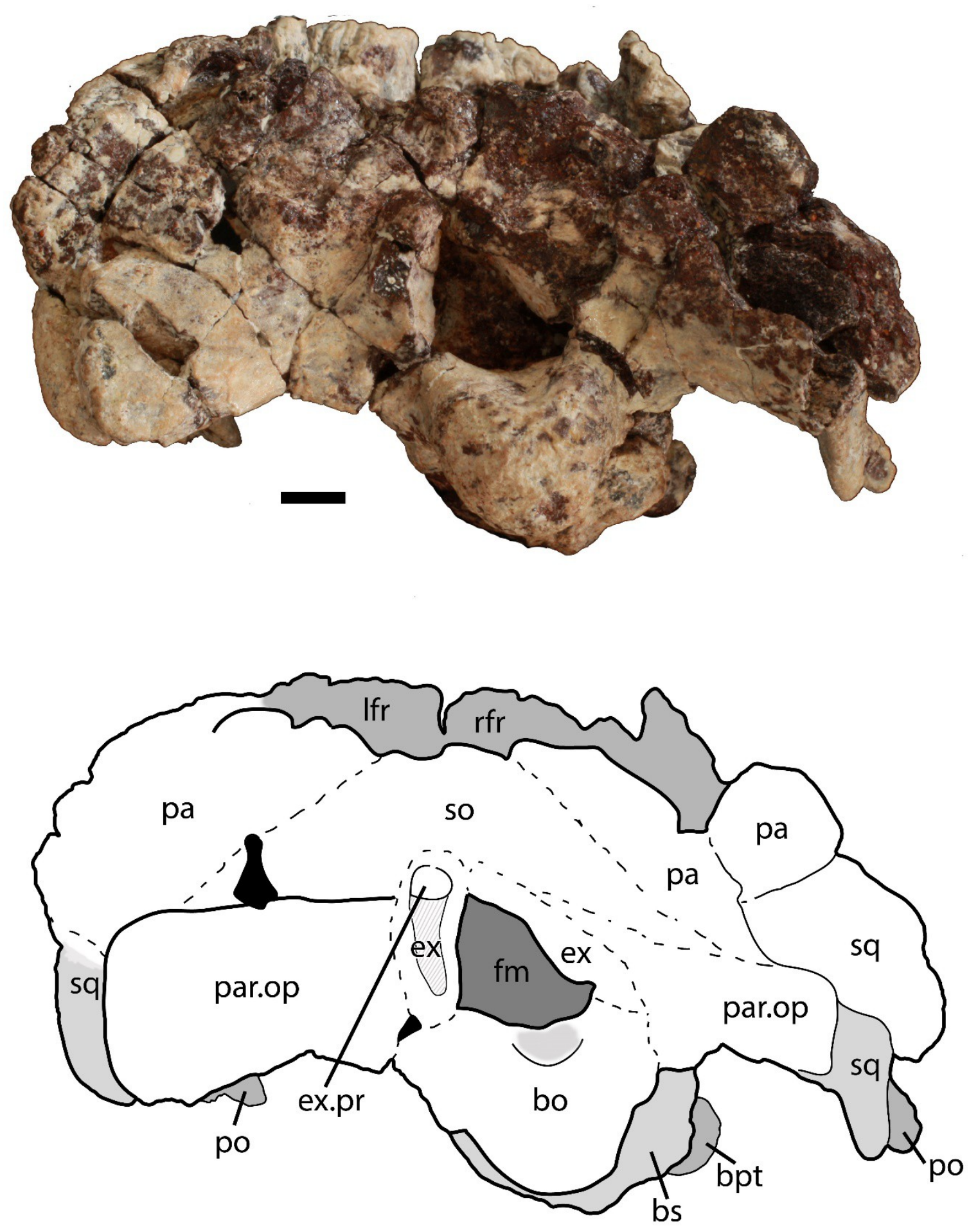

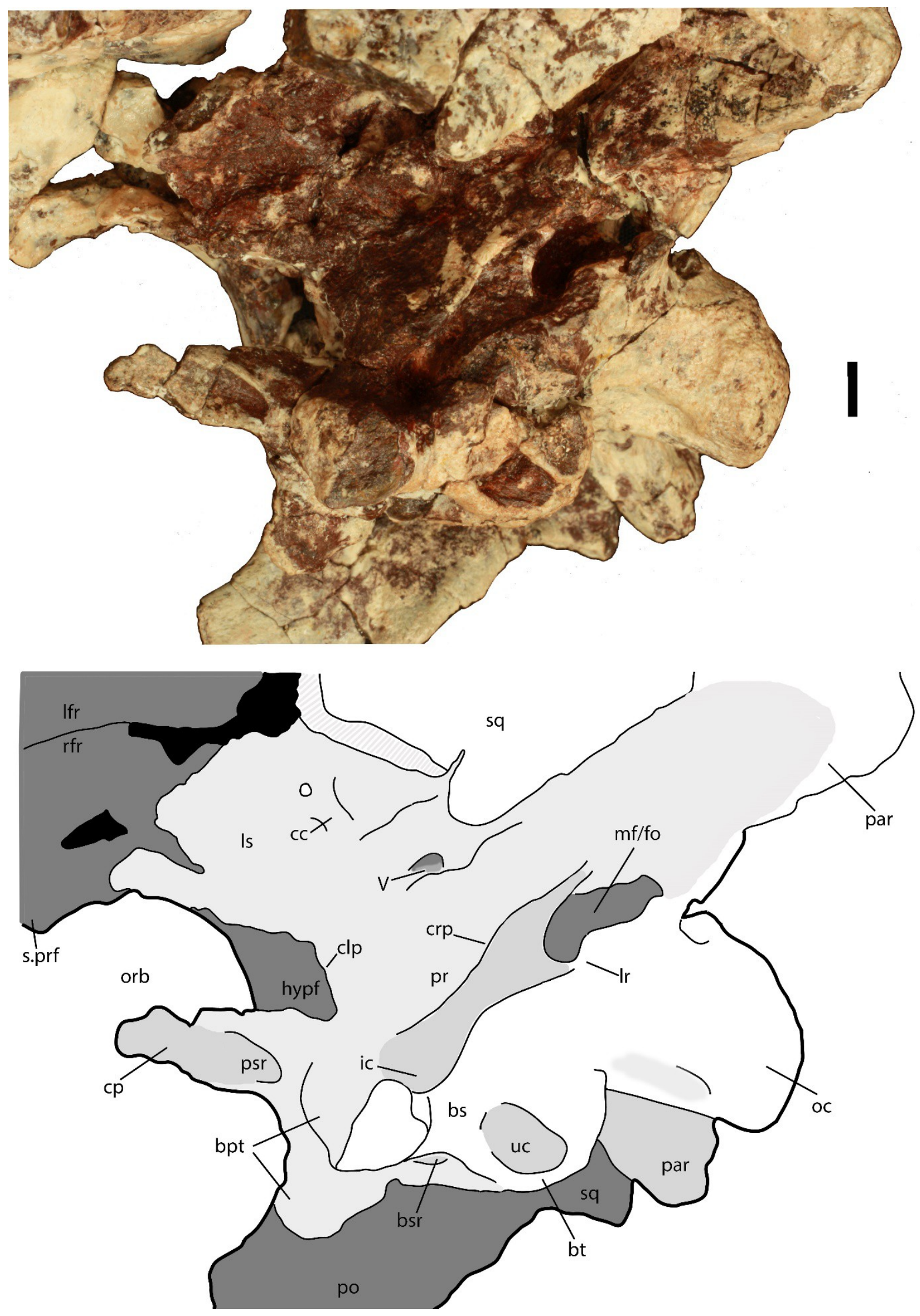


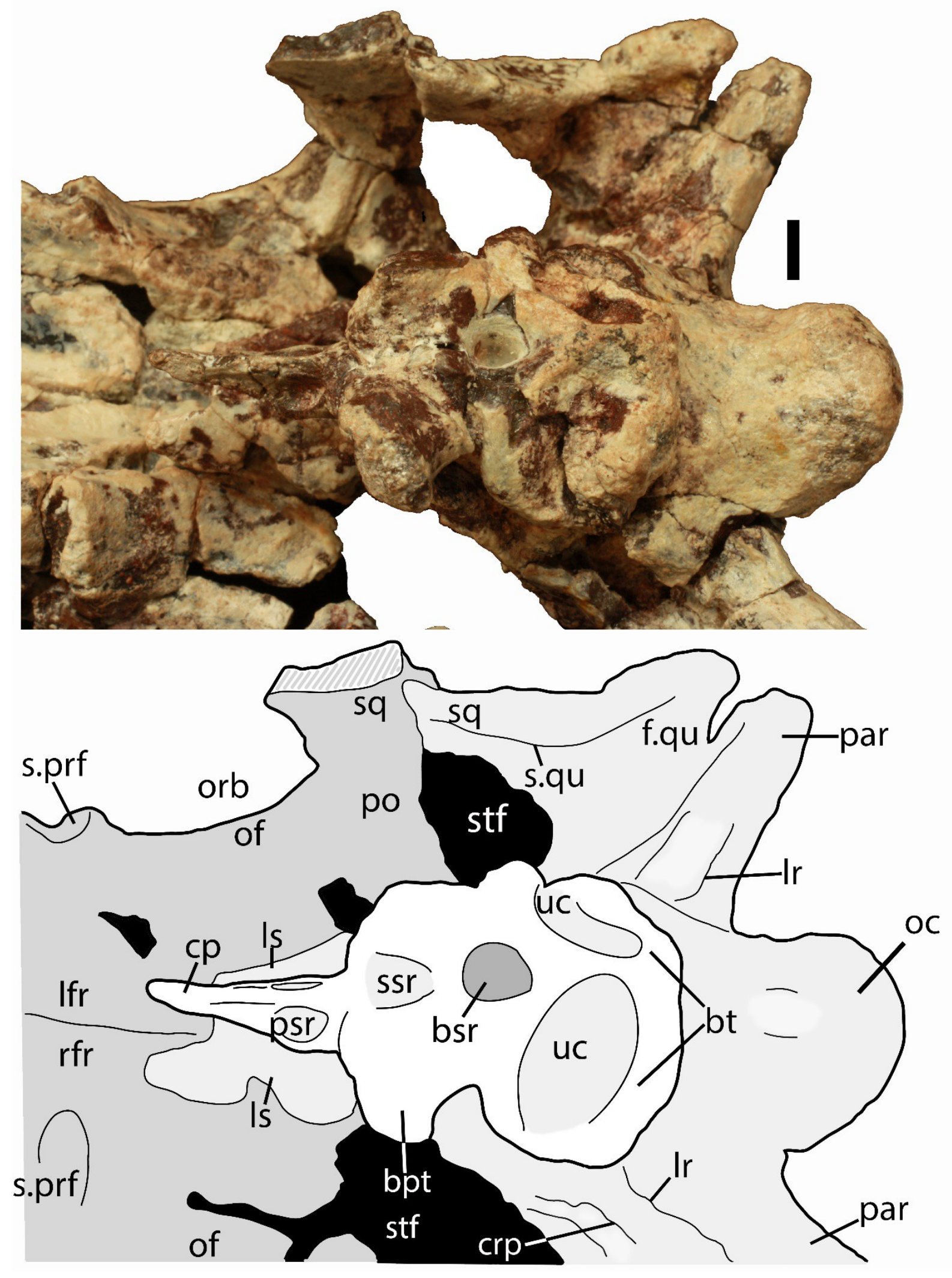



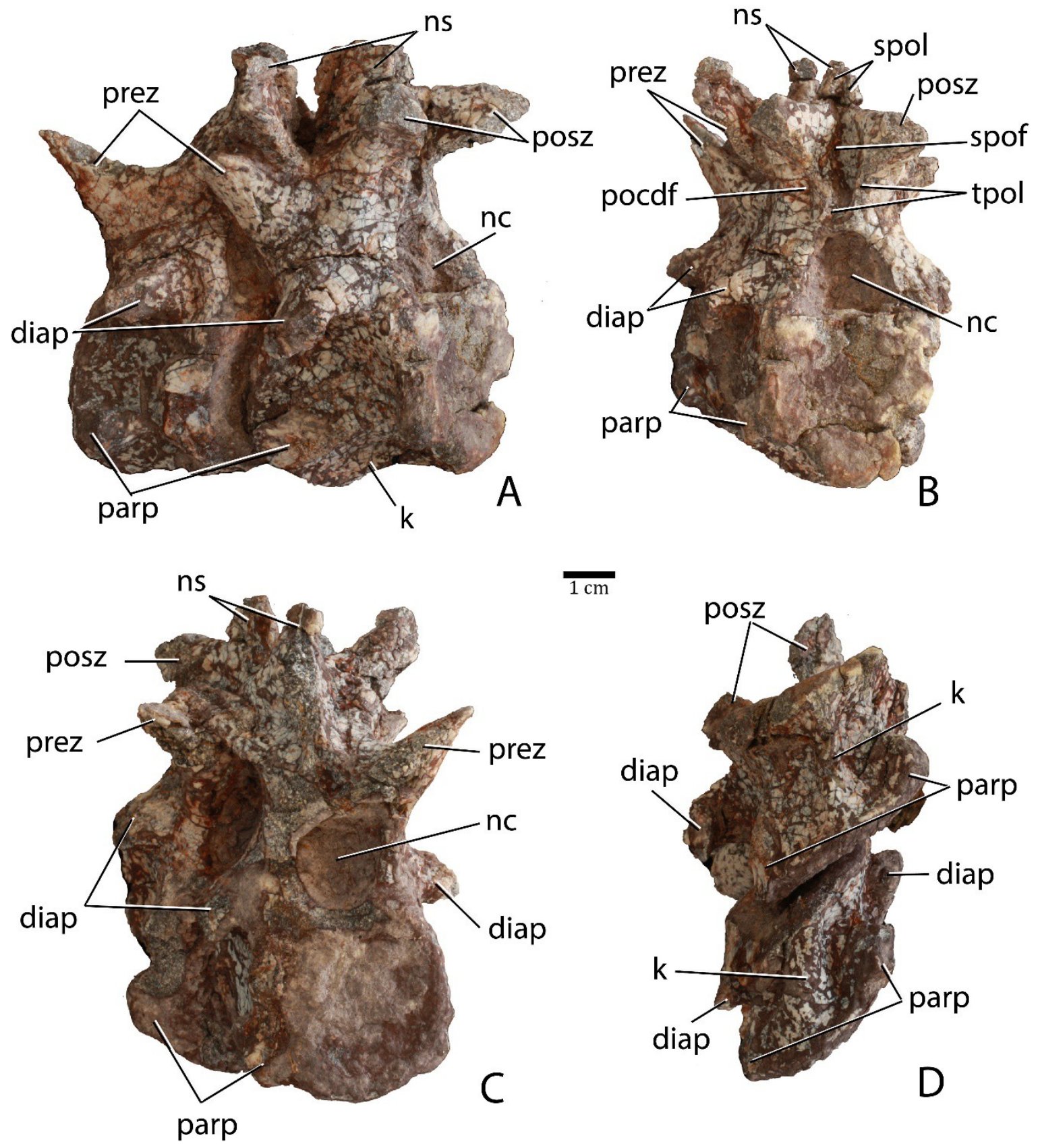


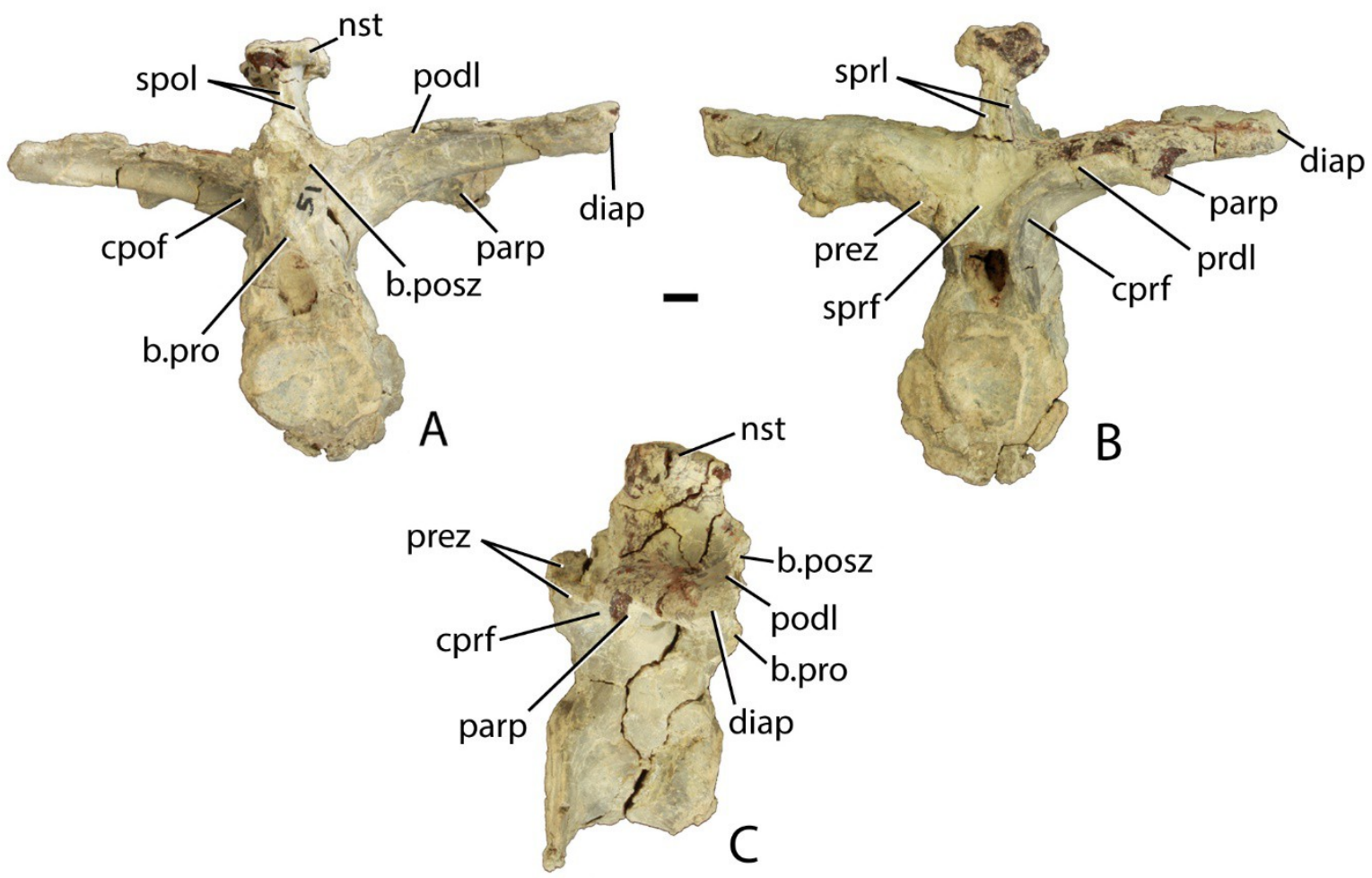



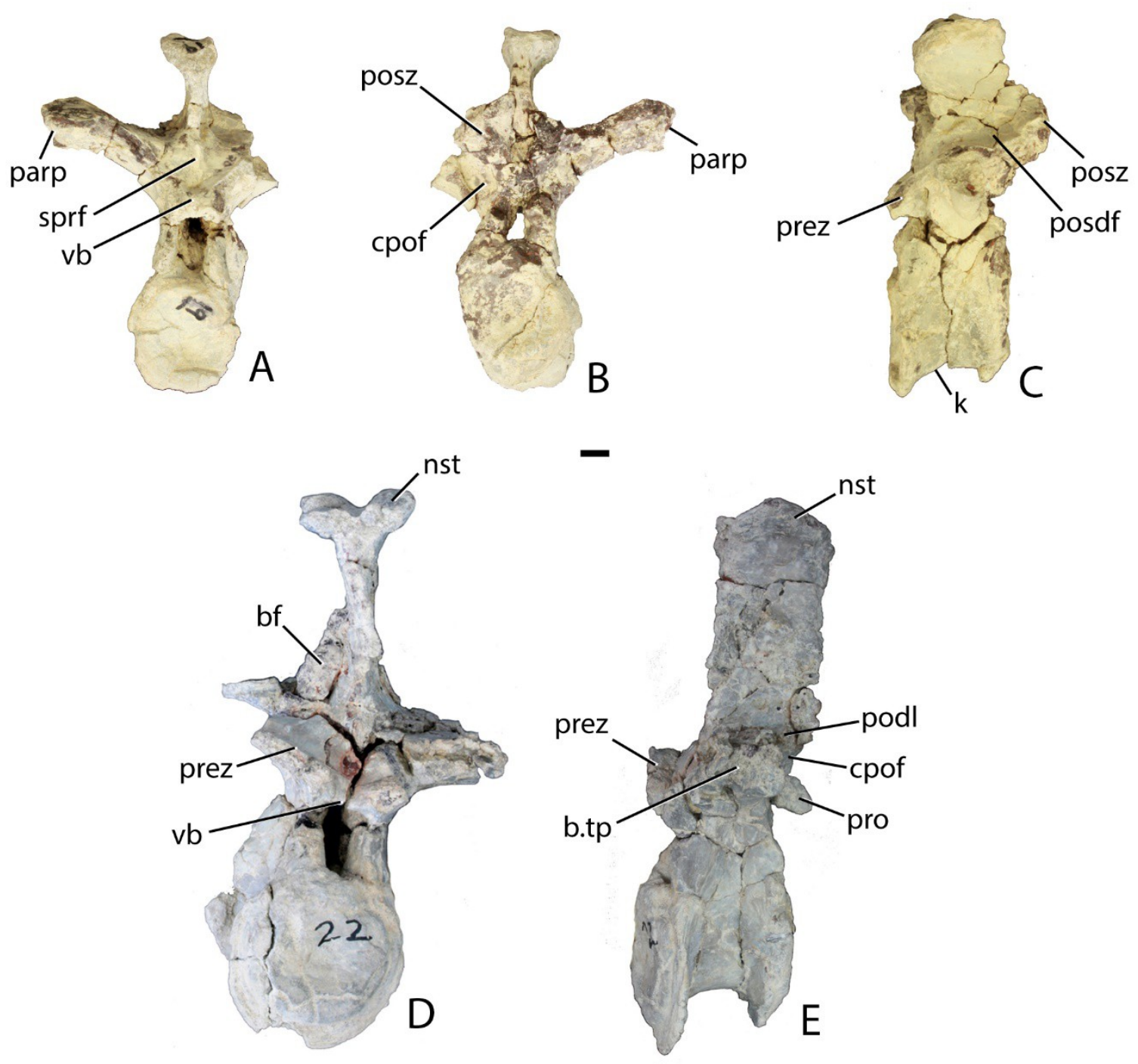

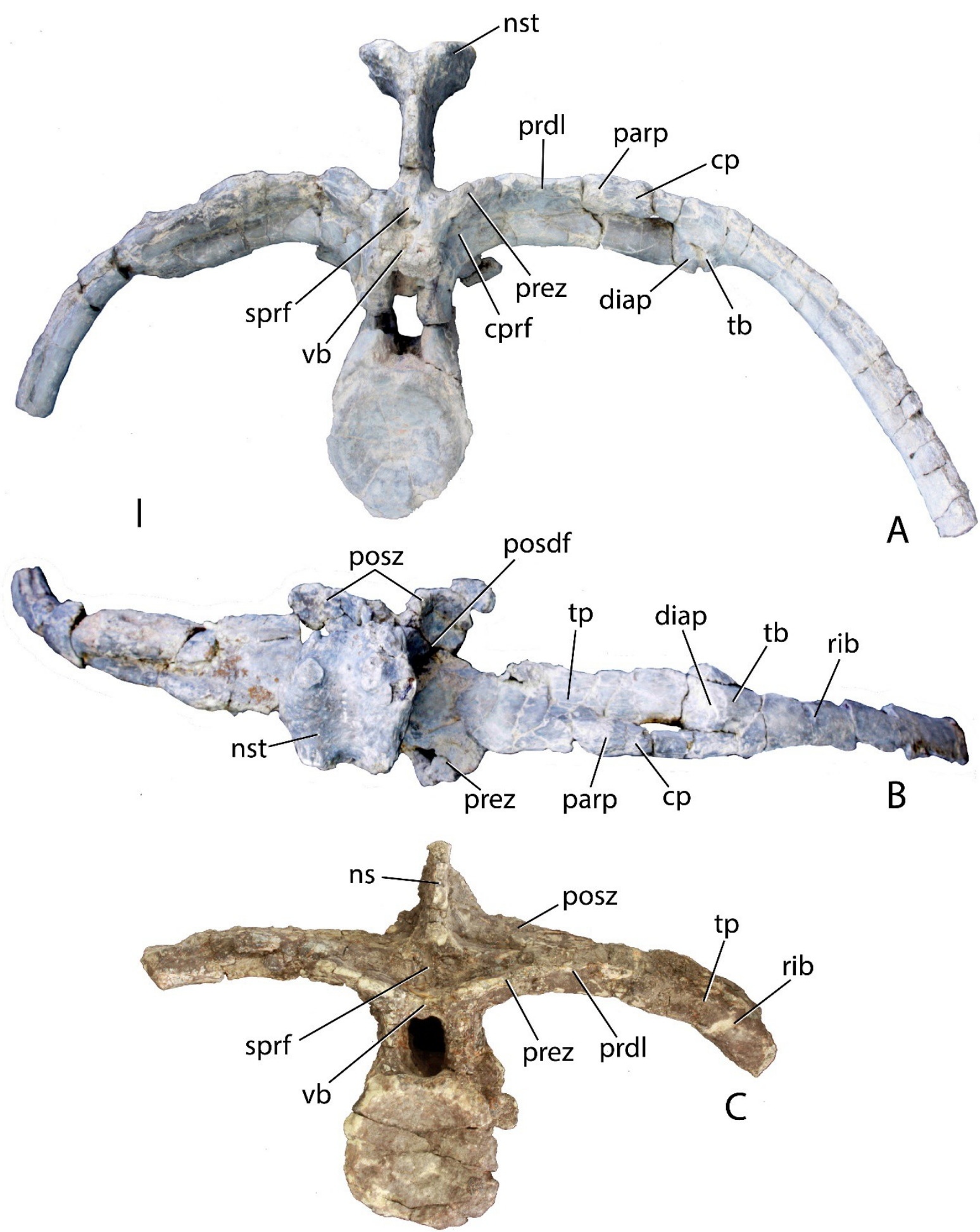

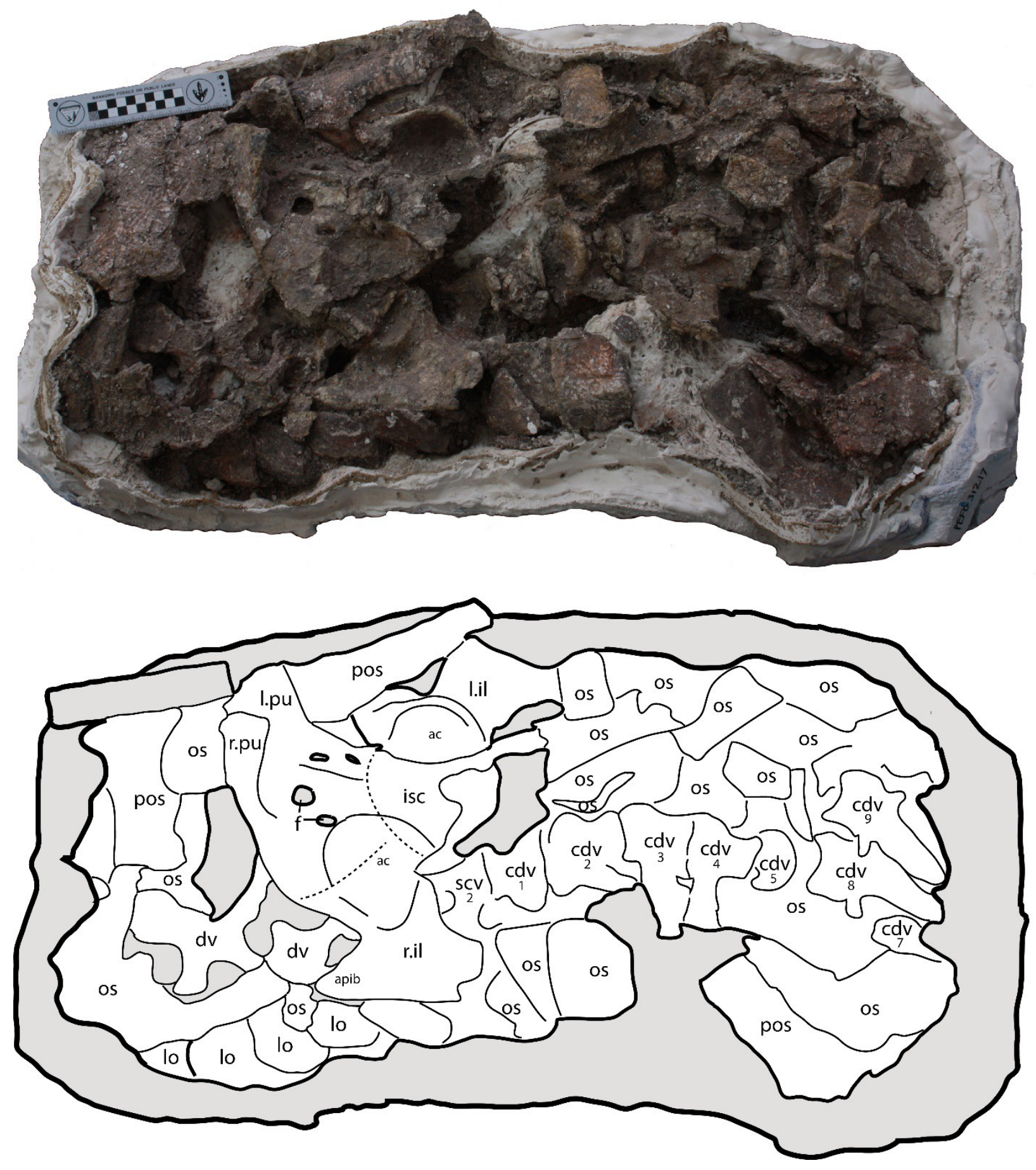

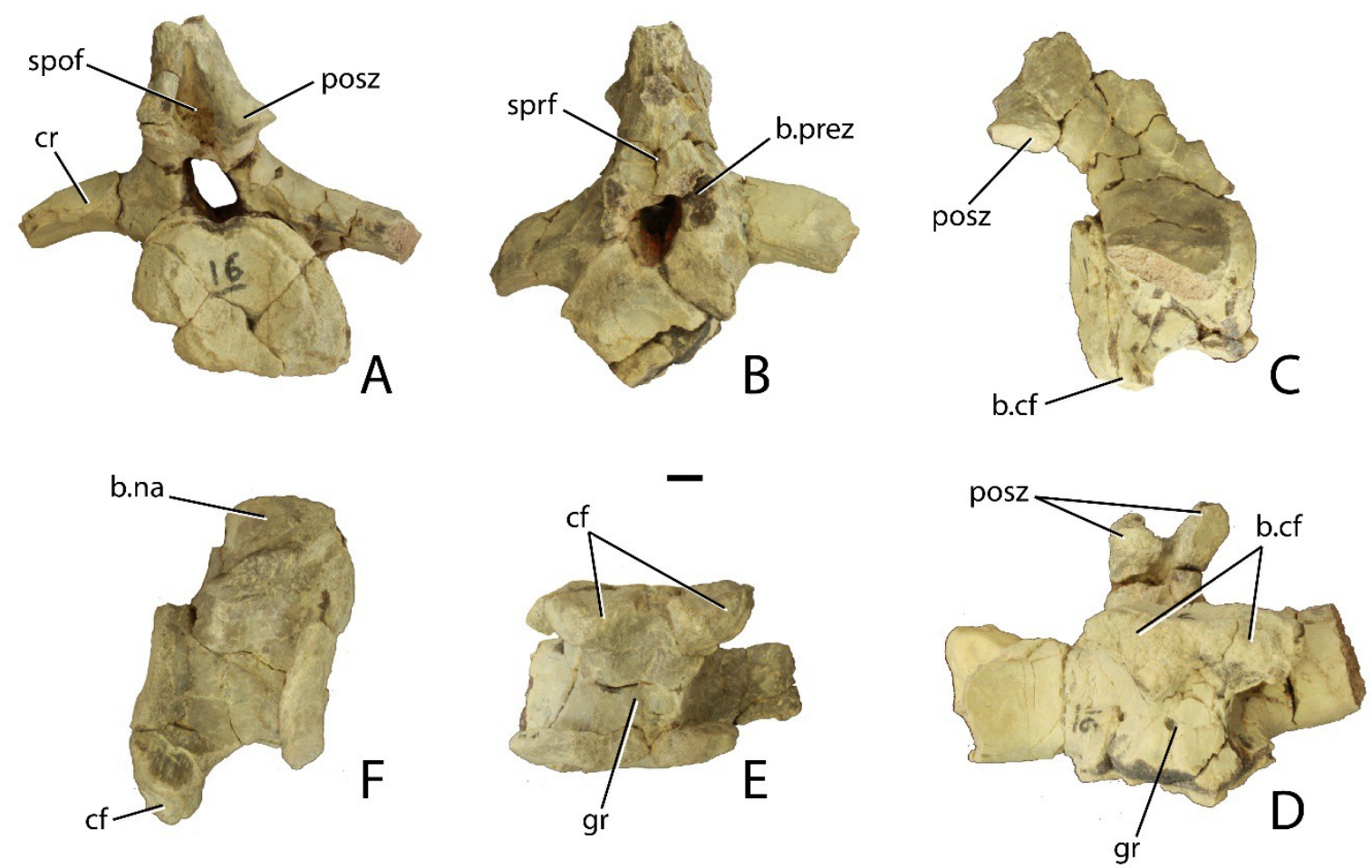


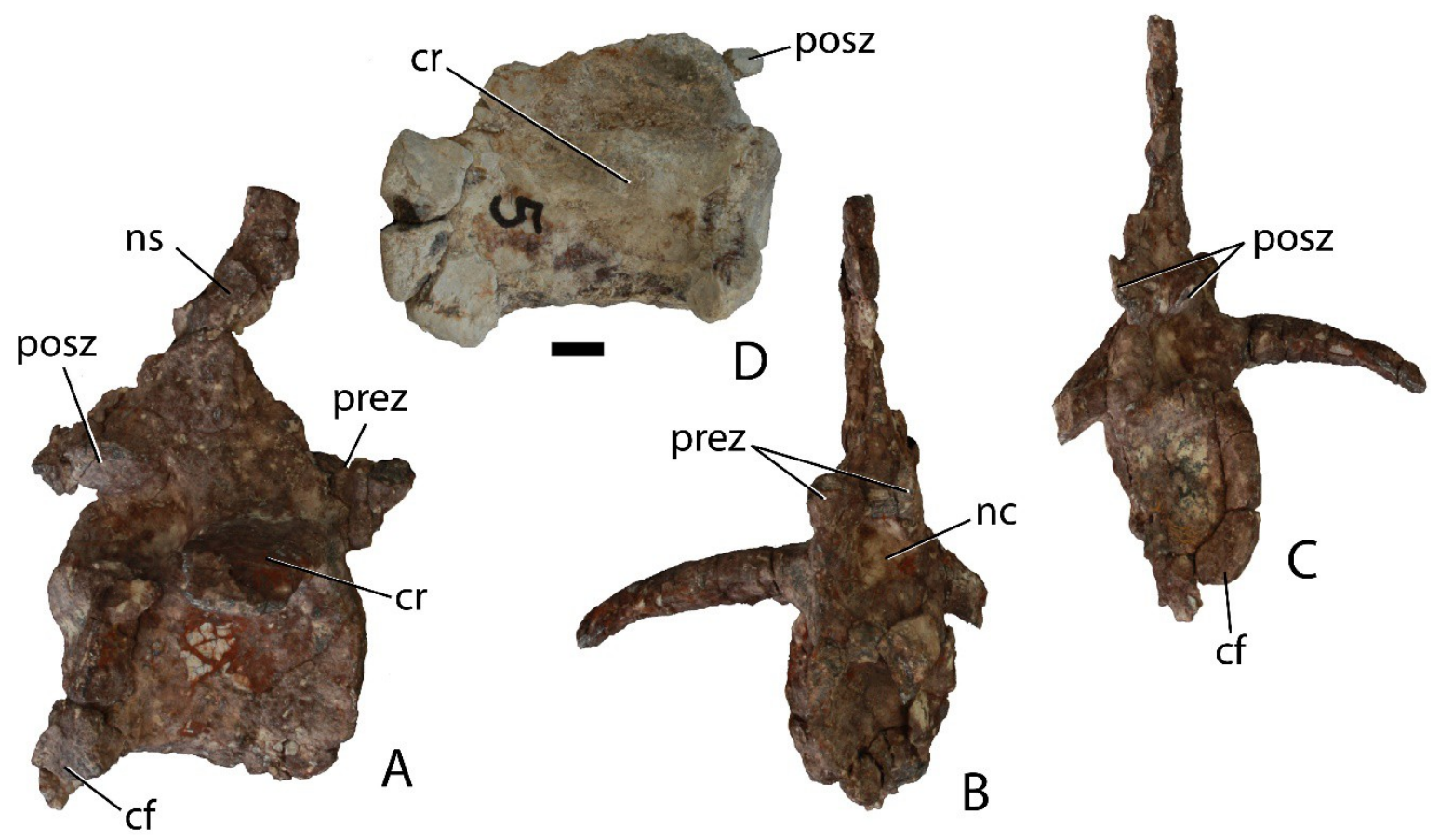



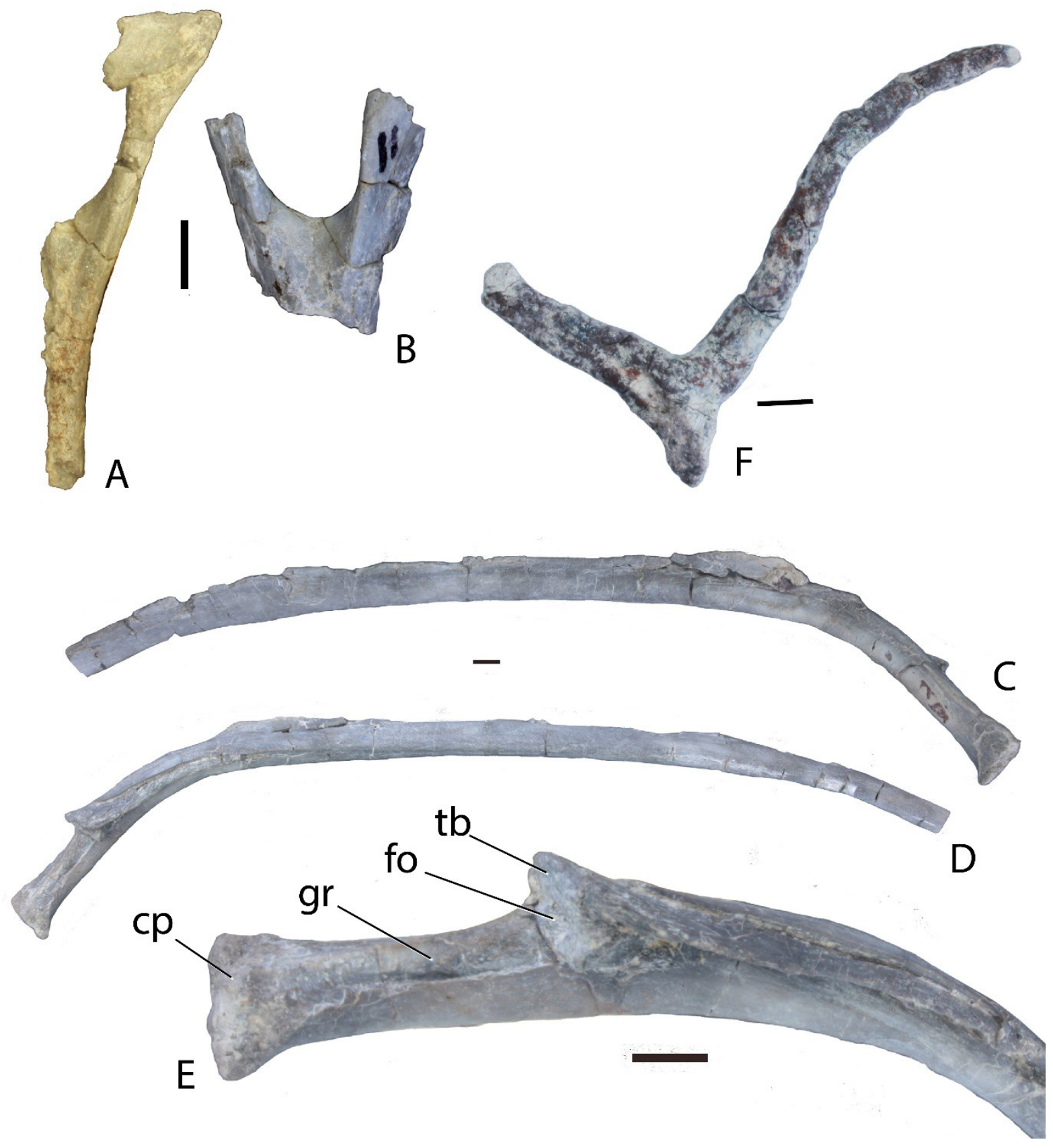


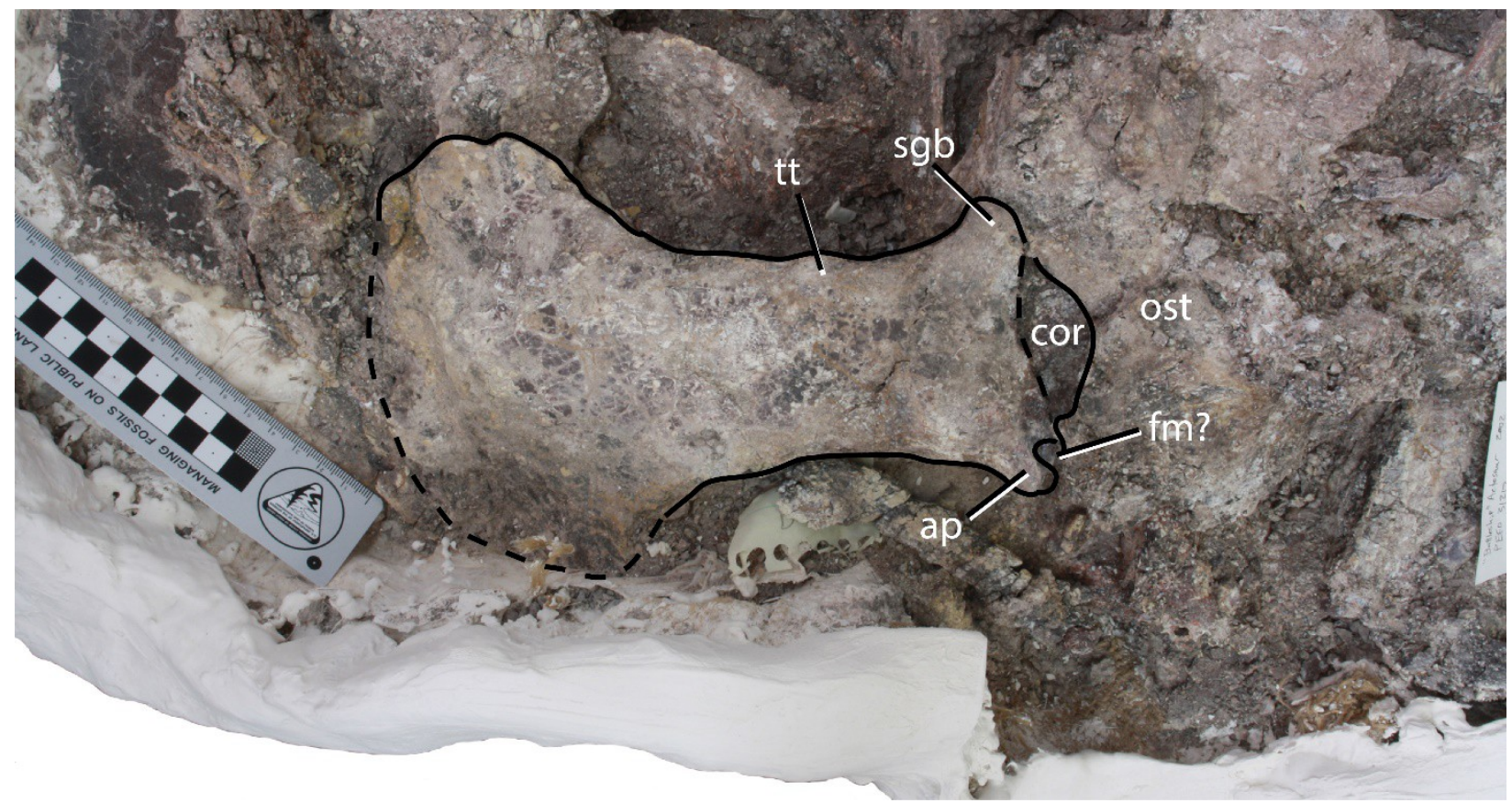



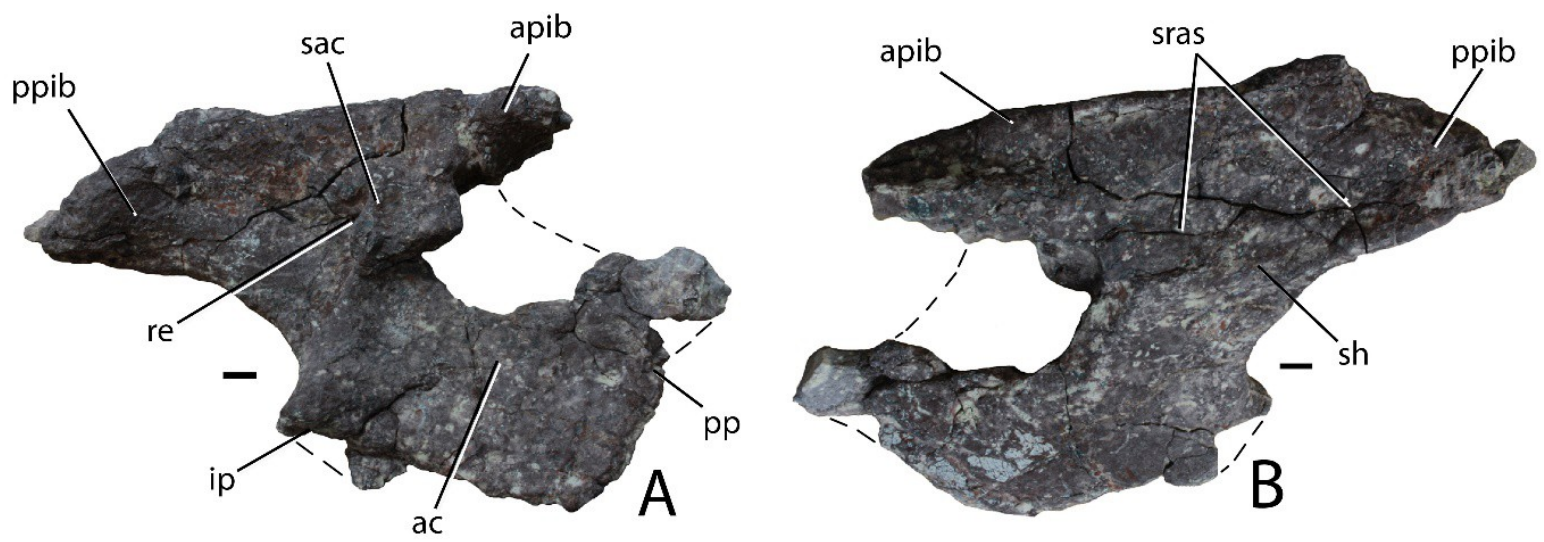


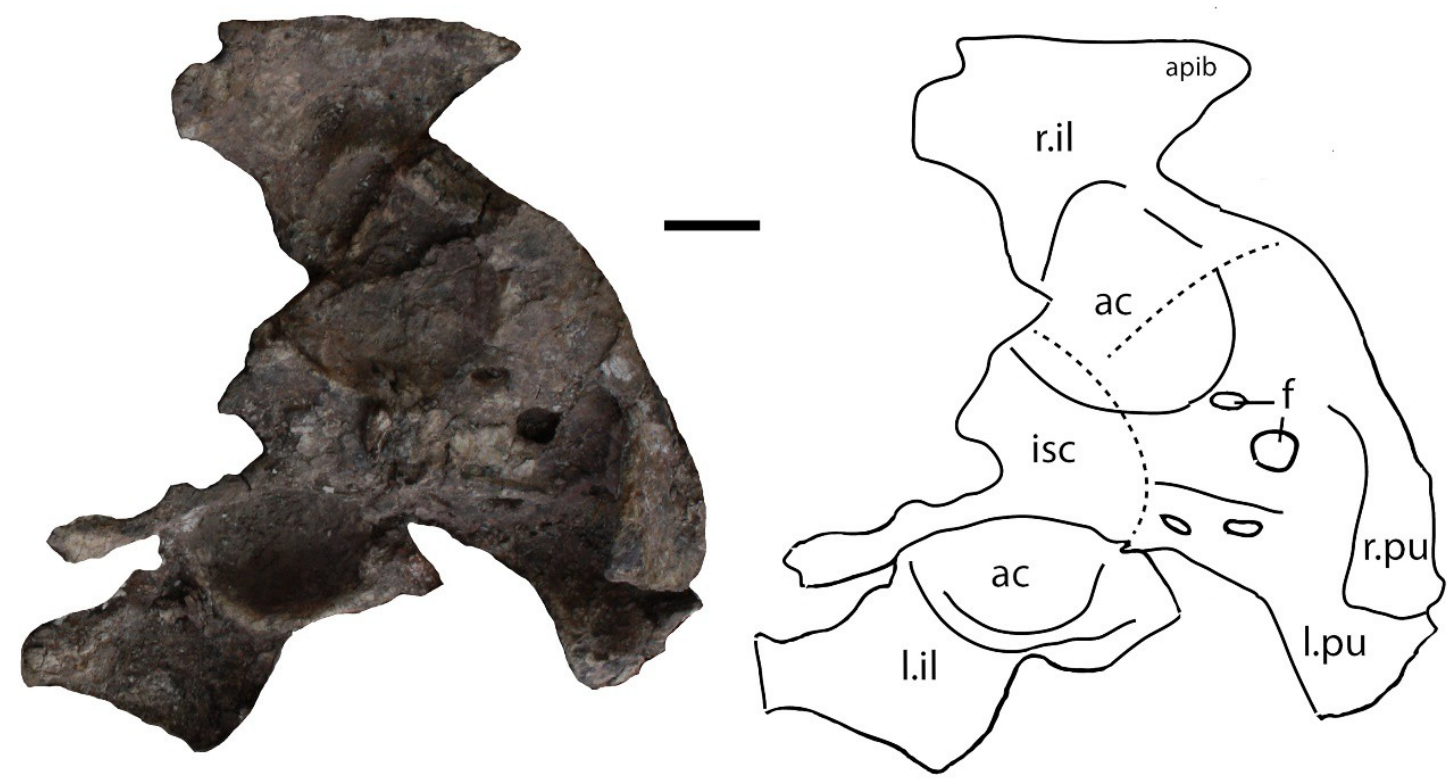




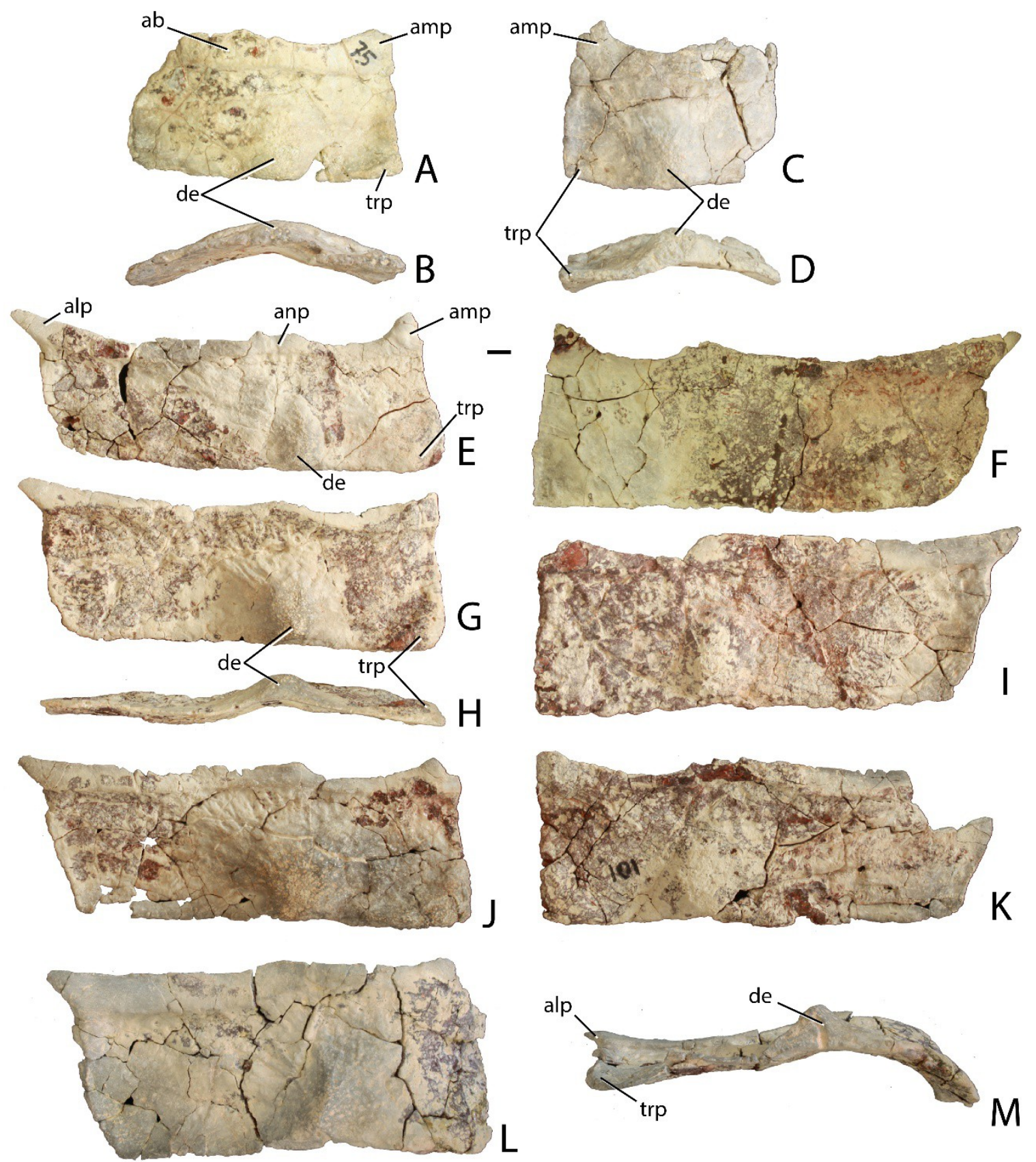




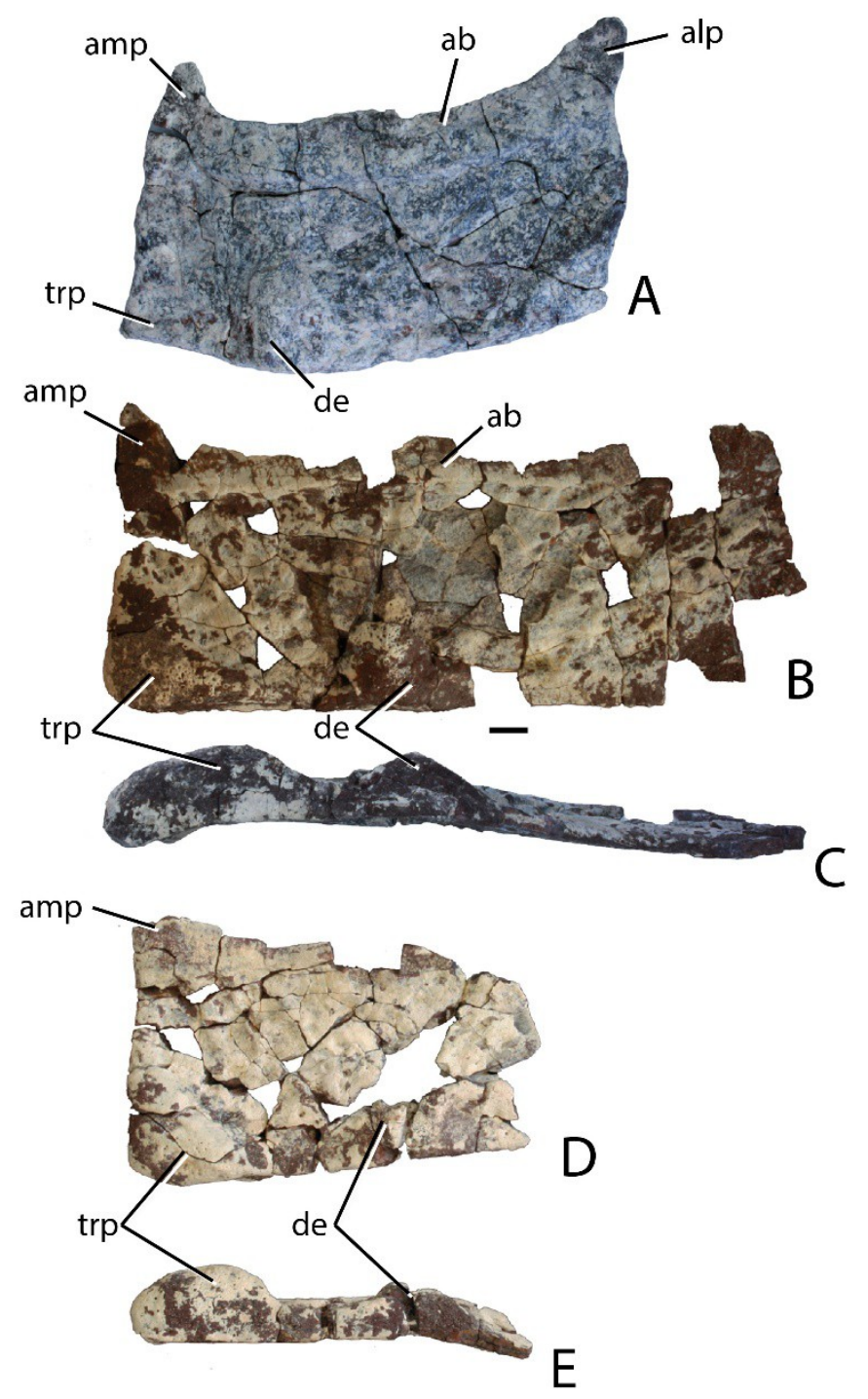




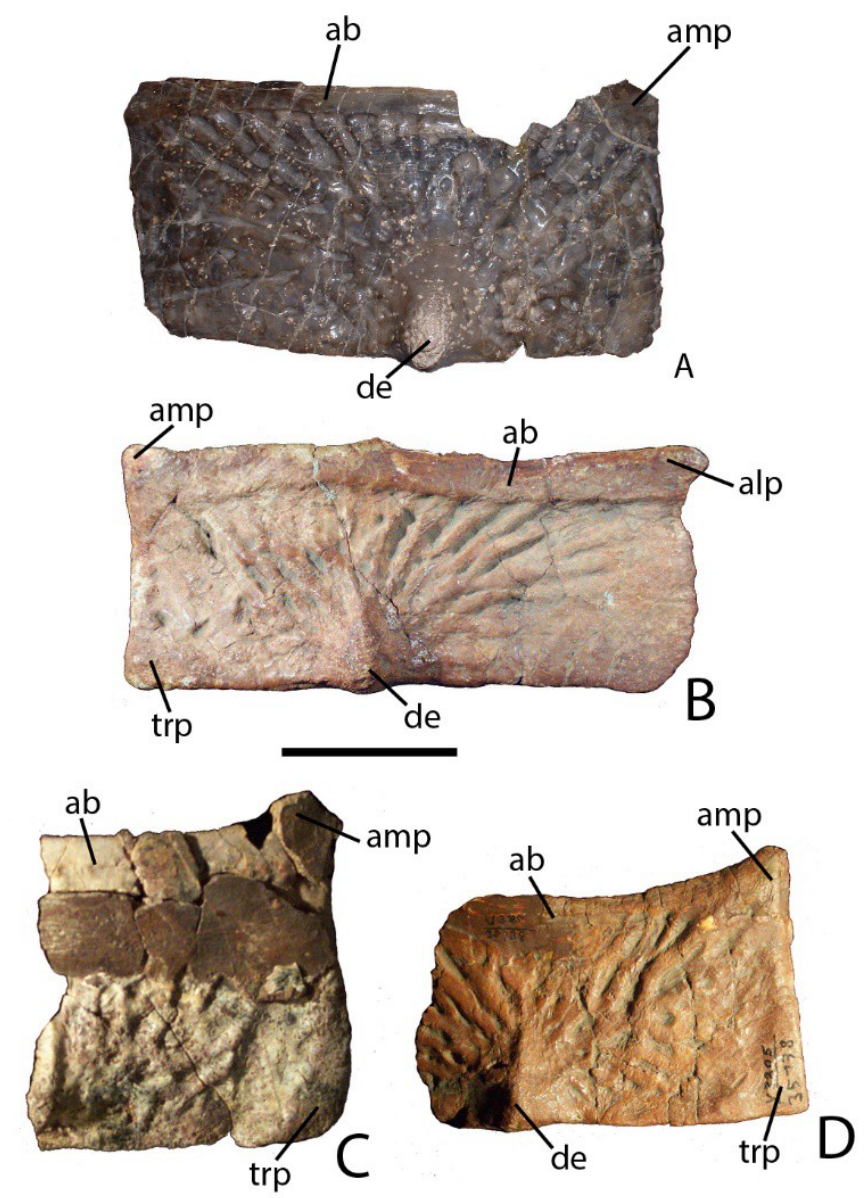




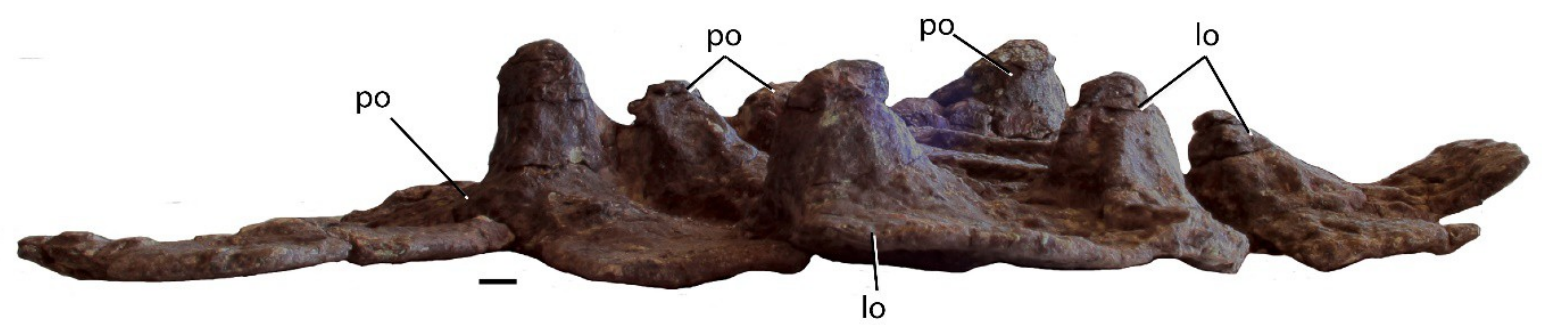




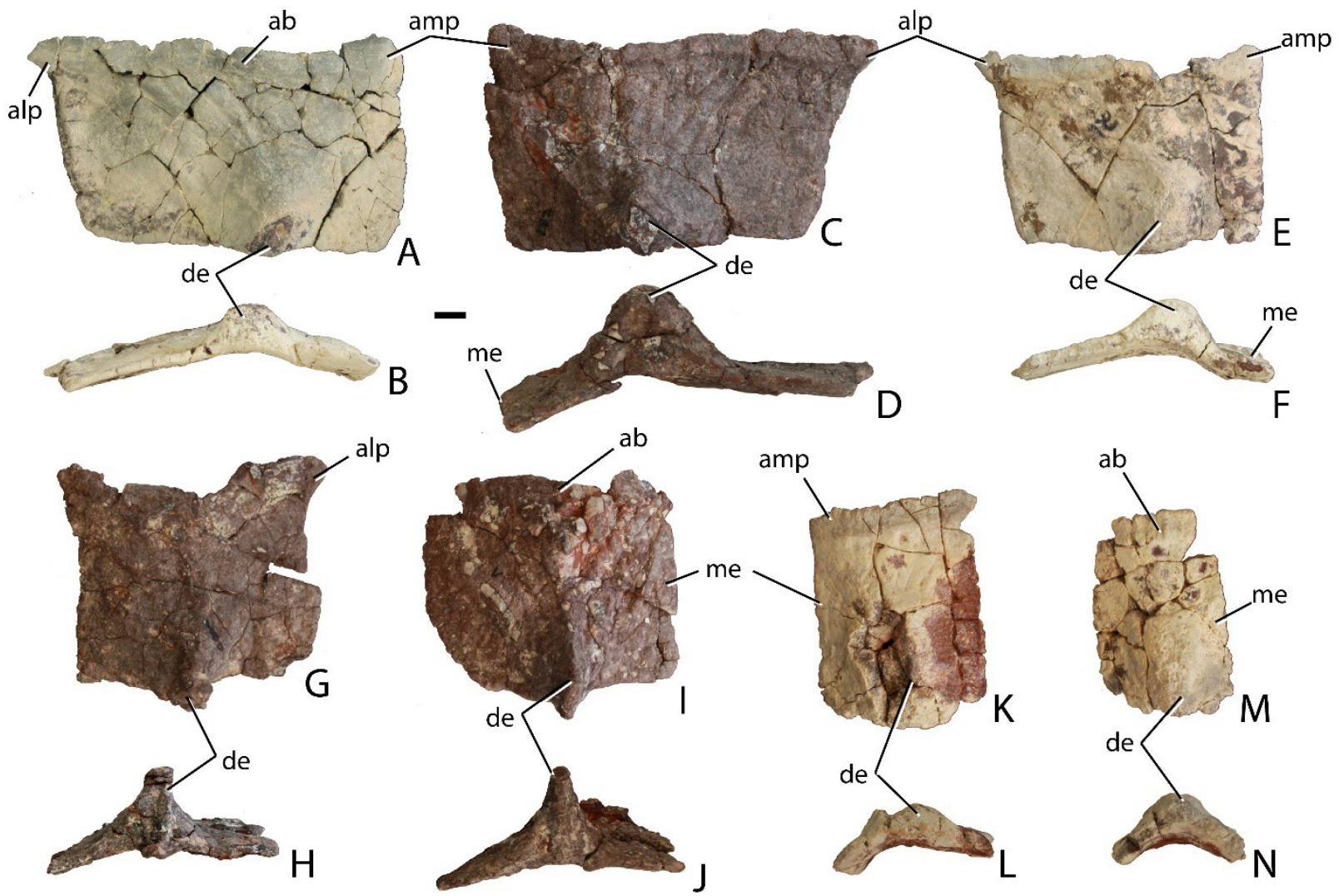



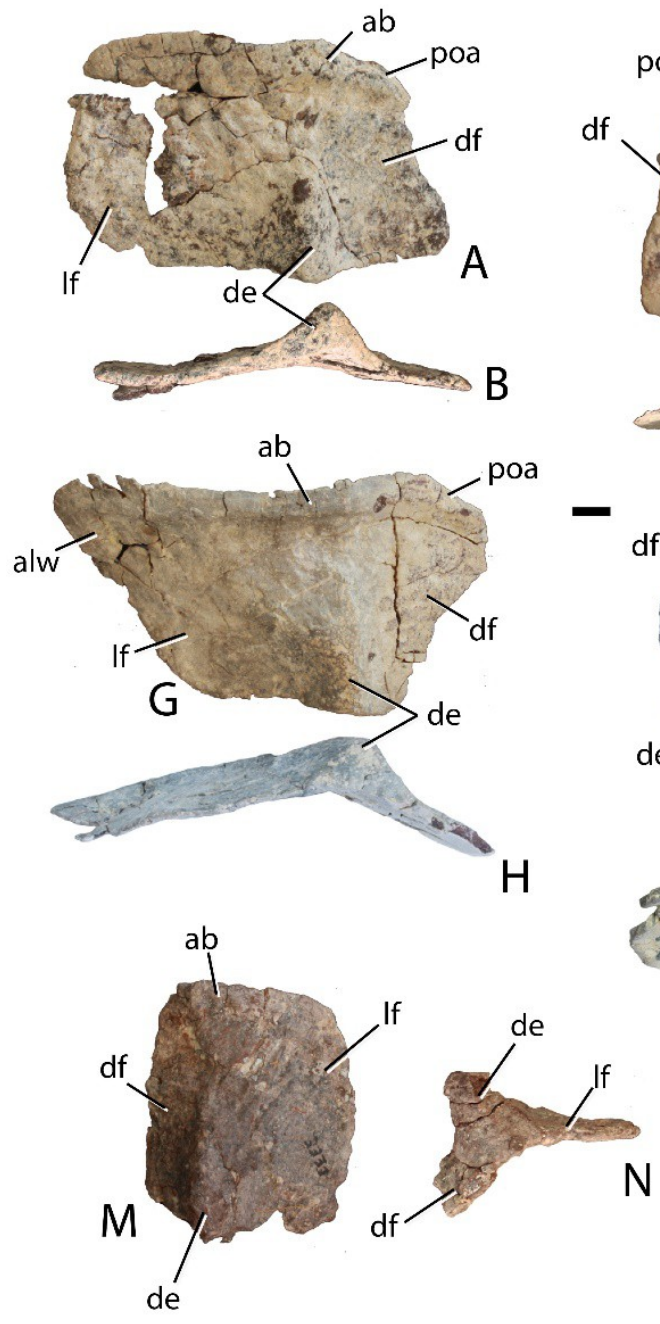
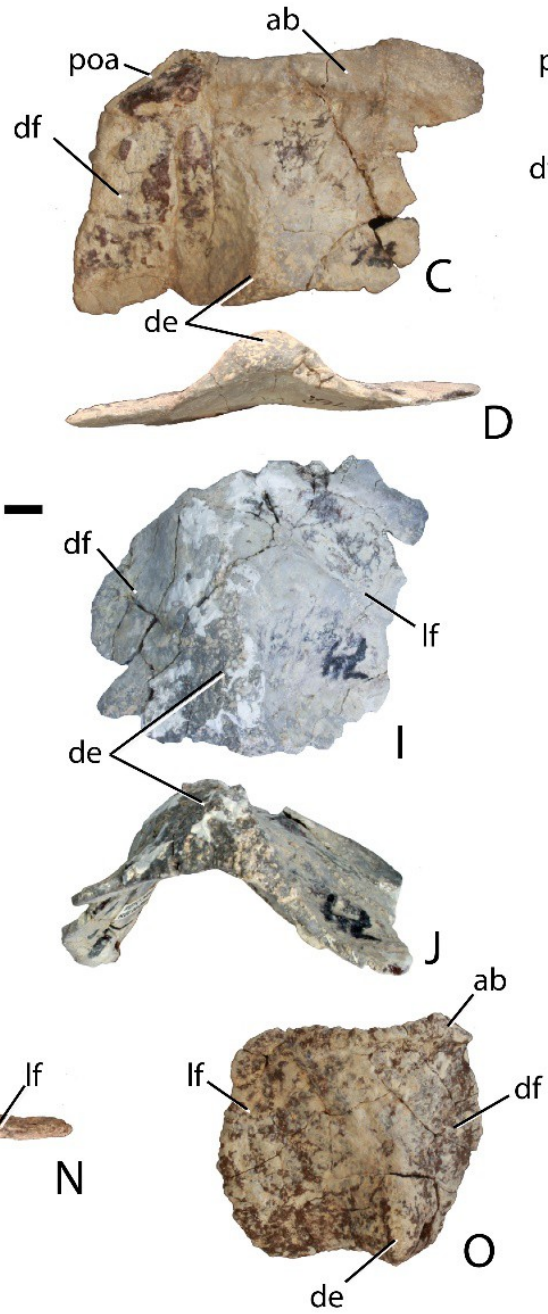
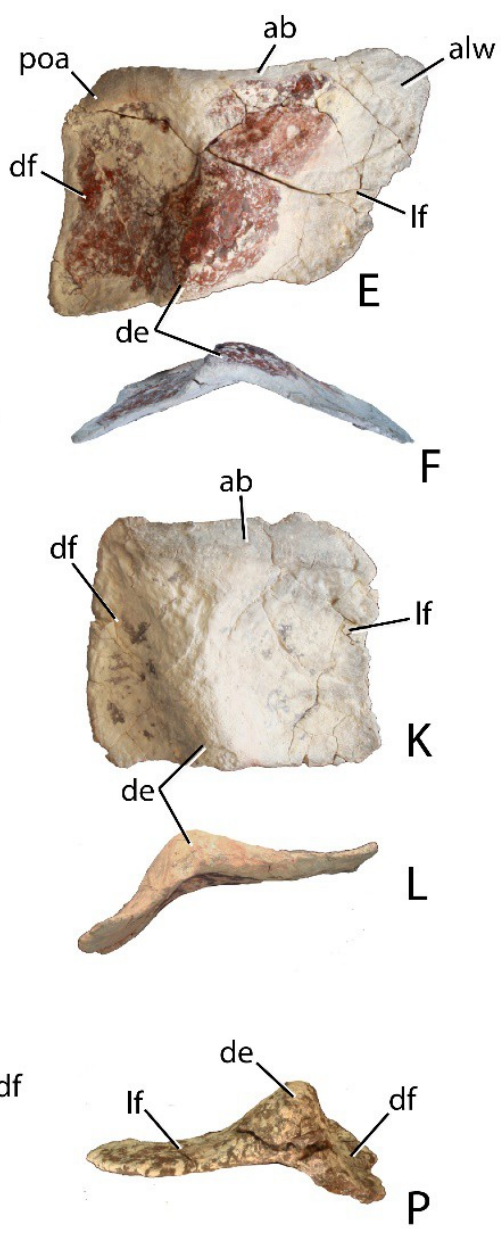


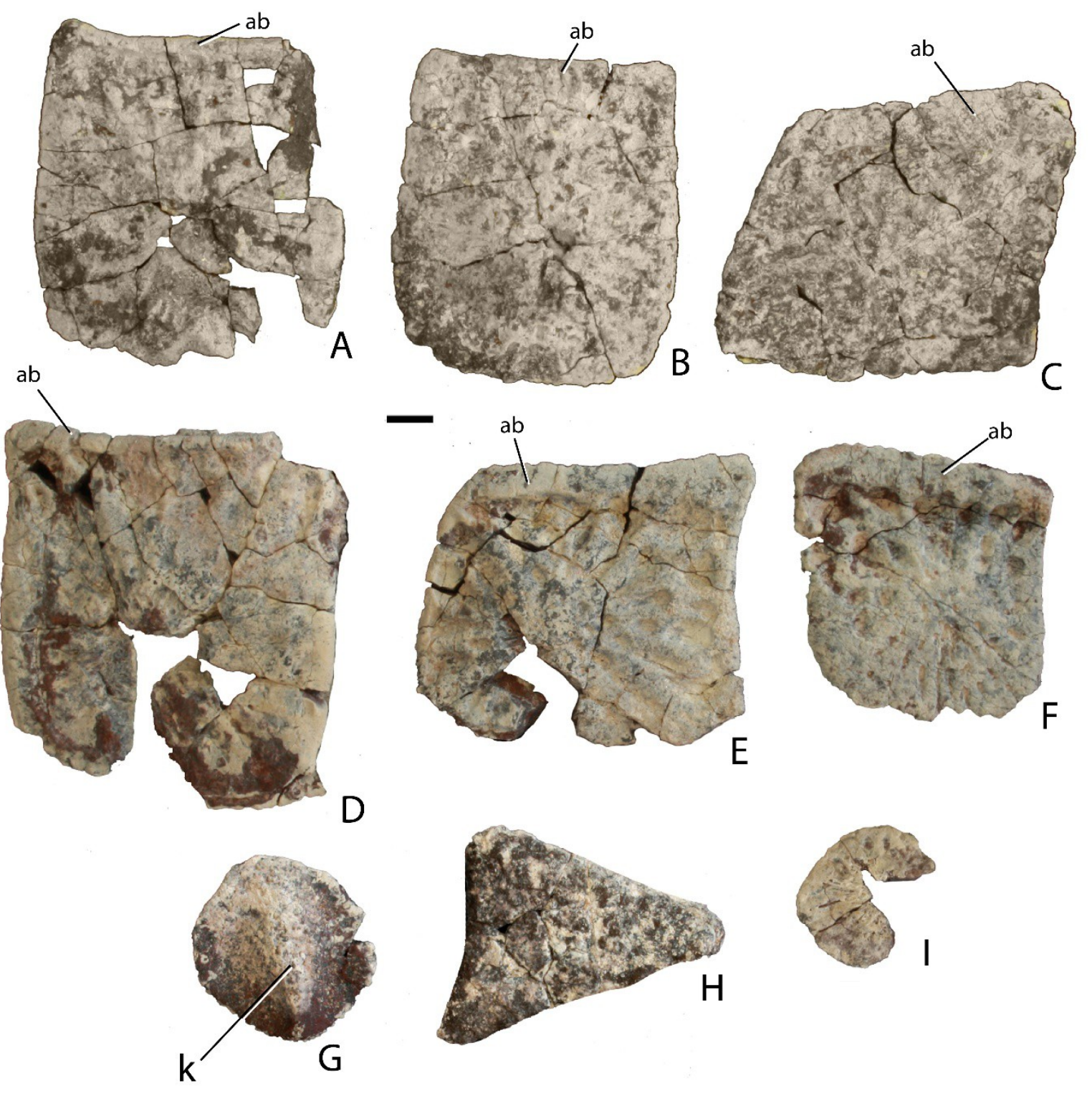




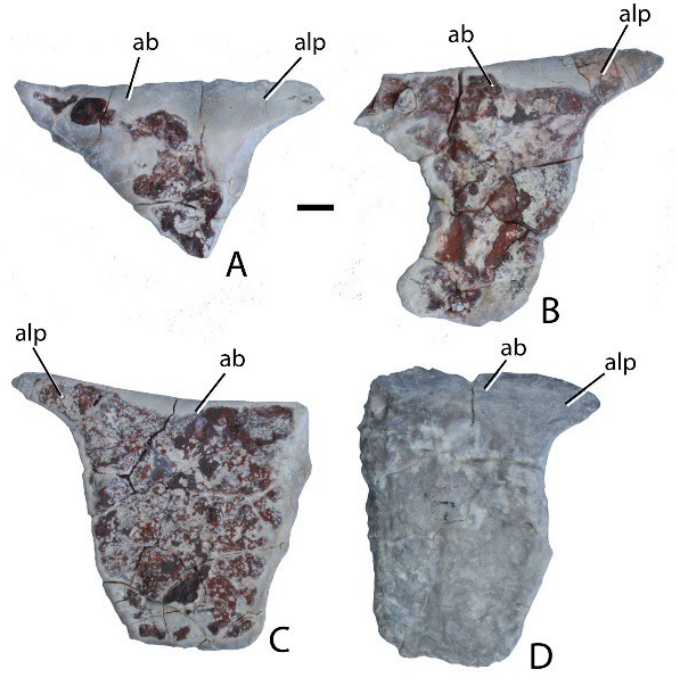




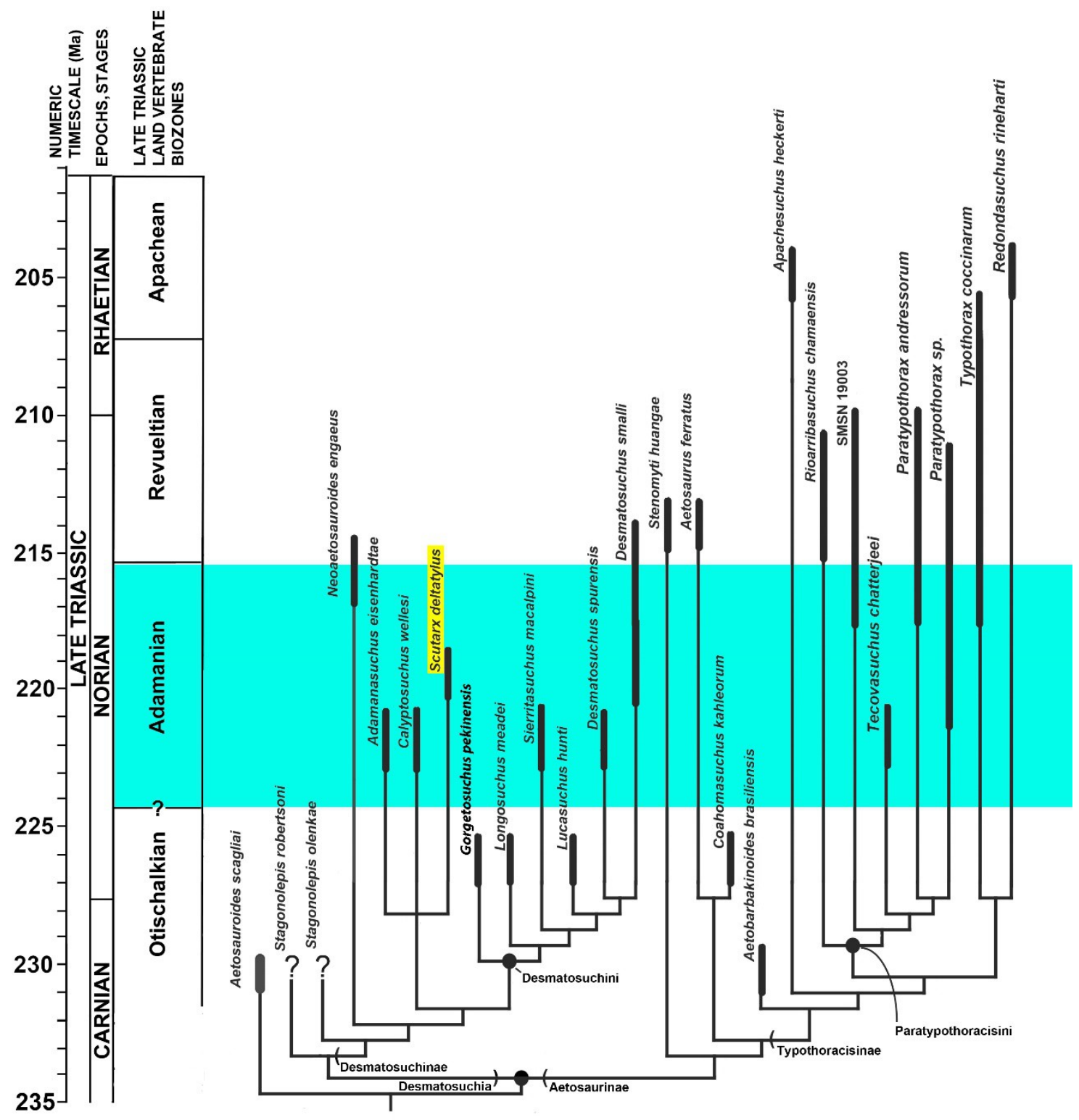

